UN IVERSITY OF COPENHAGEN

\title{
Supercritical wood impregnation
}

Kjellow, Anders Westh

Publication date:

2010

Document version

Peer reviewed version

Citation for published version (APA):

Kjellow, A. W. (2010). Supercritical wood impregnation. Forest \& Landscape, University of Copenhagen. 
FACULTY OF LIFE SCIENCES

UNIVERSITY OF COPENHAGEN

\section{PhD dissertation}

Anders Westh Kjellow

\section{Supercritical Wood Impregnation}

Academic advisor: Claus Felby

Submitted: $01 / 05 / 2010$ 
FACULTY OF LIFE SCIENCES

UNIVERSITY OF COPENHAGEN

\section{PhD dissertation}

Anders Westh Kjellow

\section{Supercritical Wood Impregnation}

Academic advisor: Claus Felby

Submitted: $01 / 05 / 2010$ 


\section{Preface}

This dissertation represents the conclusion of the author's PhD project on supercritical wood impregnation. It feels like I started the project last week, but obviously it's been considerably longer. Time flies when you're having fun - and certainly also when you're doing a $\mathrm{PhD}$.

I want to thank my supervisor Claus Felby for guidance and helpful criticism along the way. Ole Henriksen from Hampen Træforarbejdning A/S deserves special praise for his patience in teaching me about the interesting world of supercritical fluids, which was practically unknown to me before this project began. I also want to thank him for countless hours of interesting conversation, and for his help and support in times of personal trouble. I'm grateful to Dr. Monika Johannsen for kindly receiving me at the lab at the Hamburg University of Technology and for her contributions to the work on wood-biocide interactions. Likewise, I'm grateful to Dr. Jeffrey Morrell and the rest of the staff at the wood science lab at Oregon State University for receiving me at their lab. My colleagues at Department 4 at Forest and Landscape and the people at Hampen Træforarbejdning also deserve credit for helping me out whenever needed. I want to thank Milo Clauson at Oregon State University for his professional help in the supercritical lab and, more importantly, for his endless hospitality, his always helpful nature and for being a good friend. Without the help of all these people, this project could not have been completed.

Y para Yohanna - la musa de mi inspiración - gracias por todo.

The project has been supported by the Danish Forest and Nature Agency and Hampen Træforarbejdning A/S to whom I'm grateful.

Anders Westh Kjellow

Copenhagen, April 2010 


\section{List of publications}

The following publications and manuscripts are referred to in the text by their roman numerals:

I Kjellow,A.W., Henriksen,O.

Supercritical wood impregnation

The Journal of Supercritical Fluids (2009) 50: 297-304

II Kjellow,A.W., Henriksen,O., Fernandez,J.L., Madsen,H.E.L., Felby,C.

Permeability of wood to supercritical carbon dioxide

Manuscript for intended for publication

III Kjellow,A.W., Henriksen,O., Sørensen,J.C., Johannsen,M., Felby,C.

Partitioning of organic biocides between wood and supercritical carbon dioxide The Journal of Supercritical Fluids (2010) 52: 1-5

IV Kjellow,A.W., Henriksen,O.

Interactions between wood and propiconazole in supercritical carbon dioxide

International Research Group on Wood Protection, Paper prepared for the $40^{\text {th }}$ Annual Meeting, Beijing, China, 24-28 May 2009. IRG/WP 09-40461. 


\section{Table of contents}

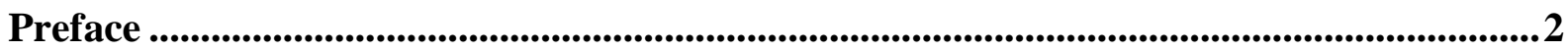

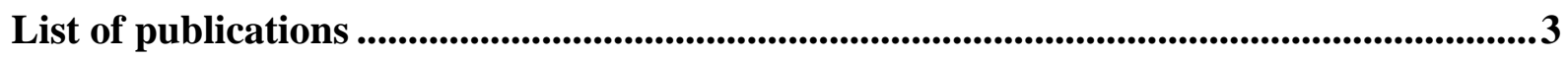

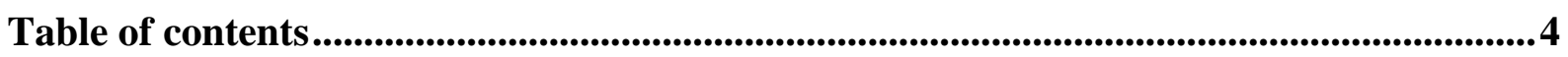

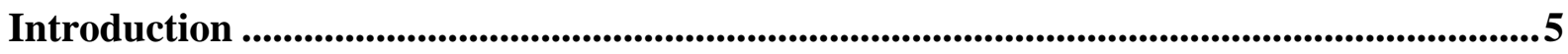

Structural and chemical composition of wood...............................................................

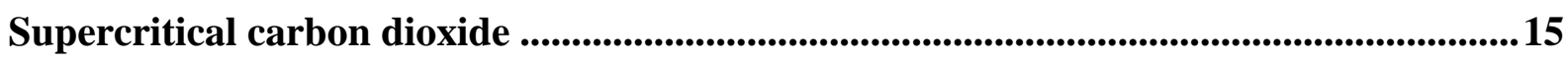

Developments in supercritical wood impregnation ......................................................18

Permeability of wood to supercritical carbon dioxide ..............................................................22

Wood-biocide interactions in supercritical carbon dioxide ............................................31

Microdistribution of biocides in supercritical impregnated wood........................................35

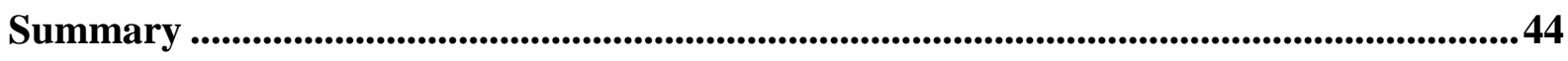

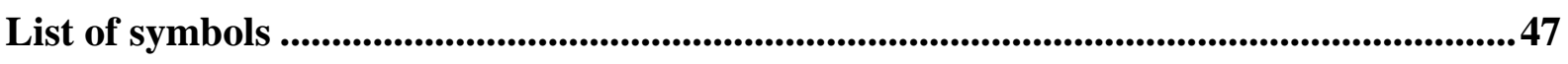

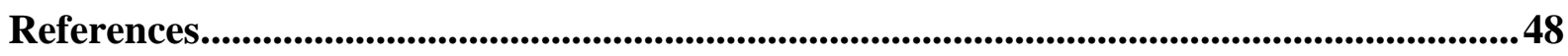

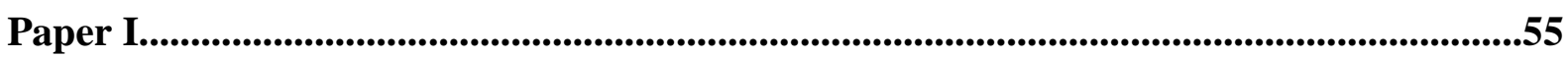

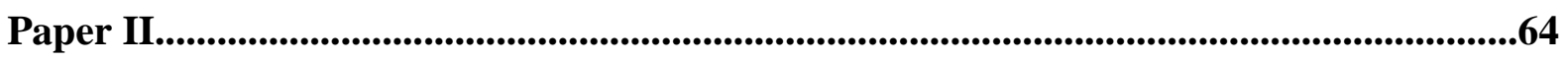

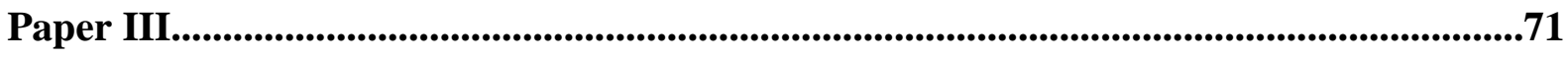

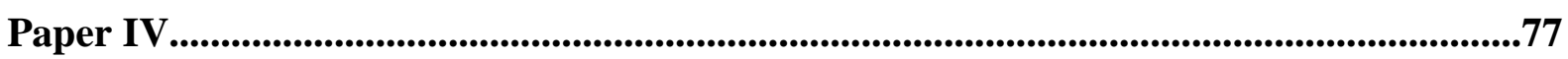




\section{Introduction}

During the past two decades, supercritical carbon dioxide has been investigated as a possible solvent for wood impregnation because of its unique physical properties [1]. Supercritical $\mathrm{CO}_{2}$ combines a gas like viscosity and surface tension with a liquid like density. The high density makes supercritical carbon dioxide act as a solvent while the low viscosity and surface tension allow it to penetrate wood rapidly and efficiently. Combine these properties with a high diffusivity and the ability to fine tune solubility through pressure and temperature control and you have a very attractive solvent for wood impregnation.

Traditionally, wood impregnation has been carried out using liquid solvents for transport of biocides into wood [2]. The different varieties of the traditional pressure impregnation processes involve using pressure, vacuum, or a combination the two to force a liquid solution of biocides into the wood. Their continued use for well over 150 years is testimony to the effectiveness and usefulness of these processes.

Nevertheless, wood impregnation using liquids have some unwanted technical and environmental issues. Many low permeability wood species provide a substantial resistance to flow of fluids which makes it difficult or impossible to impregnate these 'refractory' species with liquid solvents [3]. Consequently, the list of wood species that can be impregnated using liquid solutions is limited. After impregnation the wood will be wet from excess treatment liquid and will need additional time to dry [4]. In cases where the end use of impregnated products requires application of surface treatments such as paints the end consumer can be forced to delay the application of such until the wood has dried sufficiently. The environmental issues include difficulties in avoiding exposure of workers and the environment to treatment solutions [3].

The use of supercritical carbon dioxide as solvent provides a potential solution to the limitations of the liquid impregnation processes. Because of its low viscosity and surface tension, supercritical $\mathrm{CO}_{2}$ can penetrate the refractory species otherwise considered nontreatable. Furthermore, since $\mathrm{CO}_{2}$ at atmospheric pressures is a gas ${ }^{1}$, the treated wood is dry and can be used immediately after impregnation. The exposure of workers to treatment solutions is greatly reduced, if not eliminated, since the treatment solution only exists at

\footnotetext{
${ }^{1}$ At atmospheric pressure, $\mathrm{CO}_{2}$ is a gas at temperatures above $-78.5^{\circ} \mathrm{C}$. Below this temperature it exists as a solid.
} 
pressures above the critical point of $\mathrm{CO}_{2}$, i.e. in closed loop systems. Similarly, the exposure of the environment to run off of excess treatment fluid is eliminated because the wood is dry after treatment.

The supercritical wood impregnation process is described in [5] and is illustrated in figure 1. The process can roughly be divided into three steps: a pressurization phase, an impregnation phase, and a depressurization phase.

Although the supercritical impregnation procedure is theoretically simple, it is difficult to control in practical use. Because of the relatively high pressures involved, there is a risk of developing excessive pressure gradients in the wood which can lead to collapse or split of the wood which most scientist or practitioners in the area will be familiar with. Another challenge is ensuring the required transport of biocides through the wood substrate. The seriousness of these challenges became apparent when the worlds first commercial supercritical wood impregnation plant went out of business after only three months of operation due to an excessive failure rate of the impregnated products. Although the plant has since resumed operation, the incident illustrated the fact that supercritical wood impregnation is not a simple operation and highlighted the need for a better understanding of the process.

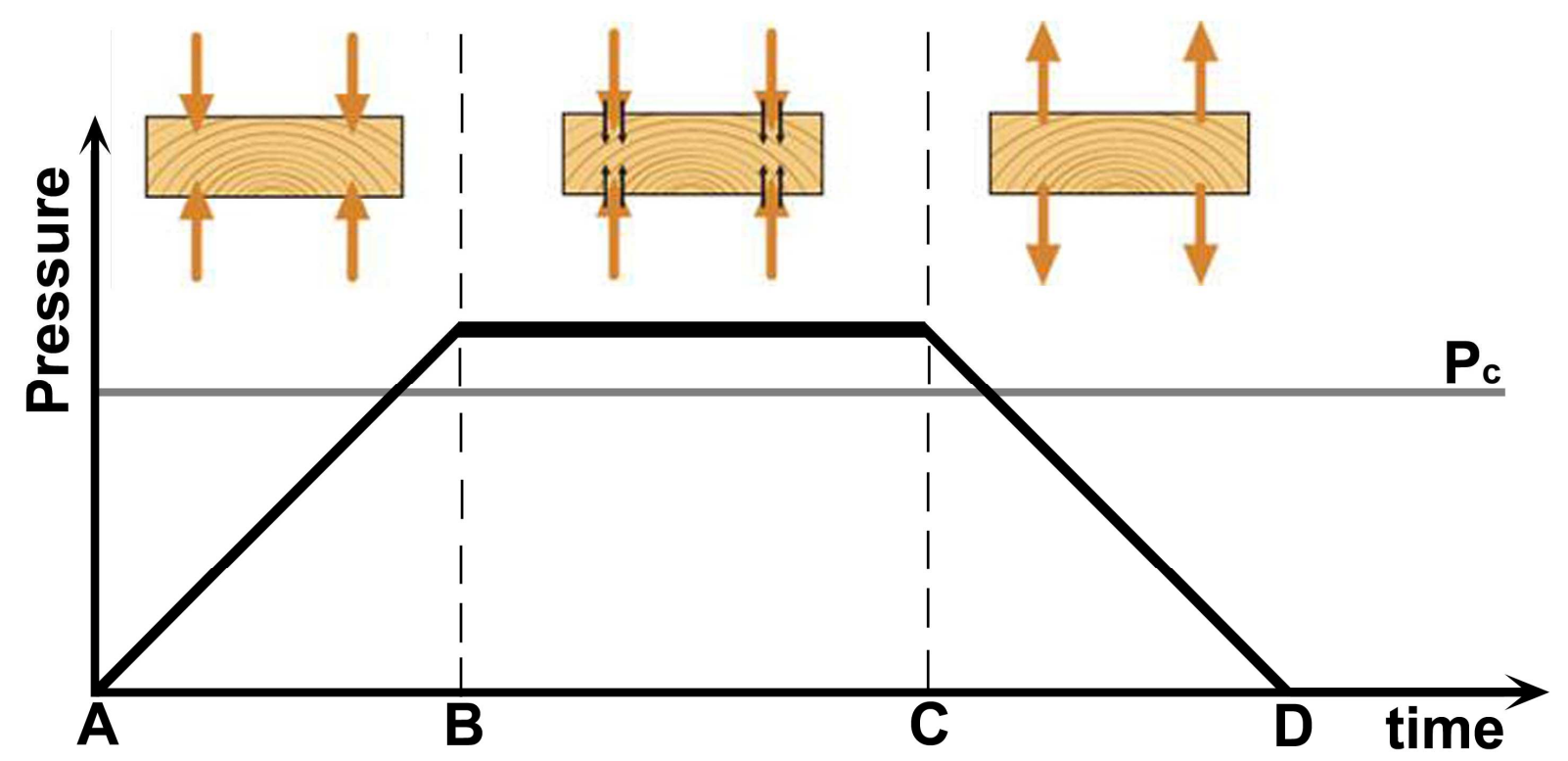

Figure 1. Main steps in the supercritical wood impregnation cycle. At point 'A' wood is placed in a treatment vessel and $\mathrm{CO}_{2}$ is forced into the wood (brown arrows) by increasing the pressure beyond the critical pressure $\left(P_{c}\right)$ of $\mathrm{CO}_{2}$. At supercritical conditions, between points ' $B$ ' and ' $C$ ', the dissolved biocides (black arrows) move with the $\mathrm{CO}_{2}$ to the interior of the wood. Between points ' $C$ ' and ' $D$ ' the pressure is decreased back to atmospheric levels. The $\mathrm{CO}_{2}$ exits the wood leaving the biocides behind. 


\section{Objective and outline}

The main objective of the presented $\mathrm{PhD}$ project was to gain a better understanding of the supercritical wood impregnation process. As of 2010, the process has developed from labscale scientific experiments to industrial scale commercial production but the fundamental understanding of the process is still only developing. Initially, the available scientific literature within the area was reviewed (Paper I). Next, our research efforts were focused on three specific areas of interest, namely, 1) permeability of wood to supercritical carbon dioxide (Paper II), 2) movement of biocides in the wood during impregnation (Paper III and IV), and 3) microdistribution of biocides in the cell wall after impregnation.

The review will, together with the introductory chapters of the present dissertation, provide the reader with a background to supercritical wood impregnation in general and to the proceeding chapters and papers in this dissertation.

Supercritical wood impregnation is an interdisciplinary discipline which requires understanding of the chemical and structural composition of wood as well as the thermodynamic behavior of compressed gasses. Although basic introductory chapters can be left out of dissertations, it was in this case thought necessary to include such chapters since few readers will have a background spanning both areas of science. Thus, for readers with a non-wood background an introductory chapter is provided on wood structure and composition with emphasis on the chemical and structural features relevant for the wood impregnation process. For readers with a non-supercritical background a short introduction is given to the thermodynamic behavior of compressed gasses. 


\section{Structural and chemical composition of wood}

Supercritical wood impregnation is concerned with forcing a fluid $\left(\mathrm{CO}_{2}\right)$ through a wood matrix. The structural composition of the network determines the ease at which fluids can be forced through it. Wood is the secondary xylem, i.e. water conducting tissue, of trees or other woody plants. In a living tree, the xylem is responsible for conduction of water and nutrients, storage of metabolites and mechanical support. Flow of $\mathrm{CO}_{2}$ through the wood has to be conducted via the same flow paths that were used for the transport of water, nutrients and metabolites in the standing tree.

The structural composition of wood may vary. Generally, there are two basic designs of wood with gymnosperm wood being fundamentally different than angiosperm wood. There are, however, as many varieties of the basic structures as there are species. In this context, focus will be on the structure of gymnosperm wood exemplified with the wood of Norway spruce, used for experimental work in Paper II, III, and IV, as well as commercial impregnation.

The complexity of the structure of wood becomes apparent when magnified a few hundred times (figure 2$)^{2}$. What superficially appears a solid material is actually quiet porous. In the case of Norway spruce the porosity is about $64 \%$ [6]. Due to the high porosity, wood impregnation would be relatively straight forward if all the cavities in the wood were well interconnected. However, this is not the case.

Wood is made up of a matrix of dead wood cells or, rather, cell walls of dead wood cells. The longitudinal oriented tracheid is the most dominant cell type in gymnosperms in general, accounting for about $95 \%$ of the cells of Norway spruce [7]. Each tracheid has the form of a hollow tube with a length-to-width ratio of about 100/1 where the cell wall surrounds an empty cell lumen. In Norway spruce, the tracheid length varies between 1.7-3.7 $\mathrm{mm}$ and diameter (width) between 20-40 $\mu \mathrm{m}$ [7].

In the living tree, the transport of water from the roots to the leaves occurs through the tracheid lumens. Because of the limited length of the tracheids the water must move through numerous tracheids as it moves upwards in the tree. Water moves from one lumen to another through intercellular openings in the cell walls comprised of bordered pit-pairs, which appear as donut shaped apertures in the cell walls (figure 3). Each pit-pair is an ingenious piece of

\footnotetext{
${ }^{2}$ To increase readability all figures in this chapter are placed at the chapter end (page 12).
} 
bioengineering that serves to ensure pit aspiration in the event that air embolisms spread and disrupt the liquid flow path from the root to the leaves $[8,9]$.

For this purpose each pit-pair is equipped with a valve system consisting of an impermeable disc, the torus, suspended in a permeable net, the margo (figure 4). In the sapwood of the living tree the margo and torus is positioned in the middle of the pit cavity allowing flow of water from on cell to the next through the permeable margo (figure 5). While allowing passage of water, the margo will trap an air-water meniscus by capillary action preventing the spread of embolisms to the adjacent cell [10]. The pressure difference between air filled tracheid and the adjacent water filled tracheid, where water is under tension, will force the pit membrane (torus and margo) across pit chamber until the torus blocks the aperture (figure 6 and 7) of the pit border of the water filled tracheid [8,11]. Thus, breakage of the water column in the adjacent cell is prevented (figure 8).

Softwoods pay the price of decreased conductivity for having the security against embolisms provided by the bordered pits [11]. In a living tree, as much as $50 \%$ of the total resistance to flow may be accounted for by the pits [12]. However, wood preservers pay an even higher price for the torus-margo system. When pits are aspirated, it is impractical, if not impossible, to force liquids through the wood using conventional pressure treatment techniques. What's worse, pit aspiration is not a rare phenomenon in the living tree. In addition to being caused by embolisms, it can be brought about by fungal attack and will, in many species, occur as a natural process in the transition zone between sapwood and heartwood [13]. This leaves the heartwood of many species close to untreatable by conventional pressure impregnation methods. However, since the heartwood of many wood species often has a high degree of natural durability due to the deposition of extractives with biocidal properties [13], the refractory nature of heartwood is in many cases not a problem.

It is of greater concern to the wood preserver, that pit aspiration may be inflicted as a result of the lumber drying process. Some wood species are more prone to pit aspiration than others. In some species like Norway spruce, pit aspiration will occur throughout the wood during the drying process. The effectiveness of the aspirated bordered pits in preventing liquid flow was demonstrated by Peek and Goetsch [14] who recorded the time it would take for samples of pine and spruce (presumably Scots pine an Norway spruce) to equilibrate pressure in the radial direction when pressurized with either air or water. After pressurizing dry Norway spruce (moisture content $15 \%$ w/w) with water to 5 bar for 8 hours they were unable 
to detect any pressure increase at a distance of $10 \mathrm{~mm}$ from the radial surface. The pine samples reached pressure equilibration ( 5 bar) after about 1 hour. The use of higher pressures to increase penetration of liquids does not solve the problem, because the wood will often collapse at pressure differences of about 16 bar in softwoods [15].

Apart from the lateral flow path through the longitudinal tracheids, flow can also occur through the rays running in the radial direction through the wood connecting the phloem with the xylem. The rays in Norway spruce make up about 5 percent of the wood and consist of tracheids as well as parenchyma cells [7]. In the living tree, the rays function as lateral flow paths through which metabolites, water, and nutrients can be moved from the phloem to the xylem. Every longitudinal tracheid is connected to at least one ray cell via semi-bordered pits, i.e. only the longitudinal tracheid side of the pit is bordered [7]. The openings of these pits are about 1-2 $\mu \mathrm{m}$ in diameter and do not have the torus/margo system of the bordered pit-pairs between longitudinal tracheids. They are therefore always open (figure 9). Finally, flow can occur through resin canals which occur at regular intervals throughout the wood (figure 10), often plugged by resin (figure 11). The ability of supercritcal carbon dioxide to solubilize resin [16], means that the resin canals might be explain the slightly increased permeability of supercritical extracted wood we found in paper II.

\section{Chemical composition}

In Paper III we examined the interactions of selected organic fungicides with wood under supercritical conditions. Wood is a chemically diverse material primarily consisting of three biopolymers, cellulose, hemicellulose, and lignin. The biosynthetic pathway, structure, and interactions of these polymers are still not fully clarified [17]. For a detailed discussion of these issues the reader is referred to textbooks on wood chemistry e.g. $[7,18]$ and reviews on plant biopolymers e.g. [19-21]. Here it will suffice to briefly discuss the role and abundance of these polymers in Norway spruce. By far the larger part of the mass of (dry) gymnosperm wood is accounted for by the cell walls of the longitudinal tracheids. Tracheids are highly specialized to fulfill the dual function of being conducting as well as weight supporting tissue of the standing tree. Lignocellulose accounts for more than $98 \%$ of the dry mass of Norway spruce. Of these polymers, cellulose is the most abundant making up about $42 \%$ [18]. 
Cellulose is a non-branched polysaccharide made from polymerization of glucose molecules with a high degree of polymerization [7]. The cellulose molecules are joined by hydrogen bonds to form para-crystalline molecules which themselves are bundled together to form micro-fibrils which crisscross the cell wall [19]. In the primary cell wall and in the s1 and s3 layers of the secondary wall the micro-fibrils are oriented in all directions. In the thicker s2 layer of the secondary wall the micro-fibrils run close to parallel with the longitudinal direction [3]. The primarily axial orientation of the micro-fibrils account for the anisotropic behavior of wood with regard to moisture induced shrinking and swelling [22]. Hemicellulose, the other important polysaccharide in wood, consists of several different sugars. In Norway spruce, the main hemicellulose sugars are mannose, xylose, glucose, galactose, and arabinose, and hemicellulose accounts for about $25 \%$ of the wood dry mass [23]. Hemicellulose is a branched molecule with a low degree of polymerization of about 200. In the cell wall hemicellulose functions as an adhesive bonding together the wood biopolymers and supporting the cellulose framework, but the exact mechanisms of interaction are still being debated $[17,24]$. Together with cellulose, the highly hydrophilic hemicellulose is responsible for the hygroscopic behavior of wood. The polysaccharide micro-fibrils have a high tensile strength but are weak in compression. To provide the cell wall with the rigidity needed to support growth on land, terrestrial plants incorporate lignin into the cell wall [25]. Lignin is a randomized network of polyphenolic compounds produced from the coupling of the lignin precursors, coniferyl-, sinapyl, and p-coumaryl-alcohol [26]. The resulting polymer is a complex, randomized phenolic structure with numerous types of linkages and functional groups [21]. Lignin makes up about 27 percent of Norway spruce [18]. Mechanically it has a high hardness, making the combined lignin/cellulose/hemicellulose composite both rigid and strong. Lignin also imparts hydrophobicity to the otherwise hydrophilic cell wall components and is therefore important for hydrolic properties of the xylem [27]. Summarizing, the chemical composition of wood is complex and variable even without accounting for extractives which may be present in smaller amounts. It has both hydrophilic and hydrophobic properties and will interact with most liquids and gases. 


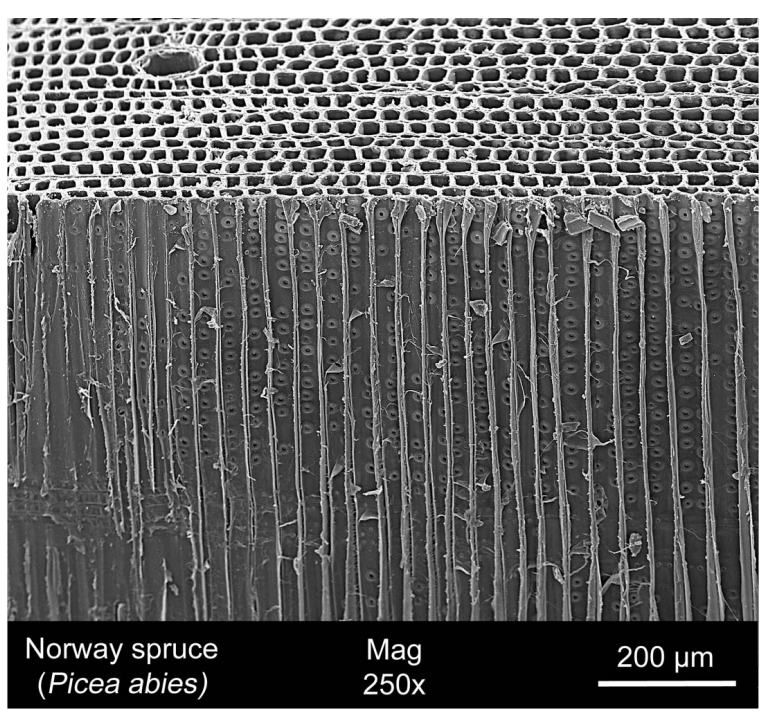

Figure 2 SEM image of the radial and axial (top) surfaces of wood from Norway spruce. The bordered pits connecting the longitudinal tracheids are evident as donut shaped apertures in the longitudinal tracheid walls.

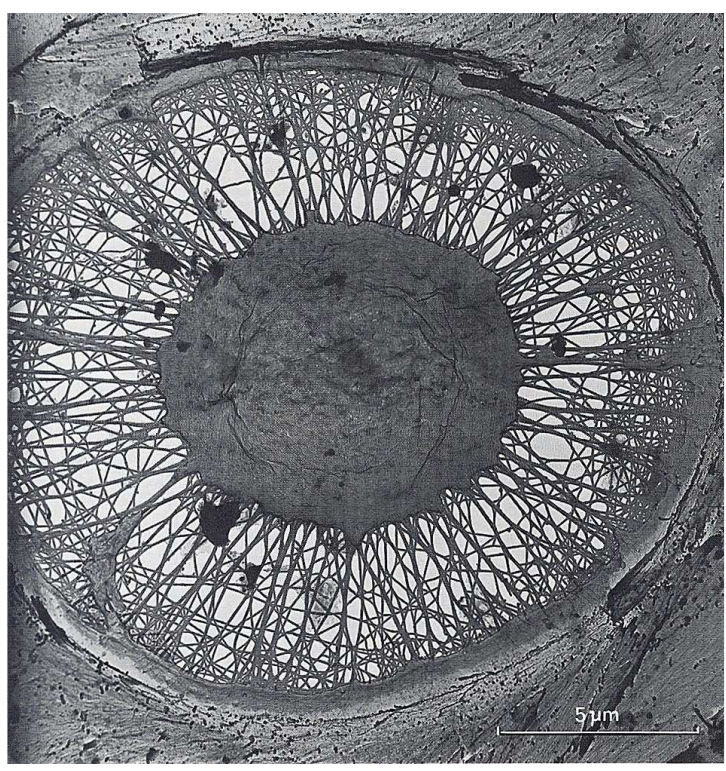

Figure 4. SEM image of a non-aspirated bordered pit in Tsuga canadensis. The torus is suspended in the middle of the pit by the margo. Image from Zimmermann (1987) [11].

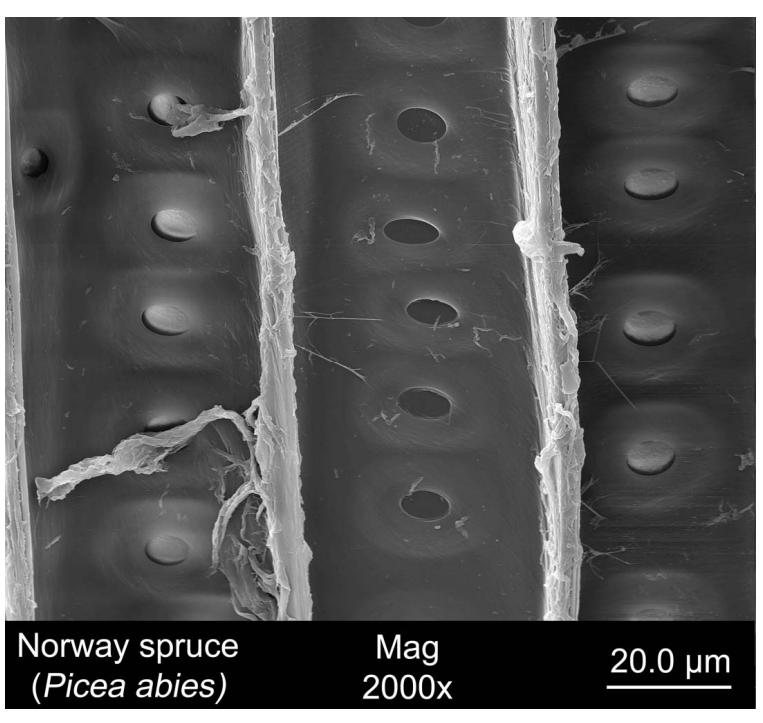

Figure 3. SEM image showing the bordered pits in the radial cell walls of longitudinal tracheids in Norway spruce.
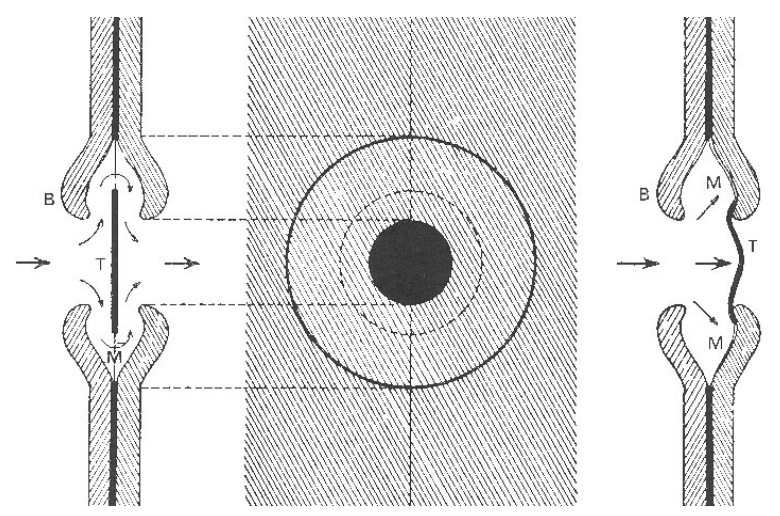

Figure 5. Schematic presentation of the flow paths in a softwood bordered pit (left). On the right, flow is obstructed by the aspirated torus. Image from Zimmermann (1987) [11]. 


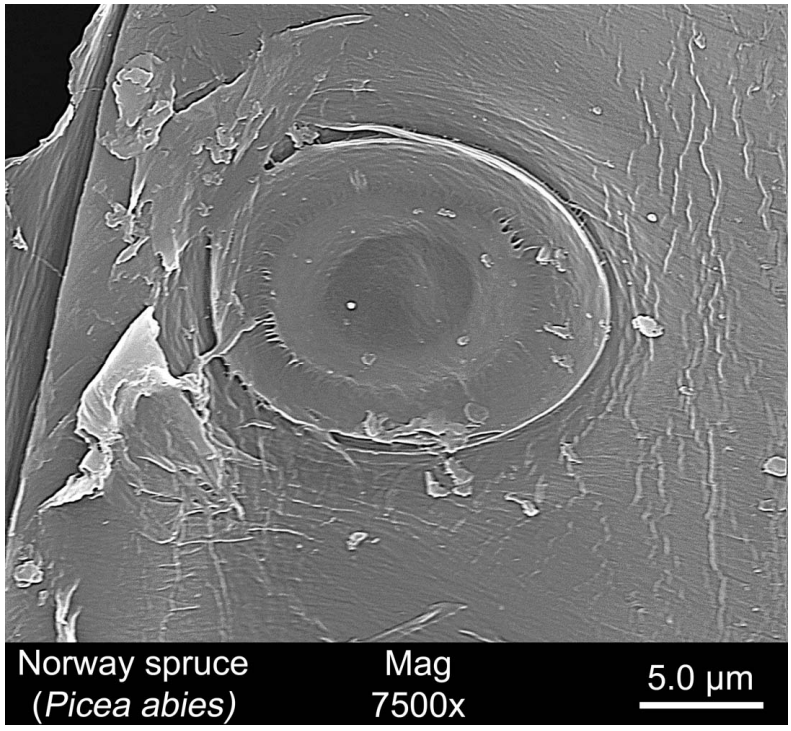

Figure 6. SEM image of an aspired bordered pit in Norway spruce seen from the radial surface. The aperture of the pit border is visible through the torus. The network of the margo is also evident.

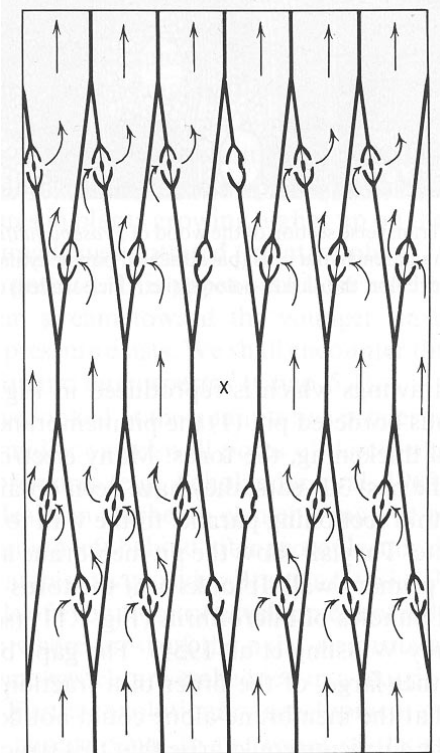

Figure 8. Schematic presentation of the effect of pit aspiration on the flow of sap in the xylem. The tracheid marked ' $x$ ' is aspirated and the air is prevented from entering the neighboring cells. Image from Zimmermann (1987) [11].

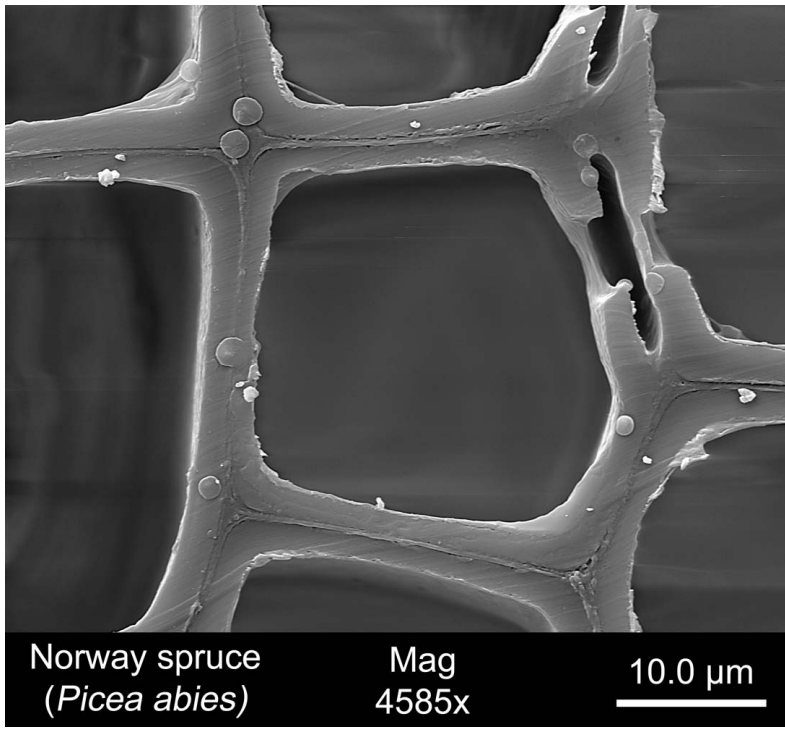

Figure 7. SEM image of the axial surface of a single longitudinal tracheid in Norway spruce showing an aspirated bordered pit.

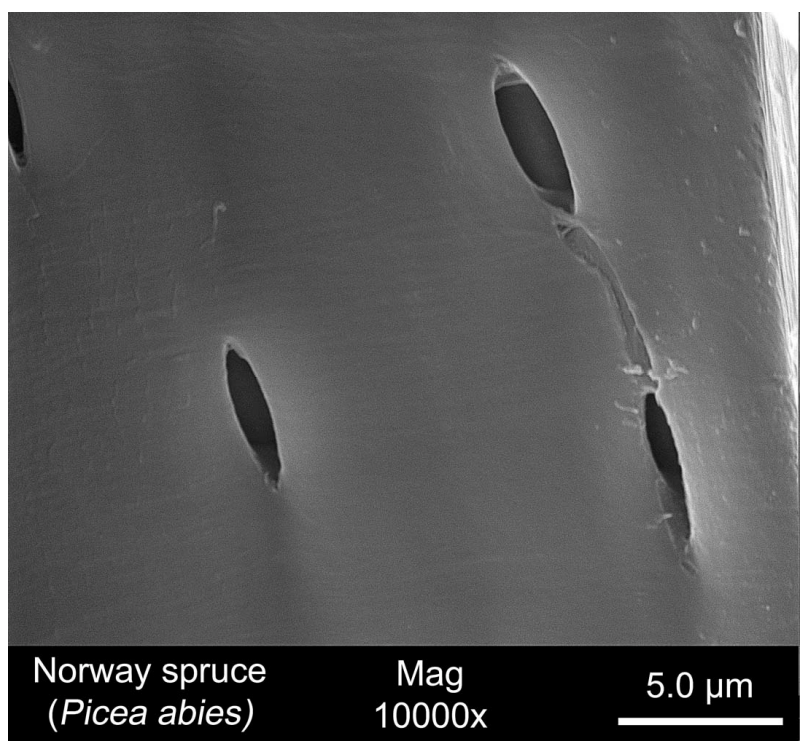

Figure 9. SEM image of the piceoid pores in the cross fields of Norway spruce. 


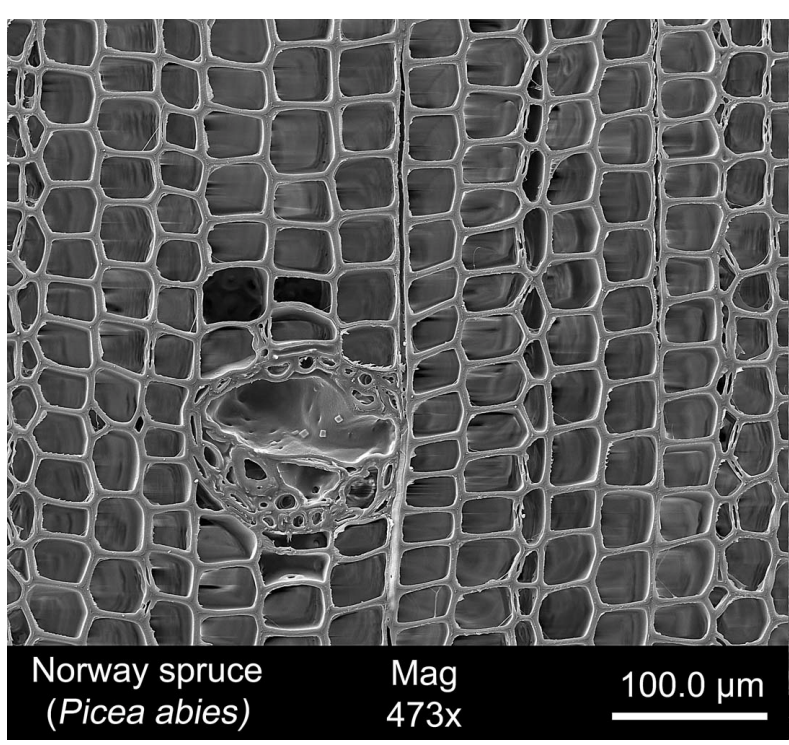

Figure 10. SEM image of the axial surface in Norway spruce containing a resin canal.

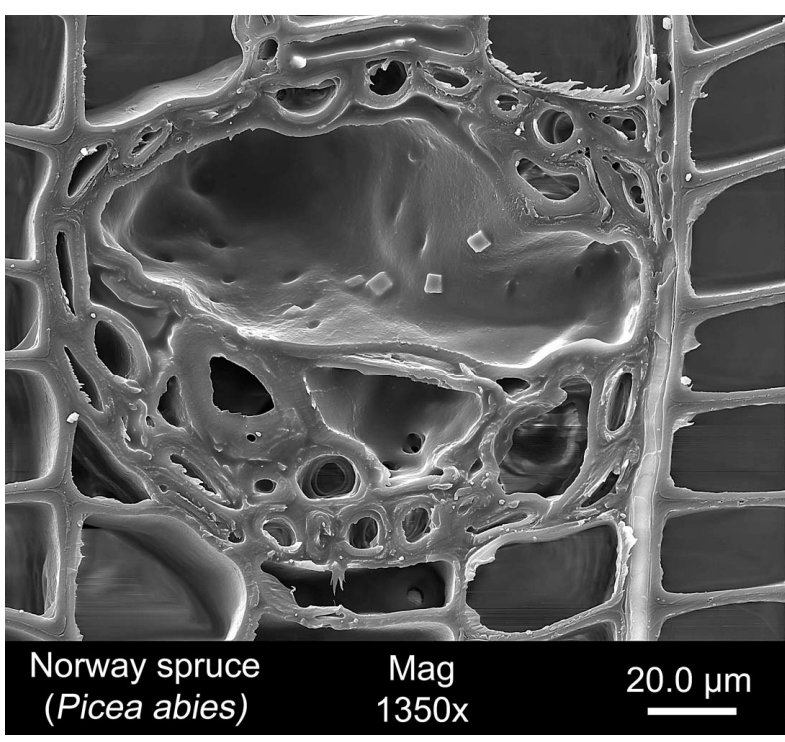

Figure 11. Close up of the resin canal in figure 10, showing the blockage of the pit by resin. 


\section{Supercritical carbon dioxide}

In 1822, a French Baron by the name of Cagniard de la Tour made the first scientific description of what would later be known as a supercritical fluid [28]. He filled gun barrels partly with liquids such as water, ethanol, and a few others. He then added a marble to the gun barrels and forged the ends of the barrels tight. The Baron then heated the gun barrels to see what effect the application of heat and pressure would have on the liquids inside. He took the highly pressurized barrels to his ear (!), and listened to the sound of the marble rolling back and forth inside. To his surprise, with sufficient heating of the gun barrels, the sound of the marble would indicate that the liquid had somehow disappeared. What Cagniard de la Tour observed was not the disappearance of the liquid however, but its conversion to a supercritical fluid.

Figure 12 shows a temperature-pressure (TP) phase diagram of carbon dioxide. The phase boundary separating the liquid phase from the gas phase, is a plot of the vapor pressure of the liquid as a function of temperature. At the phase boundary, the two phases are in thermodynamic equilibrium, i.e. Gibbs free energy of the liquid phase equals Gibbs free energy of the gas phase. However, the molar volume of the two phases may be very different, especially at lower temperatures. With increasing temperature at the phase boundary, the molar volume of the two phases approaches each other because of the pressure induced compression of the gas and the thermal expansion of liquid. At the critical point, the molar volume of the two phases, as well as other physical properties, becomes identical and the two phases merge into a single phase termed a supercritical fluid. 


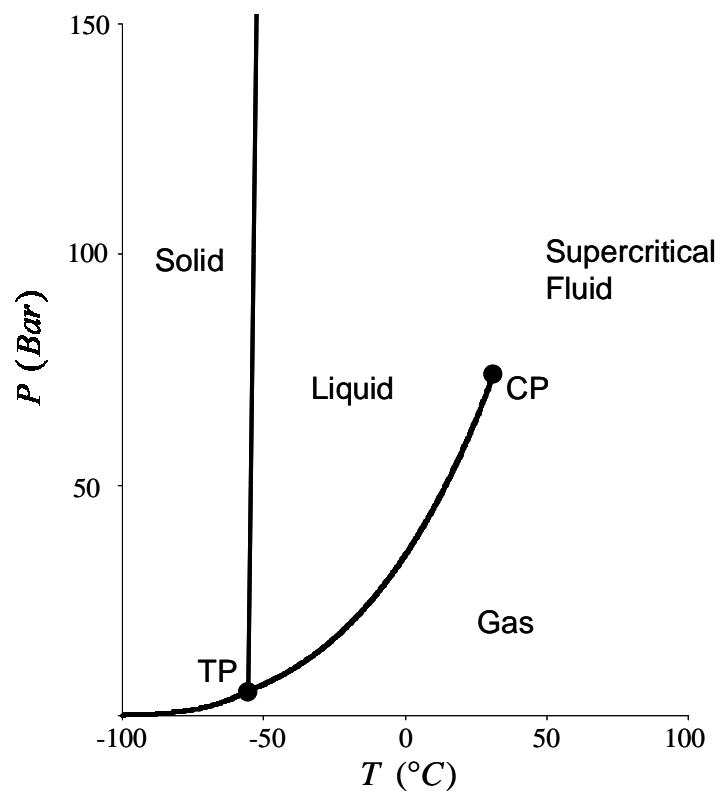

Figure 12. Phase diagram of carbon dioxide showing the conditions at which the different phases are thermodynamically stable. TP: triple point at $-55.6{ }^{\circ} \mathrm{C}, 5.2 \mathrm{bar}$. $C P$ : critical point at $31.1^{\circ} \mathrm{C}, 72.8 \mathrm{bar}$.
Above the critical temperature $\left(\mathrm{T}_{\mathrm{c}}\right)$ it becomes impossible to produce the liquid phase from compression of the gas phase. With isothermal compression of the gas at temperatures above $T_{c}$ the molar volume of the gas decreases continuously but never condenses to a liquid. Even in the supercritical fluid the intermolecular attractive forces are not strong enough to prevent the molecules from drifting apart. In other words, the supercritical fluid will expand to fill out whichever system that contains it and such a substance is, per definition, a gas. However, because of the high level of compression, the properties of supercritical fluids are different from those of gases existing at atmospheric pressures.

Because of the high density, supercritical carbon dioxide may function as a, primarily, non-polar solvent. The solubility of non-polar compounds in supercritical $\mathrm{CO}_{2}$ will largely be dependent on the chemical properties of the compounds and the physical conditions of the $\mathrm{CO}_{2}$. Figure 13 shows how the solubility of naphtalene in $\mathrm{CO}_{2}$ at $45^{\circ} \mathrm{C}$ varies with pressure. At low pressures, below about 60 bar, the solubility of naphtalene in carbon dioxide is negligible. At higher compression the solubility increases. The slope of the solubility curve has its maximum at around 100 bar and here the solubility of naphtalene can be increased or decreased significantly with relatively small changes in pressure. 


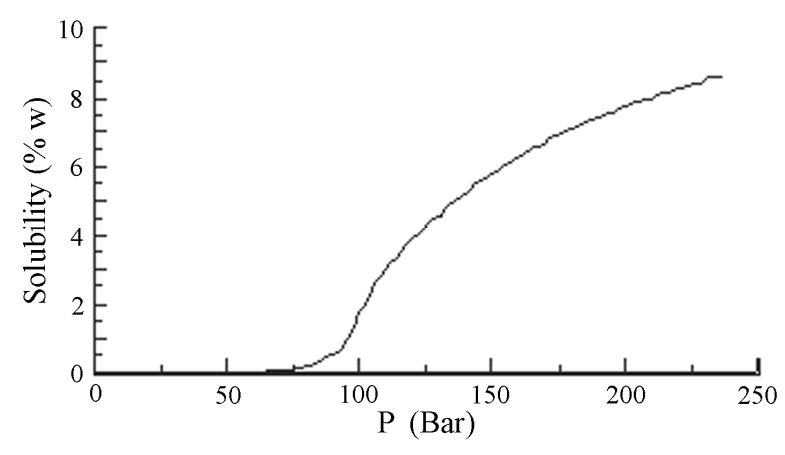

Figure 13. The dependence of solubility of naphthalene in carbon dioxide at $45^{\circ} \mathrm{C}$ on pressure. Data collected by Val Krukonis ${ }^{3}$.

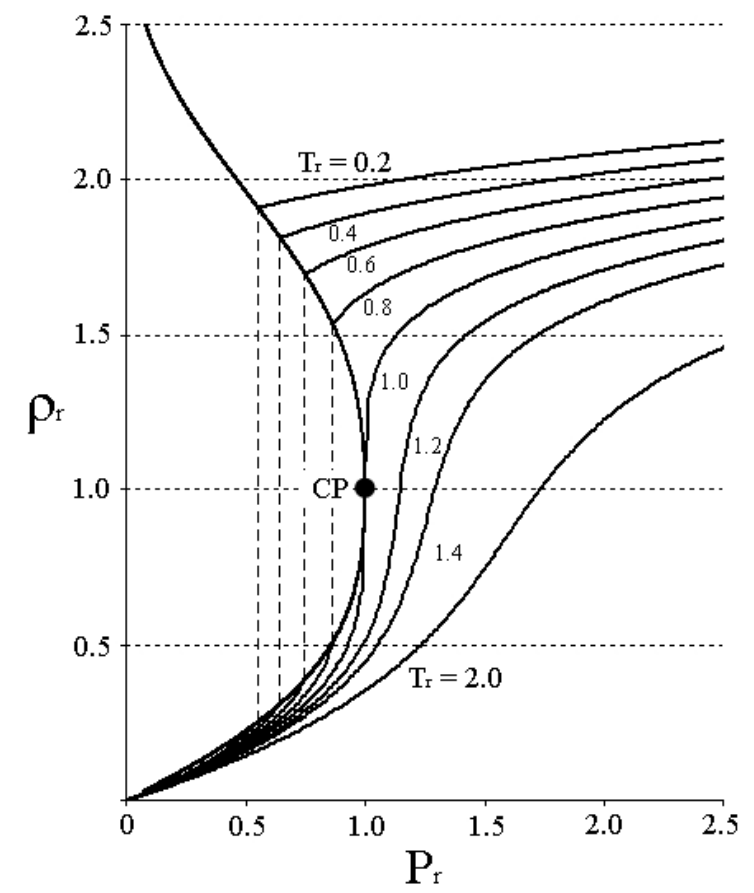

Figure 14. The dependence of the density of carbon dioxide on pressure for various isotherms. $P_{r}$ : reduced pressure $\left(P / P_{c}\right), \rho_{r}:$ reduced density $\left(\rho / \rho_{c}\right)$, $T_{r}$ : reduced temperature $\left(T / T_{c}\right)$. The critical density of $\mathrm{CO}_{2}$ is $0.467 \mathrm{~g} / \mathrm{ml}$.

Using supercritical solvents therefore gives the benefit of controlling solubility to an extent that is not possible using liquid solvents. This is illustrated further in figure 14 above. The figure shows how relatively small changes in temperature and pressure can result in large changes in carbon dioxide density, especially for conditions near the critical point. Notice, in figure 14 , how the shape of the isotherm for $\mathrm{T}_{\mathrm{r}}=1.4\left(\approx 43.5^{\circ} \mathrm{C}\right)$ is roughly the shape of the solubility isotherm $\left(45^{\circ} \mathrm{C}\right)$ for naphtalene in figure 13 . Since solvent power of $\mathrm{CO}_{2}$ is closely related to its density, solvent power can be manipulated by temperature and pressure control.

Despite its high density, supercritical carbon dioxide has low viscosity and very low surface tension. These properties are especially useful when impregnating wood and explain why supercritical fluids can penetrate wood matrices more effectively than liquid solvents.

\footnotetext{
${ }^{3}$ Val Krukonis, 360 Merrimack Street, Lawrence, MA 01843
} 


\section{Developments in supercritical wood impregnation}

In Paper I, the scientific developments within the field of supercritical wood impregnation were reviewed.

Research efforts have primarily been focused on answering the questions 1) what effect does supercritical treatment have on physical and mechanical properties of wood? 2) can supercritical treatment deliver a sufficient amount of biocide to the wood? 3) does supercritical impregnation slow down biodegradation rates? In addition, there have been some efforts concentrated at modeling the supercritical wood impregnation process.

All published research on supercritical wood impregnation has been carried out using carbon dioxide. A number of studies have examined the effect of supercritical carbon dioxide on the mechanical wood properties - mainly MOR (modulus of rupture) and MOE (modulus of elasticity) [29-33]. Some of these studies report of significant changes in physical properties, while others did not observe any significant changes as a result of treatment. The same was true for studies on wood composites [33-35]. Pressurization and depressurization rates are not consistently stated in these studies and it is likely that some of the reported adverse effects on physical properties were caused by development of excessive pressure differences in the samples. The fact that the physical properties of many samples were unaffected, even after exposure to treatment pressures above 300 bar as reported in [32] seems to suggest that supercritical carbon dioxide in itself does not significantly affect the physical properties of wood. Similarly, the strength of the internal bonds between wood and adhesives in wood composites seem to be unaffected by exposure to supercritical carbon dioxide [36]. However, the jury is still out on this issue and will remain so until someone makes a study where samples are pressurized and depressurized at low rates so the potential influence of the differential pressure factor can be dismissed.

Because the exposure to supercritical carbon dioxide does not seem to be a source of damage to the wood on its own, impregnation of any wood species should be possible. The key to avoiding damages in the wood structure lies in controlling pressurization and depressurization rates so that excessive pressure differentials in the wood do not develop. The density of carbon dioxide increase by a factor of more than 450 from 1 to 150 bar at $40{ }^{\circ} \mathrm{C}$ indicating the significant mass flow through the wood during supercritical impregnation. Permeability is a measure of the resistance of an object to fluid flow. It is therefore a key 
parameter in determining how fast a piece of wood can be pressurized and depressurized without being damaged [37]. Several studies have investigated the effect of different pressurization rates on the development of pressure differentials inside treated samples [15,38-42]. Most of these studies concluded that pressurization rates and depressurization rates were correlated with internal pressure response and, thus, the permeability of the samples. Oddly, the only study that actually measured the permeability of the samples was unable to find a correlation between internal pressure response and permeability of softwood samples [40]. A few studies have examined the influence of exposure to supercritical carbon dioxide on the permeability of samples $[40,43]$. These are discussed further in the next chapter and in Paper II.

Biocide deposition and distribution are important criteria for any wood impregnation process. Several investigators have measured deposition and distribution after supercritical impregnation. Experiments have been carried out on both solid wood and on wood composites and with a range of organic biocides and have shown supercritical carbon dioxide being able to impregnate a wide range of wood species and wood composites with organic biocides [32,44-50]. The studies have showed that supercritical carbon dioxide can impregnate wood with a sufficient amount of biocides. However, many studies report of more or less pronounced concentration gradients in impregnated samples. Concentration gradients are unwanted since they mean that if the core of a sample is to meet a concentration target, the outer part of the sample will be over-treated resulting in a waste of biocide.

The reasons for the observed gradients are seldom discussed in detail but some attempts have been done at clarifying the influence of operating conditions on biocide distributions [47-50]. Although distributions seem to be influenced by operating conditions it is difficult to draw any definitive conclusions about the influence based on the available literature. Kang et al. [50], for example, investigated the distribution of cyproconazole in ponderosa pine impregnated at the four combinations of temperature and pressure $\left(\mathrm{T}=40\right.$ or $60{ }^{\circ} \mathrm{C} ; \mathrm{P}=103$ or 206 bar). At $60{ }^{\circ} \mathrm{C}$, the deposition in samples treated at $206 \mathrm{bar}\left(370 \mathrm{~g} / \mathrm{m}^{3}\right)$ was higher than the deposition at 103 bar $\left(153 \mathrm{~g} / \mathrm{m}^{3}\right)$ perhaps reflecting the density increase of $\mathrm{CO}_{2}$ at higher pressure. However, at $40{ }^{\circ} \mathrm{C}$ the deposition at 206 bar $\left(378 \mathrm{~g} / \mathrm{m}^{3}\right)$ was substantially lower than the deposition at 103 bar $\left(510 \mathrm{~g} / \mathrm{m}^{3}\right)$ making it difficult to reach a conclusion about the influence of any of the three parameters, temperature, pressure, and density. 
Lucas et al. [51] indicated that wood-biocide interactions under supercritical conditions might be substantial. Wood-biocide interactions might therefore be an important factor in determining deposition and distribution of biocides in supercritical impregnation.

In paper III and Paper IV we examined the interactions between wood and biocides in an atmosphere of supercritical carbon dioxide and hypothesized that the reason for the observed concentration gradients in impregnated wood could be due to the wood filtering the biocides from the $\mathrm{CO}_{2}$ as the fluid mixture moves through the wood matrix. We also showed that the prevailing physical conditions had a large influence on the magnitude of the wood/biocide interactions. It should therefore be possible to influence the concentration gradients by controlling the impregnation conditions.

The ultimate goal of the supercritical impregnation process is to make the impregnated wood products less susceptible to biological degradation such as breakdown by fungi and/or insects. Several studies have investigating the biological performance of impregnated wood products. Most of these have been laboratory decay tests [52-57], but a few results from field tests have also been reported [58,59]. These studies conclude that if a sufficient amount of biocide is delivered to the wood biodegradation rates will decrease compared to non-treated controls. In other words, biocides deposited by the supercritical impregnation process retain their toxicity and supercritical impregnated wood can therefore slow down biodegradation. Finally, a report comparing the performance of commercially available supercritical impregnated wood with pressure (liquid) impregnated samples as well as non-treated controls under tropical (Malaysia) and temperate (Denmark) conditions is available [60]. In this report, biodegradation was of the supercritical impregnated samples was slowed down significantly compared to non-treated controls. The performance of the supercritical impregnated samples was comparable with samples impregnated by conventional methods.

Summing up past research, it can be concluded that supercritical impregnation can be performed without significantly altering the physical appearance and properties of the impregnated wood. However, one must be aware of the limitations given by the wood itself and must design an impregnation schedule that takes into account the properties of the material being impregnated. Even though supercritical $\mathrm{CO}_{2}$ penetrates wood much more easily than liquids, care must still be taken to allow the wood to equilibrate pressure during the pressurization and depressurization phase. Due to a lack of progress on the modeling front 
of supercritical wood impregnation research, designing an optimal treatment schedule is for the most part currently down to trial and error.

Supercritical wood impregnation has been shown capable of depositing a sufficient amount of biocides inside wood samples and the supercritical impregnated wood have been shown capable of slowing biodegradation rates. However, the movement of biocide through the wood matrix during impregnation seem to be strongly related to the design of the impregnation schedule and therefore to the prevailing physical conditions during impregnation. Thus, in designing an impregnation cycle for supercritical wood impregnation, one has to consider not only how fast the $\mathrm{CO}_{2}$ can be transported in and out of the wood, but just as importantly how fast the biocides will be transported to the core of the wood. 


\section{Permeability of wood to supercritical carbon dioxide}

Permeability is a measure of the ability of a porous object to conduct fluids. The higher the permeability, the larger the flow the sample conducts at a given differential pressure. In supercritical wood impregnation, the bulk flow of $\mathrm{CO}_{2}$ in and out of the wood is achieved by creating a pressure difference between the exterior and the interior of the wood, i.e. by pressurizing and depressurizing the impregnation vessel. If the pressure differences build up to level that exceeds the internal strength properties of the wood, it will fail. The phenomenon is known from traditional pressure impregnation techniques using liquids and from impregnation using supercritical carbon dioxide. Excessive pressure differences during pressurization will likely result in collapse, while excessive pressure differences during depressurization will lead to split. The critical pressure difference at which damages occur will depend on the species being impregnated. For liquid pressure impregnation of softwoods it is often used as a general rule that the impregnation pressure should not exceed 14-16 bar [61]. Wood species with high permeability should be able to withstand higher pressurization and depressurization rates than low permeability species because they will equilibrate pressure differences more rapidly. Designing an optimal treatment schedule for a given species will thus depend on the permeability of that species. It is therefore of interest to examine wood permeability.

Permeability calculations for wood are frequently based on Darcy's Law for flow of fluids through porous media which states that [62]:

$$
\text { Conductivity }=\frac{\text { Flux }}{\text { Gradient }}
$$

For wood measurements conductivity is termed permeability and can write a general equation for permeability ${ }^{4}$ :

$$
k_{1}=\frac{Q_{V} \mu / A}{\Delta P / L}=\frac{Q_{V} L \mu}{\Delta P A}
$$

Darcy's Law is based on several assumptions including 1) the flow is viscous and linear, 2) the porous media is homogeneous, 3) the fluid is incompressible, and 4) there is no interaction between the fluid and the porous media.

\footnotetext{
${ }^{4}$ Symbol explanations are given in the list of symbols, page 47.
} 
All of these assumptions are violated to a certain extend in the case of flow through wood. Although longitudinal flow is predominant, flow can occur in three directions. The flow path is continuously obstructed by pits and the flow is forced to change direction to get from one tracheid to another which may cause non-linear flow, violating the first assumption. Considering the second assumption, wood is structurally complex and non-homogeneous. The third assumption is violated when permeability is measured by gases and supercritical fluids but not when the measuring fluid is a liquid. As for the fourth assumption, because of the complex chemical structure of wood most liquids and many gases will interact with wood. Nevertheless, in the lack of a perfect model Darcy's Law has been the preferred option for wood permeability calculations.

Because of the importance of wood permeability, not only supercritical impregnation but also conventional liquid pressure impregnation, data on wood permeability can be found in the literature for several species and measured with both liquids and gasses e.g. [63-65]. Permeability values are generally higher when measured by gases than when measured by liquids. For modeling of the supercritical wood impregnation process, correct permeability values are important input parameters that determine the maximum rate of mass transfer through the wood during pressurization and depressurization.

Traditionally, wood characterization for the supercritical wood impregnation process, has been carried out using permeability measurements carried out with gasses at low pressures as no permeability data exist for supercritical fluids. However, these values may not reflect the true permeability towards supercritical fluids which have densities closer to liquids. Therefore, in Paper II, the permeability of Norway spruce to supercritical carbon dioxide was measured.

For the calculation of the permeability, an equation suitable for supercritical fluids was developed, since equations could only be found in the literature for liquids and gasses. Since Darcy's Law assumes that the measuring fluid is incompressible, compensation is required for compressible fluids such as gasses and supercritical fluids.

To allow permeability to be calculated for compressible fluids such as gasses, equation (2) is written in differential form:

$k_{2}=-\frac{Q_{V} \mu}{A \mathrm{~d} P / \mathrm{d} x}=-\frac{Q_{V} \mu \mathrm{d} x}{A \mathrm{~d} P}$ 
Historically, gas permeability has been calculated in the wood science literature by the following equation:

$k_{g}=\frac{Q_{V} L \mu P_{I N}}{A \Delta P \bar{P}}$

The derivation of the equation is given below.

$Q_{V}$ is substituted with $V / t$ in equation (3):

$Q_{V}=\frac{V}{t} \Rightarrow k_{g}=-\frac{V \mu \mathrm{d} x}{t A \mathrm{~d} P}$

It is assumed that the gas can be described by the ideal gas law:

$P V=n R T$

Substituting V with nRT/P in equation (5) yields:

$V=\frac{n R T}{P} \Rightarrow k_{g}=-\frac{n R T \mu \mathrm{d} x}{t A P \mathrm{~d} P} \quad \Leftrightarrow \quad k_{g} P \mathrm{~d} P=-\frac{n R T \mu \mathrm{d} x}{t A}$

Integration and evaluation of integrals yields:

$$
\begin{aligned}
& k_{g} \int_{P_{\text {OUT }}}^{P_{I N}} P \mathrm{~d} P=-\frac{n R T \mu}{t A} \int_{L}^{0} \mathrm{~d} x \\
& \mathbb{\Downarrow} \\
& k_{g} \frac{\left(P_{I N}^{2}-P_{\text {OUT }}^{2}\right)}{2}=\frac{n R T \mu L}{t A} \\
& \mathbb{} \\
& k_{g}=\frac{2 n R T \mu L}{t A\left(P_{I N}-P_{\text {OUT }}\right)\left(P_{I N}+P_{\text {OUT }}\right)}
\end{aligned}
$$

Since the $\left(P_{I N}+P_{\text {OUT }}\right) / 2$ equals $\bar{P}$ and $P_{I N}-P_{\text {OUT }}$ equals $\Delta P$ we arrive at equation (4):

$$
\begin{aligned}
& \frac{\left(P_{I N}+P_{\text {OUT }}\right)}{2}=\bar{P} \quad ; \quad\left(P_{I N}-P_{\text {OUT }}\right)=\Delta P \quad ; \quad n R T=P V \\
& \Downarrow \\
& k_{g}=\frac{V L \mu P_{I N}}{t A \Delta P \bar{P}} \quad \Leftrightarrow \quad k_{g}=\frac{Q_{V} L \mu P_{I N}}{A \Delta P \bar{P}} \quad \text { (=eq. (4)) }
\end{aligned}
$$

Equation 4 (= eq. 11) has been used extensively in the literature when calculating gas permeability of wood e.g. [66-71]. Experiments are usually done by applying a pressure differential over small wood dowels at pressures very close to atmospheric levels and recording the resulting volumetric gas flow through the dowel. The pressure differential is usually created by drawing a vacuum on one the outlet of the dowel or by creating a slightly increased pressure at the inlet. Equation 4 might be adequate to calculate permeability at 
atmospheric levels. However, when calculating permeability at higher pressures, as is needed when calculating permeability for supercritical fluids, equation 4 might not give a correct estimate of the permeability since the supercritical fluid will not show ideal gas behavior.

To allow for the calculation of permeability of non-ideal gases we look at mass flow instead of volumetric flow. The general expression for permeability measured with compressible fluids (eq. 3) still applies:

$k_{3}=-\frac{Q_{V} \mu}{A \mathrm{~d} P / \mathrm{d} x}=-\frac{Q_{V} \mu \mathrm{d} x}{A \mathrm{~d} P}$

$Q_{V} / A$ is the velocity, $v$, of the flow through the object:

$\frac{Q_{V}}{A}=v \Rightarrow k_{3}=-\frac{v \mu \mathrm{d} x}{\mathrm{~d} P} v=-\frac{k_{3} \mathrm{~d} P}{\mu \mathrm{d} x}$

Dividing $v$ with the specific volume, $V_{m}$, yields the flux of matter, $J$, through the object:

$J=\frac{v}{V_{m}}=-\frac{k_{3} \mathrm{~d} P}{V_{m} \mu \mathrm{d} x}$

Multiplication with $A$ yields the mass flow per time unit, $Q_{M}$ :

$Q_{M}=A J=-\frac{k_{3} A \mathrm{~d} P}{V_{m} \mu \mathrm{d} x}$

$\Uparrow$

$k_{3} \frac{\mathrm{d} P}{V_{m}}=-\frac{Q_{M} \mu \mathrm{d} x}{A}$

If conditions are constant, $Q_{M}$ has the same value at any point in the object and can be calculated from the volume of the gas at either inlet or outlet pressure from an equation of state. It is assumed that $V_{m}$ is a known function of $T$ and $P$. Integration of eq. (16) yields:

$k_{3} \int_{P_{I N}}^{P_{\text {OUT }}} \frac{\mathrm{d} P}{V_{m}}=-\frac{Q_{M} \mu L}{A}$

Since $P_{\text {OUT }}<P_{I N}$, the integral on the left hand of equation 17 is negative and we term it $-I_{P}$. The integral can be approximated by numerical integration. Finally, we arrive at:

$k_{3}=\frac{Q_{M} L \mu}{I_{P} A}$

Equation 18 was used for the calculations of permeability values in Paper II. A custom made apparatus was assembled for the collection of data (Figure 15). 


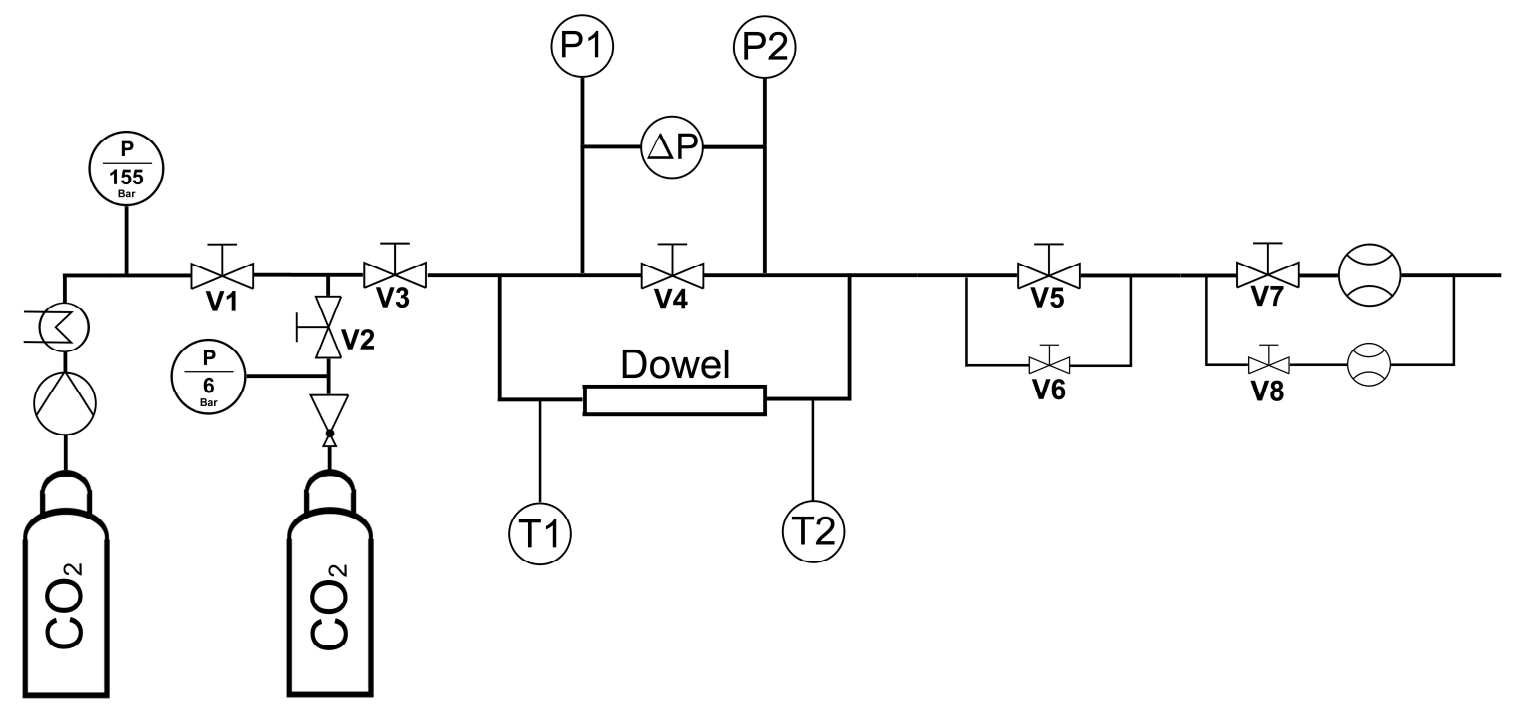

Figure 15. Schematic presentation of the experimental set-up for measuring permeability at high pressure.

A wood dowel, glued into a metal tube with epoxy, was mounted on the apparatus in such a way that a pressure differential could be established over the dowel. With the pressure differential established, the resulting volumetric flow through the dowel was measured with either a liquid displacement flow meter or a bubble flow meter. From the collected data (flow rate, inlet pressure, differential pressure, temperature, fluid viscosity) the permeability was calculated using eq. (18).

For every dowel, three measurements were carried out in succession. First, the permeability was measured at atmospheric levels by applying an inlet pressure of 6 bar and leaving the outlet open to the atmosphere. A second measurement was then taken at supercritical conditions $\left(\mathrm{P} \sim 155\right.$ bar, $\mathrm{T} \sim 45{ }^{\circ} \mathrm{C}$ ). Finally, after depressurizing the dowel, a third measurement was taken at atmospheric levels to investigate the effect of the exposure to supercritical conditions on the permeability of the wood. Pressurization and depressurization was done at a constant rate of 5 bar per minute to avoid building up excessive pressure differences which could potentially damage the dowel.

Effect of supercritical $\mathrm{CO}_{2}$ on the post-treatment permeability of Norway spruce

Comparing the permeability from the atmospheric measurements, before and after exposure to supercritical conditions, we found a slight but statistically significant increase in permeability 
after treatment (Paper II). The average increase was found to be $12 \%$ with individual changes ranging from $-14 \%$ to $+62 \%$ (Figure 16).

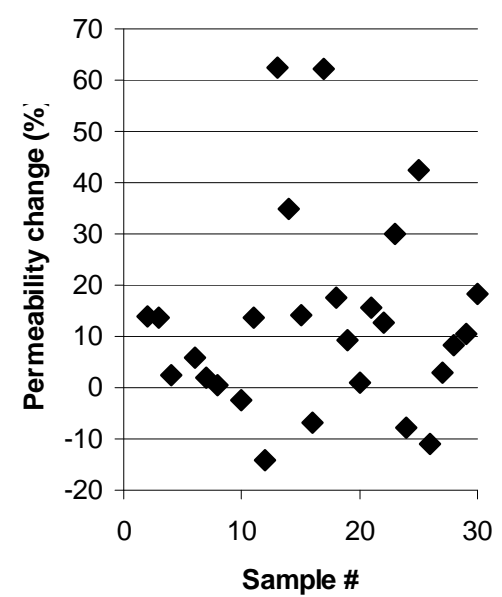

Figure 16. Permeability change in percent as a result of exposure to supercritical $\mathrm{CO}_{2}$.
In a similar study, Sahle-Demessie et al. [43] compared the permeability of Douglas fir dowels before and after exposure to supercritical carbon dioxide. They found the average permeability to increase $133 \%$. Similar to the findings in Paper II, they observed a large variation in the results with one fifth of the samples recording a decreased permeability after treatment. Douglas fir contains a relatively high amount of extractives and the authors argued that solubilization and removal of extractives clogging pit membranes might be the reason for the enhanced permeability of treated samples. Likewise they suggested that redeposition of solubilized extractives on the pit membranes during depressurization might account for the decreased permeability in some samples.

As part of a study examining effects of wood characteristics on pressure response in wood during impregnation, Schneider et al. [40] examined permeability changes in 12 different species after exposure to supercritical carbon dioxide. Their study measured permeability in the radial direction and found a large variation between species. Six of the examined species had permeability increased as a result of treatment while permeability of the remaining six species was decreased. They did not propose potential explanations for the large variation.

The slightly increased permeability after treatment found in our study could possibly be caused by removal of extractives in the wood by the supercritical carbon dioxide as suggested by the authors above. If extractives clogging the pit membrane are solubilized it might cause deaspiration of the pits. However, Norway spruce contains only low amounts of extractives and no significant weight change of the dowels was observed in our study as a result of exposure to supercritical $\mathrm{CO}_{2}$. The low amount of extractives in Norway spruce is primarily located as resin in the resin canals. It is possible that supercritical carbon dioxide could extract the resin from the resin canals. Unplugging the resin canals might have a significant impact 
on the permeability of the wood, because of the canals unique anatomy. The longitudinal tracheids through which the flow must otherwise occur, are as explained earlier, geometrically narrow tubes which are limited in length. Flow through the tracheids is continuously facing obstructions in the form of dead ends at the end of the tracheids and aspired bordered pits in the cell walls. In contrast, the longitudinal resin canals have a diameter ten times or more that of the largest tracheids and run unobstructed for considerable distances through the wood. If these canals, albeit few in numbers, are unplugged by supercritical treatment it could potentially upon up large unobstructed flow paths that might account for the increased permeability as a result of exposure to supercritical carbon dioxide.

\section{Permeability of Norway spruce measured by supercritical carbon dioxide}

Compared to the measurements with gaseous $\mathrm{CO}_{2}$ at near atmospheric levels, the permeability of Norway spruce increased when measured with supercritical $\mathrm{CO}_{2}$. The measurements done at around 155 bar and $45{ }^{\circ} \mathrm{C}$ increased $250 \%$ on average compared to the low pressure measurements. Except for one outlier, individual changes ranged between 20-500 \% (figure 17).

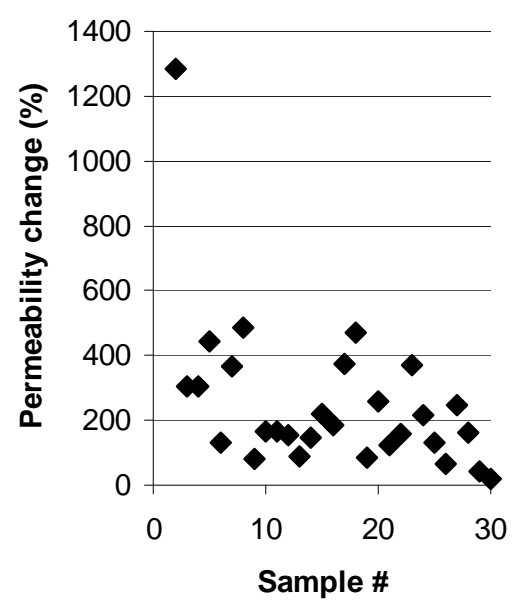

Figure 17. Percent change in permeability from measurements at close to atmospheric pressures to measurements with supercritical $\mathrm{CO}_{2}$ at 150 bar.
The substantial increase in permeability is temporary because, as was illustrated above, the permeability after treatment drops again to levels comparable to the permeability before treatment. Thus, the increase does not seem to be the result of damages like cracks and splits that might have developed during treatment. Had splits in the wood been the reason for the increased permeability above the critical pressure an increased permeability would have been expected after treatment as well.

Differences in permeability values also exist between liquid and gas measurements. Permeability values measured with a gas are often higher than when measured with a liquid. This difference has been explained by the influence of Knudsen flow, or slip-flow, which would be proportionally higher in gas flow than in liquid flow. Slip flow 
occurs at Knudsen numbers ${ }^{5}$ of 1 or above, i.e. when the mean free path of the molecules are in the same range or larger than diameter of the tube in which they are flowing [72]. In this case, the flow is primarily restricted by molecular collisions with the tube wall and not by intermolecular collisions. This creates an additional slip-flow factor because the fluid velocity at the capillary walls is different from zero as is assumed in viscous flow. Even though the diameters of the tracheids are substantially larger than the mean free path of air molecules ${ }^{6}$, the dimensions of the pits approach these values. In addition, many gas permeability measurements have been carried out by drawing a vacuum on the outlet side, increasing the mean free path and thus the Knudsen number further.

However, considering the difference in permeability from the gas measurements to the supercritical measurements, the liquid like density of the supercritical fluid would lead to a much lower mean free path compared to the gas. Thus, contrary to the observation, the permeability measured with supercritical fluids should be lower, not higher, than the permeability measured by gases.

A possible explanation for the increased permeability at supercritical pressures could be that the carbon dioxide in its supercritical state is able to permeate the numerous aspirated tori in the bordered pits separating the longitudinal tracheids. For reasons explained earlier the tori has developed with evolution to be impermeable to liquids and gases at atmospheric levels. However, it is likely that the torus at supercritical conditions could behave as a permeable membrane which would allow some degree of flow of supercritical carbon dioxide. Each tracheid has numerous bordered pits and if these become permeable, despite their aspired state, it could cause a substantial increase in permeability. This hypothesis might also explain the large spread in permeability changes between samples which ranged from $20-500 \%$. The samples showing the higher changes might be samples with a higher number of aspirated tori per volume of wood. However, no studies could be found discussing the variation and number of pits per volume of wood in Norway spruce.

The implications of the higher permeability at supercritical pressures is that, for supercritical wood impregnation, it is not sufficient to measure permeability at atmospheric levels if one wants to have a correct measure of the permeability in the entire pressure range. A precise estimate of the permeability is important when modeling the mass transfer of $\mathrm{CO}_{2}$ in and out of the wood during impregnation. The modeled pressurization and depressurization

\footnotetext{
${ }_{6}^{5}$ Knudsen number $(\mathrm{Kn})=$ mean free path $(\mathrm{m}) /$ capillary diameter $(\mathrm{m})$

${ }^{6}$ The mean free path of $\mathrm{N}_{2}$ molecules at atmospheric pressure is around $60 \mathrm{~nm}$.
} 
rates will depend on the permeability values. With the indication that permeability is higher at higher pressures, it is likely that pressurization and depressurization rates will be underestimated at higher pressures. However, additional measurements are needed to support the modeling effort. The findings presented here, naturally leads to the follow up questions: If permeability is higher at 150 bar what is it then at intermediate pressures? Is the increase linear with pressure or does it rise suddenly e.g. after passing the critical pressure? Answering these questions would be relevant goals for future research. 


\section{Wood-biocide interactions in supercritical carbon dioxide}

Wood biocide interactions are important because they may determine the transport of biocides through the wood structure during impregnation. The purpose of supercritical wood impregnation is to deposit chemicals in the wood matrix. The speed of which this can be done is important for the overall economy of the process. It therefore becomes important to know the speed at which, not only $\mathrm{CO}_{2}$ moves through the wood structure, but just as importantly how fast a given biocide dissolved in the $\mathrm{CO}_{2}$ penetrates the wood. In Paper III, it was illustrated that the velocity by which the biocides enter the wood might very well be different from the velocity of the $\mathrm{CO}_{2}$.

Several investigators have described concentration gradients in wood samples after supercritical treatment [32,44-49]. The concentration gradients arise even though in-situ pressure measurements from the interior of wood samples during impregnation can confirm the complete penetration of treatment solution in wood samples [15,38-42]. The wood seems to be filtering the biocides from the $\mathrm{CO}_{2}$ as the supercritical mixture flows through the wood. The experiment in Paper III was set up in an attempt to show whether such a chromatographic effect was indeed taking place and, if so, whether its magnitude could be quantified.

A column packed with sawdust from Norway spruce was mounted on a supercritical chromatograph (figure 18). A flow of supercritical $\mathrm{CO}_{2}$ was established through the length of the column. Three different organic biocides, tebuconazole, propiconazole, and, IPBC (figure 19) were injected separately to the pre-column stream of $\mathrm{CO}_{2}$ at various supercritical conditions: 80,100 , and 150 bar at $40{ }^{\circ} \mathrm{C}$ as well as 80,110 , and 150 bar at $50{ }^{\circ} \mathrm{C}$. The time for the fungicides to pass the wood packed column was determined using a UV-detector mounted downstream from the column.

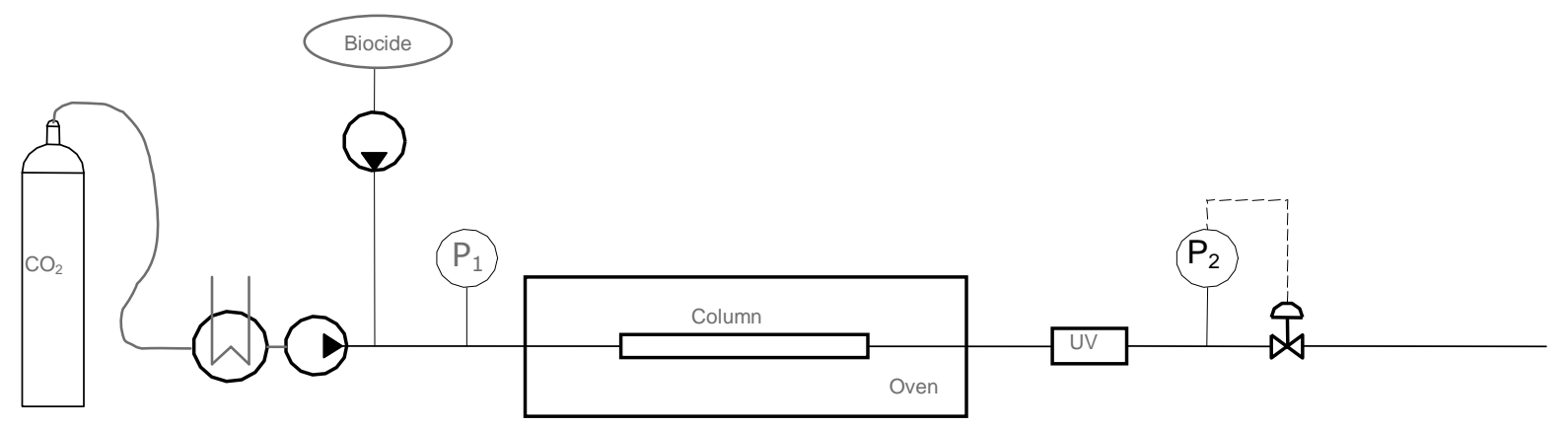

Figure 18. Schematic presentation of the experimental set up used to examine wood-biocide interactions. 


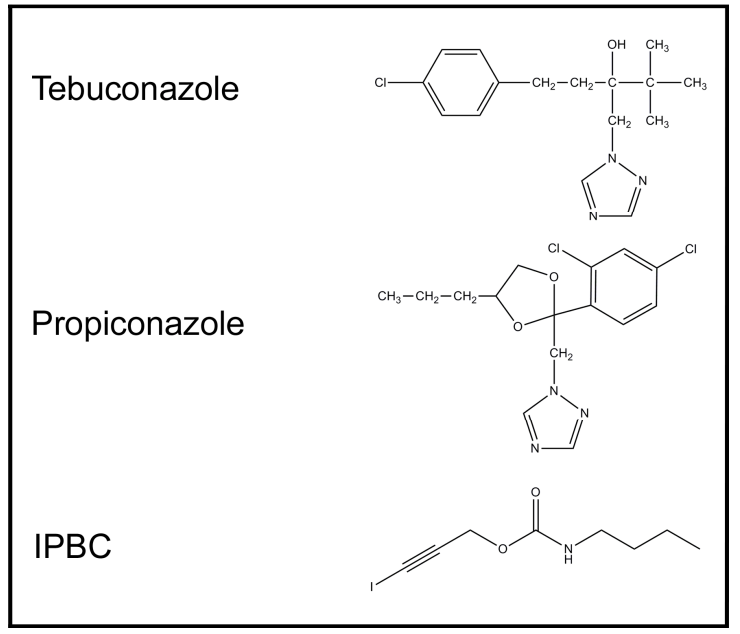

Figure 19. Chemical structure of the investigated biocides.
The results confirmed the chromatographic effect of wood. The movement of biocides through the column was significantly slower than the movement of carbon dioxide. The retention times were significantly different for the three biocides at any one pressure/temperature combination. As the physical conditions were changed, the retention times of the fungicides changed accordingly.

The retention times are measures of the degree of interaction between the biocides and the wood. The higher the degree of interaction, the longer the retention times. However, the retention times are not immediately comparable between each set of physical conditions because of the differences $\mathrm{CO}_{2}$ density and, thus, flow rate at the different conditions. Therefore, partition ratios were calculated to enable comparison of the degree of interaction between biocides and wood across the selected physical conditions. If a piece of wood is added to a vessel containing a biocide dissolved in $\mathrm{CO}_{2}$, some of the biocide will adsorb to the wood in a reversible process. Depending on the affinity of biocide to the wood and on its solubility in $\mathrm{CO}_{2}$ at the prevailing conditions, an equilibrium will be established between the concentration of biocide in the wood and in the $\mathrm{CO}_{2}$. The partition ratio is a measure of this equilibrium, i.e. the relation between the concentration of biocide in the wood and the $\mathrm{CO}_{2}$. A large partition ration indicates a strong affinity of the biocides to the wood. The partition ratios $\left(K_{D}\right)$ were calculated from:

$$
K_{D}=\frac{k^{\prime *} V_{M}}{V_{S}}
$$

where $V_{M}$ is the volume of the mobile phase and $V_{S}$ is the volume of the stationary phase. $k^{\prime}$ is the retention factor given by:

$k^{\prime}=\frac{t_{R i}-t_{M}}{t_{M}}$

where, $t_{R i}$ is the retention time of biocide $i$ and $t_{M}$ is the hold-up time, i.e. the retention time of $\mathrm{CO}_{2}$ through the column. 
The calculated partition ratios were shown to increase isobarically as temperature was increased from $40{ }^{\circ} \mathrm{C}$ to $50{ }^{\circ} \mathrm{C}$ and isothermally as pressure was decreased from 150 bar to 80 bar. Thus, the partition ratios were shown to decrease with increasing density of $\mathrm{CO}_{2}$ (figure 20).

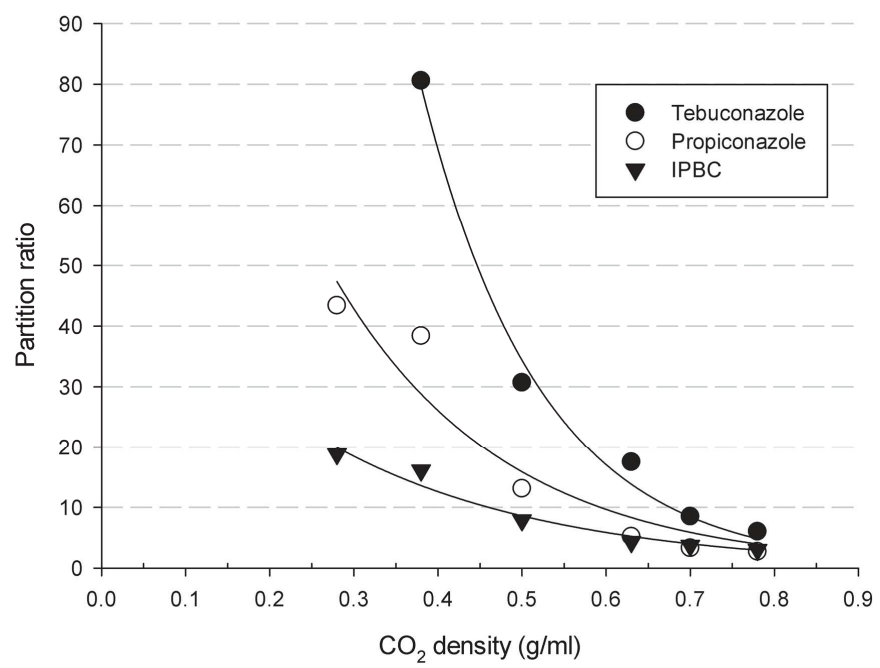

Figure 20. Partition ratios as a function of $\mathrm{CO}_{2}$ density.
The results show that when the $\mathrm{CO}_{2}$ /biocide mixture penetrates the wood during impregnation the $\mathrm{CO}_{2}$ will move faster than the biocides because of the chromatographic effect of the wood. If the direction of flow is changed too early (depressurization), a concentration gradient is likely to result because of incomplete penetration of biocides. Complete penetration of treatment fluid, which can be confirmed by in-situ pressure differential measurements, is therefore not necessarily equivalent to complete penetration of biocides. Additional impregnation time will most likely be needed to achieve satisfactory penetration of biocides.

As mentioned earlier, overall treatment time is an important parameter for the overall economy of the treatment process. A lot of publications have therefore focused on the effects of treatment on the physical integrity of the impregnated wood, i.e. will the wood be physically damaged by treatment and how fast can treatment be carried out without impairing damages? While these questions are important to answer, it is possible that the limiting factor for the overall supercritical wood impregnation time is not have fast $\mathrm{CO}_{2}$ can be forced in and out of the wood matrix, but rather how fast the biocides will be distributed in the wood.

The described method provides a means of screening existing and potential biocides with the supercritical wood impregnation process. Assuming that the goal is to get the fastest possible impregnation time, there would be an incentive to choose biocides with low partition ratios. 
A range of additional studies could be carried with the described experimental set-up, which would further enhance our understanding of wood-biocide interactions in supercritical $\mathrm{CO}_{2}$. For example, a study examining the influence of temperature at equal density would be welcome. This could be done by comparing retention times measured at e.g. $\left(40^{\circ} \mathrm{C}, 91 \mathrm{bar}\right)$; $\left(50{ }^{\circ} \mathrm{C}, 110\right.$ bar $) ;\left(60{ }^{\circ} \mathrm{C}, 129\right.$ bar $)$; and $\left(70{ }^{\circ} \mathrm{C}, 149\right.$ bar $)-$ TP-combinations that all result in a $\mathrm{CO}_{2}$ density of roughly $0.5 \mathrm{~g}^{*} \mathrm{ml}^{-1}$. Another important question is establishing the influence of wood structure on the partition ratios. The sawdust used as column material in Paper III might behave differently than solid wood and might not reflect the issues encountered when impregnating solid wood correctly. The influence of wood structure might be carried out by replacing the sawdust in the column with solid wood glued into the column. Using this approach, differences between wood species, e.g. between hardwood and softwood species could also be examined. Finally, the column material could be replaced by cellulose, hemicellulose, or lignin to investigate the relative influence of the three major wood biopolymers on the retention times. 


\section{Microdistribution of biocides}

\section{in supercritical impregnated wood}

Distribution of biocides in wood is usually described at the macroscopic level as depth of penetration. However, impregnation efficiency may be dependent on the microdistribution as well, i.e. the distribution of biocides in the individual cell walls. Certain wood destroying organisms such as soft rot fungi may be able to selectively degrade the inner parts (S2 layer) of the wood cell walls [73-75]. If biocides are only superficially deposited in the S3 layer next to the cell lumens, there might still be a risk of biodeterioration of the cell walls.

Knowledge of the microdistribution of biocides after supercritical impregnation would also give indications as to whether supercritical carbon dioxide functions as a swelling or a non-swelling solvent. Strong indications already exist that supercritical carbon dioxide acts as a swelling solvent because liquid extraction of supercritical impregnated wood yields a higher concentration of biocides when extraction is carried out with swelling solvents than with nonswelling solvents (Ole Henriksen ${ }^{7}$, personal communication).

\section{Microdistribution analyses using SEM-EDS}

An experiment was set up for measuring the microdistribution of biocides in supercritical impregnated $\operatorname{wood}^{8}$. The objective was to measure the distribution of biocides across individual cell walls using a scanning electron microscope (SEM) equipped with energy dispersive x-ray spectroscopy (EDS) for elemental detection.

The image of an SEM is produced by bombarding the sample with electrons in the form of a narrow electron beam that repeatedly scans the surface of the sample. The interaction of the electron beam with the surface of the sample causes secondary electrons to be emitted from the atoms near the surface of the sample. The secondary electrons are collected to produce the SEM image.

However, a range of other signals are produced when the primary electron beam collides with the sample. One of those signals is x-rays. When electrons are emitted from the

\footnotetext{
${ }^{7}$ Ole Henriksen, Hampen Træforarbejdning A/S, Palsgårdvej 3, 7362 Hampen, Denmark. oh@ superwood.dk

${ }^{8}$ The experiment was done in collaboration with the Department of Wood Science and Engineering at Oregon State University and Dr. Jeffrey Morrell.
} 
surface atoms as described above, they are replaced by electrons from higher energy electron orbitals within the same atom. The replacement may be accompanied by a release of energy in the form of X-rays. Each x-ray will have an energy characteristic of the element from which it originated. EDS provides information of the elemental composition of a sample by analysis of the emitted x-rays.

The technique has previously been used to examine the microdistribution of biocides in wood after conventional pressure impregnation e.g. [76-78]. These studies have examined the microdistribution of electron dense metals and metalloids such as copper, chrome, zinc, and arsenic. However, these compounds have very low solubility in supercritical carbon dioxide and could not be used in the experiment presented here. Additional studies have examined the distribution of inorganic compounds such as chlorine after conventional impregnation e.g. $[79,80]$.

In the current experiment, it was decided to impregnate with the organic fungicide IPBC (3-iodo-2-propynylbutylcarbamate CAS 55406-53-6). IPBC contains iodine which only occurs naturally in trace amounts in wood. Consequently, it should be possible to establish the distribution of IPBC in the wood by mapping the presence of iodine atoms. In addition, IPBC has a relatively high solubility in supercritical carbon dioxide. It was assumed that with an atomic number of 53, the electron density would be sufficient to enable detection in small amounts.

Accordingly, wood cubes (19 x 19 x 19 mm) from Southern yellow pine (Pinus taeda) were impregnated with IPBC by supercritical carbon dioxide. Southern yellow pine was chosen because its relatively thick cell walls would allow for better resolution between biocide loadings in the inner and outer parts of the cell walls.

The pine cubes were impregnated to a target level of $500 \mathrm{ppm}(\mathrm{w} / \mathrm{w})$, a level close to use level concentrations. After impregnation, cell walls of the inner parts of the samples had to be exposed. The easiest way of doing this would have been cutting the samples with a razorblade to achieve clear cut surfaces of the cell walls for analysis. Cutting the samples would, however, potentially cause relocation of biocides, due to the sliding motion of the blade. Thus, the samples had to be exposed without a knife blade contacting the cell walls. The initial approach was to initiate a split in the sample with a razorblade and then carefully follow the split through by pulling the sample apart without the help of the razor blade. However, the exposed radial or tangential surfaces produced by this approach turned out to be 
too fuzzy when examined in the SEM. As an alternative, small samples about $10 \times 10 \times 3 \mathrm{~mm}$ were frozen in liquid nitrogen before being broken across the longitudinal tracheids by clamping down on each "end" of the sample with a set of flat-nosed pliers (also cooled by liquid nitrogen) and then snapping the sample in two pieces. This approach caused many of the tracheids to break in such a way that a clean fracture was achieved at an angle of $90^{\circ}$ to the longitudinal axis exposing the inner layers of the cell walls nicely for analysis (Figure 1).

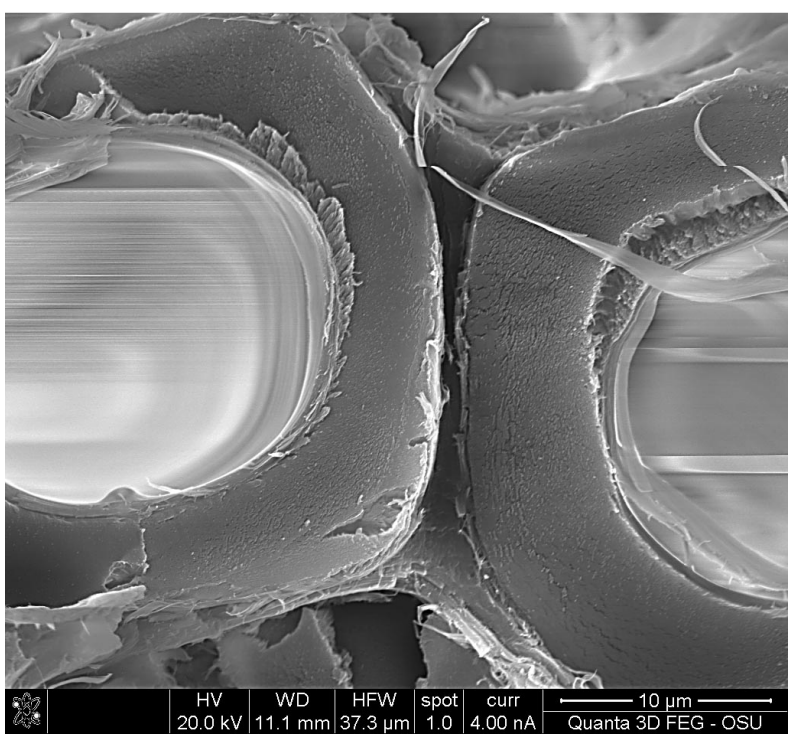

Figure 1. Cell walls of longitudinal tracheids exposed by breaking frozen samples cooled by liquid nitrogen.
Samples were examined for distribution of iodine by SEM-EDS. The acceleration voltage was set at $20 \mathrm{kV}$ with a current of 4 nA. The working distance was about 11 $\mathrm{mm}$ and the spot size was set to 1 . The microscope was zoomed in on the cell walls of the sample and information on the distribution of iodine was collected by mapping the presence of iodine in the view area. Using this approach the impregnated samples were compared to non-treated controls.

However, no iodine was found in any of the impregnated samples, i.e. no difference in iodine was detected between the samples and the controls. Figure 2 shows a typical distribution map and its corresponding image from one of the non-treated control. The distribution map shows the background noise in the cell wall when scanning for x-rays emitted by iodine atoms.
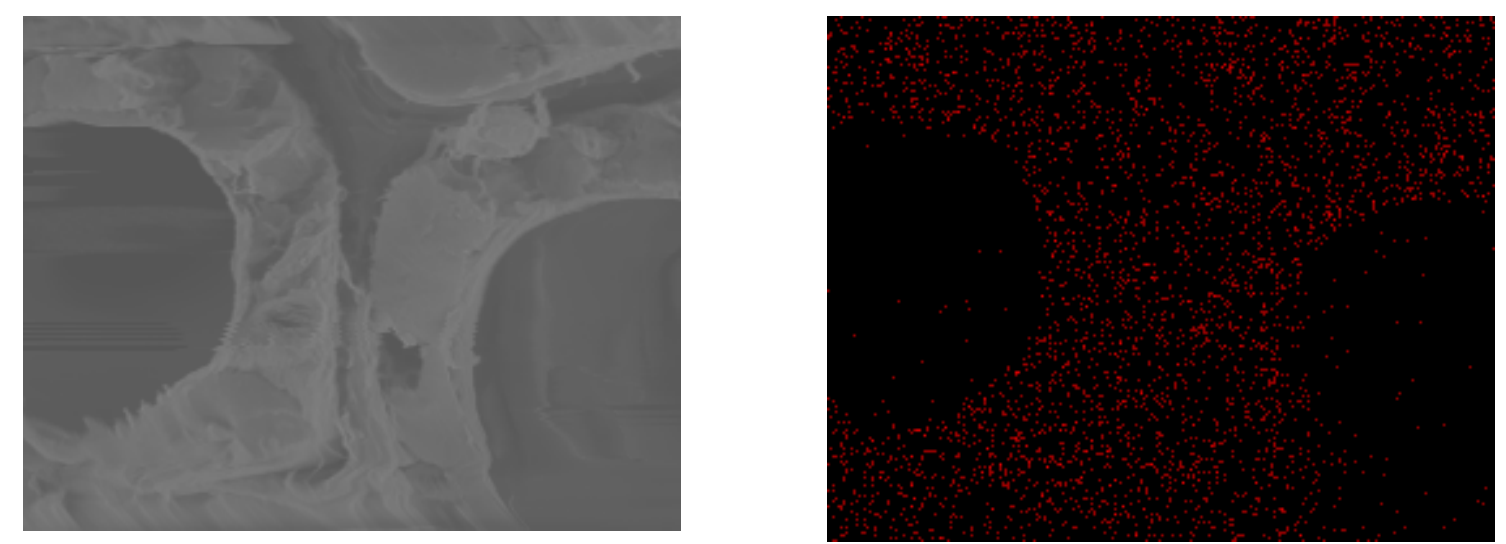

Figure 2. SEM image of exposed cell walls of Southern yellow pine (left) and the corresponding distribution map (right). The distribution map shows the background noise in the control sample (non-treated) when analyzing for iodine. 
A second set of samples were impregnated to $2000 \mathrm{ppm}$, four times the previous concentration, and analyzed for iodine content. 2000 ppm IPBC is equivalent to about 900 ppm iodine, but even with the elevated concentration it was not possible to register a difference between non-treated and treated samples.

\section{Microdistribution analyses using SEM-WDS}

After failing to map the distribution of biocides using the SEM-EDS, the experiment was repeated, this time using a scanning electron microscope equipped with wavelength dispersive spectrometry (WDS) for element detection. WDS uses the same x-rays as EDS to analyze the elemental composition of a sample, but whereas EDS scans a broad range of energies and, thus, wavelengths at the same time, WDS only analyses one wavelength and, thus, one element at a time.

The advantage of WDS is a lower detection limit than EDS. The disadvantage is that only one element can be analyzed at a time and that the spatial resolution is lower than EDS. The lower resolution meant that the microdistribution analysis across a single cell wall could not be performed. It was only possible to analyze for a larger area containing about three cell walls and the lumens in between. Since it was not possible examine microdistribution on a cell wall level, the samples for WDS analysis could be prepared by cutting with razor blades, as possible biocide "smearing" by the blades would not be an issue.

Samples for the experiment were impregnated with IPBC using supercritical carbon dioxide to a target level of $2000 \mathrm{ppm}$. Additional samples were vacuum treated with IPBC dissolved in white spirits to target levels of $6000 \mathrm{ppm}$. All samples were analyzed for iodine content by SEM-WDS and compared to non-treated controls. As had been the case with the EDS measurements, it was not possible to register any difference in iodine content between non-treated and treated samples. Not even the vacuum treated samples treated to $6000 \mathrm{ppm}$ gave a response.

Because of the inability to spot iodine, attention was changed from IPBC to propiconazole to examine if the chlorine atoms of this biocide could be detected. A new set of samples were impregnated with propiconazole, this time to a target level of $4000 \mathrm{ppm}$, equivalent to about $850 \mathrm{ppm}$ chlorine. In addition, samples were vacuum treated with 
propiconazole in white spirits to a target level of $6000 \mathrm{ppm}$. The treated samples were, together with non-treated controls, analyzed by SEM-WDS for chlorine content.

This time an increased level of chlorine was detected in the supercritical impregnated samples. However, the increase was only apparent in some of the samples. Figure 3 shows the distribution of chlorine in a non-treated control. Figure 4 shows the distribution of chlorine in four different supercritical impregnated samples. As is evident from figure 4 only two of the four samples (\#1 and \#4) had a clearly increased content of chlorine. Sample \#3 had a slightly increased content in the lower part of the analyses area, while sample \#2 did not seem to be different from the non-treated control. Two of the vacuum impregnated samples were also examined (figure 5). They did not differ noticeably from the non-treated controls, although one of the samples showed a slight increase.

The apparent difference in distribution between the samples was surprising. Because of their relatively small dimensions $(19 \times 19 \times 19 \mathrm{~mm})$ it was expected that distribution would be more or less uniform. The above samples were exposures of the radial surfaces. However, it was not noticed whether exposures were done in latewood or earlywood areas of the samples. The observed differences might have been due to some of the exposures being done in a latewood zone and some in an earlywood zone.

To examine this hypothesis, another set of samples were prepared from the same material as used for the radial exposures but this time with the tangential surfaces exposed, some in the latewood zone and some in the earlywood zone.
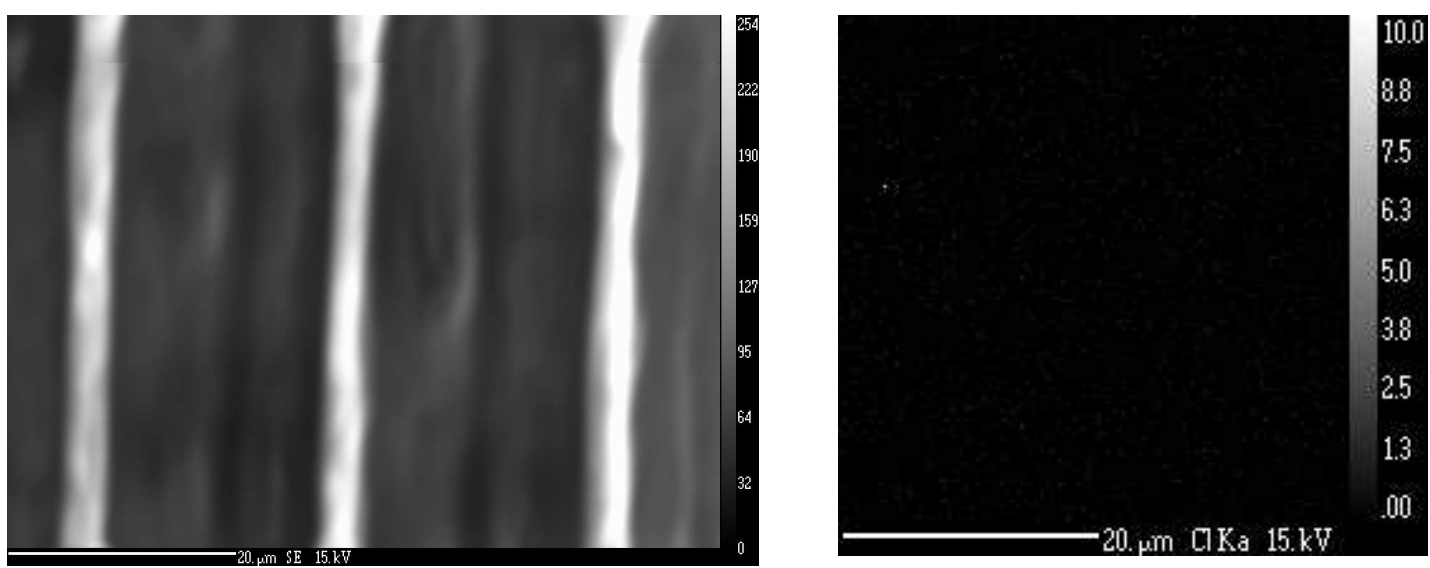

Figure 3. SEM image of the scanned area of a radial surface of Southern yellow pine control (non-treated) containing three exposed cell walls (left), and the corresponding distribution map (328x313 pixels) of chlorine as measured by SEM-WDS (right). 

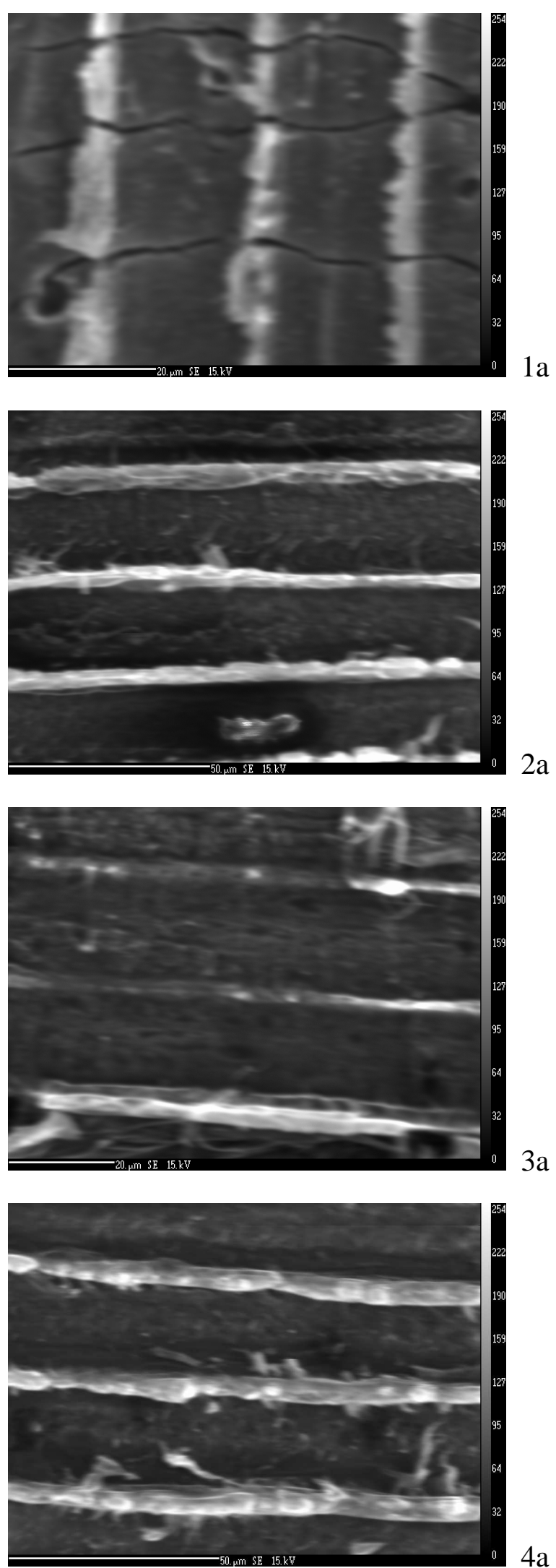

$4 \mathrm{a}$
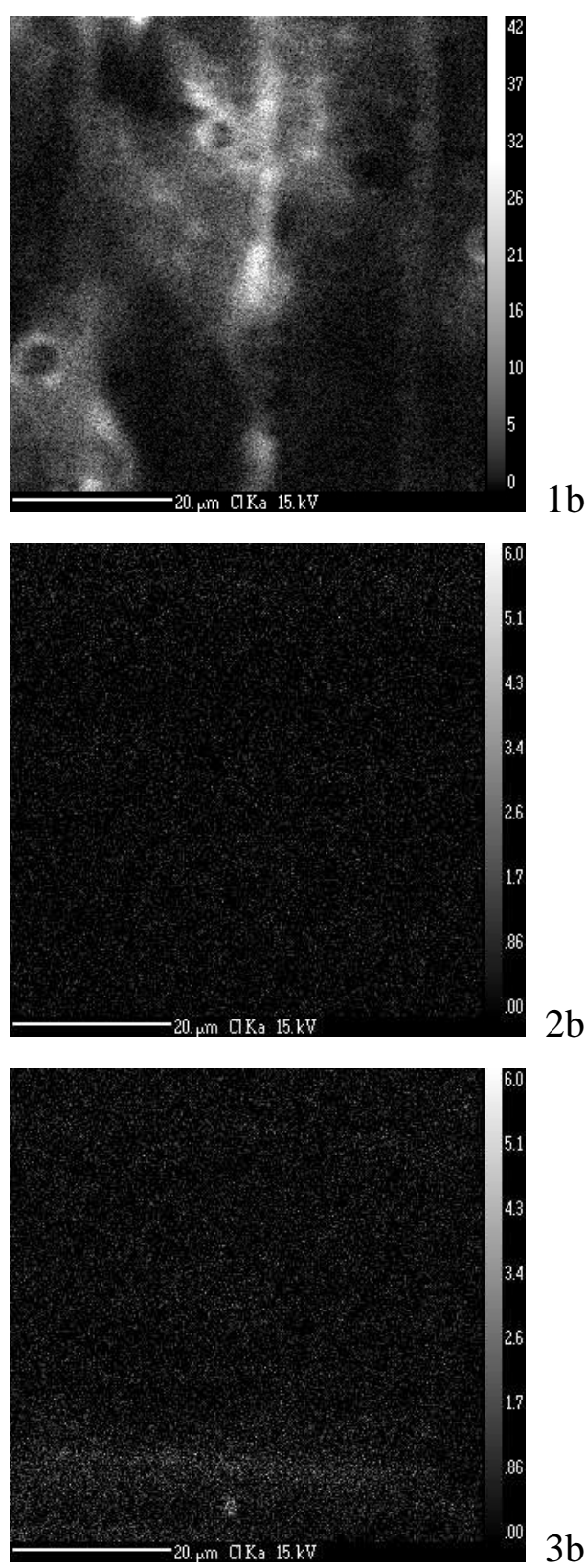

$3 b$

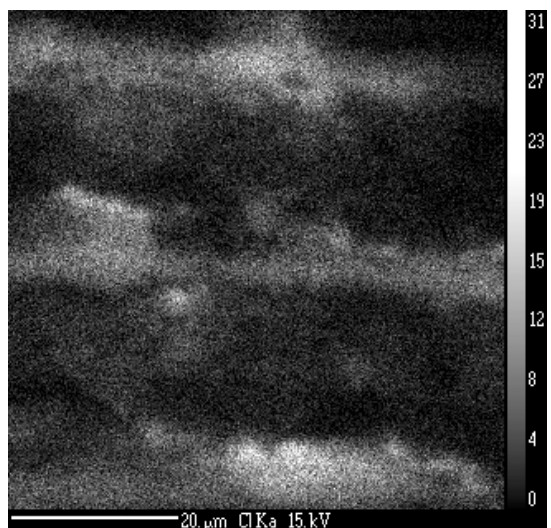

$4 b$

Figure 4. SEM images (left) of the scanned areas of radially exposed surfaces of Southern yellow pine, supercritical impregnated with propiconazole. The corresponding distribution maps (328x313 pixels) of chlorine as measured by SEM-WDS are shown on the right. 

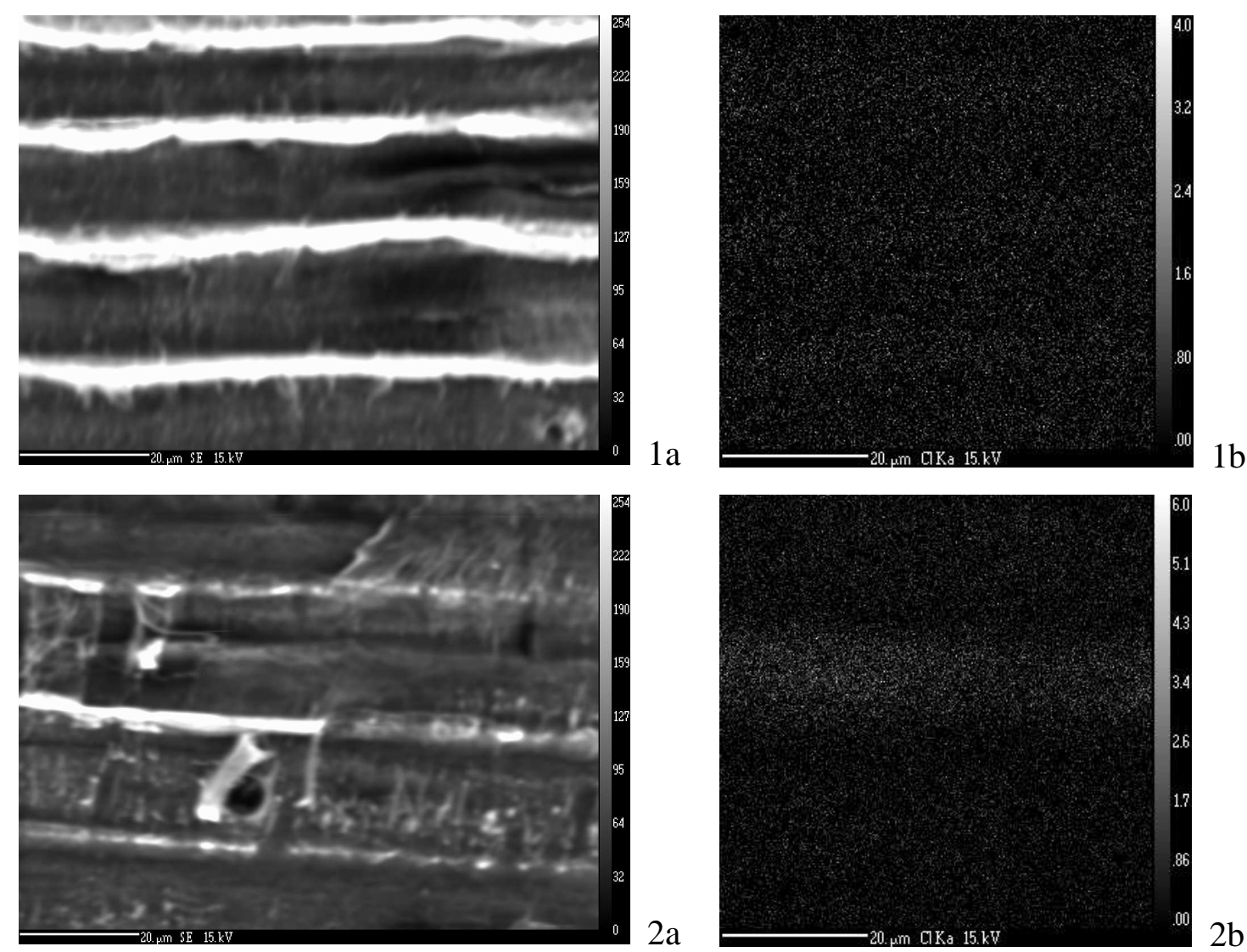

Figure 5. SEM images (left) of the scanned areas of radially exposed surfaces of Southern yellow pine, vacuum impregnated with propiconazole. The corresponding distribution maps (328x313 pixels) of chlorine as measured by SEM-WDS are shown on the right.

Figure 6 show the distribution of chlorine in the latewood and earlywood of the samples impregnated with propiconazole. An elevated concentration of chlorine is evident in both the earlywood and the latewood. However, the chlorine seemed to be concentrated in the rays rather than longitudinal tracheids. This tendency was also observed for the vacuum impregnated samples. This time the vacuum impregnated samples had a higher concentration of chlorine than the supercritical impregnated samples, but again the majority of the chlorine content seemed to be concentrated in the rays rather than the longitudinal tracheids.

The results indicate that the distribution of biocides after supercritical impregnation, as well as vacuum impregnation, is less uniform than what would be expected. The images of tangential surfaces suggest that the biocides might be present in higher concentrations in the rays than in the longitudinal tracheids. This seemed to be the case for supercritical as well as vacuum impregnated samples, although two of the four radially exposed supercritical impregnated samples apparently also had an even distribution in the longitudinal tracheids. 

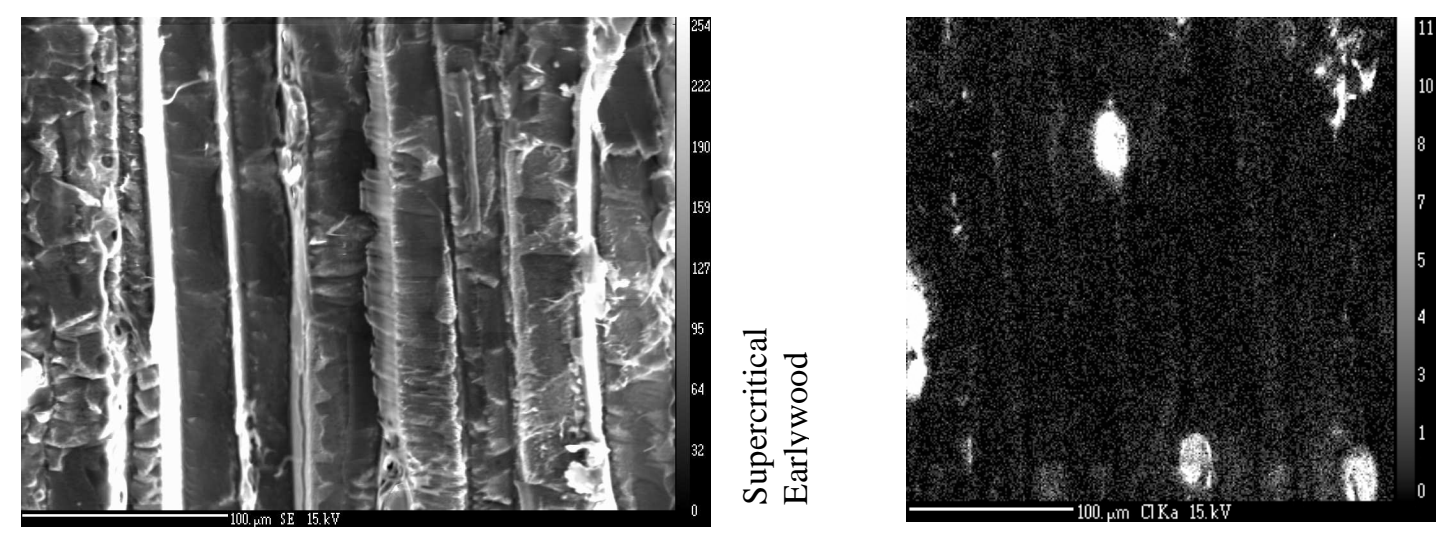

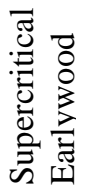
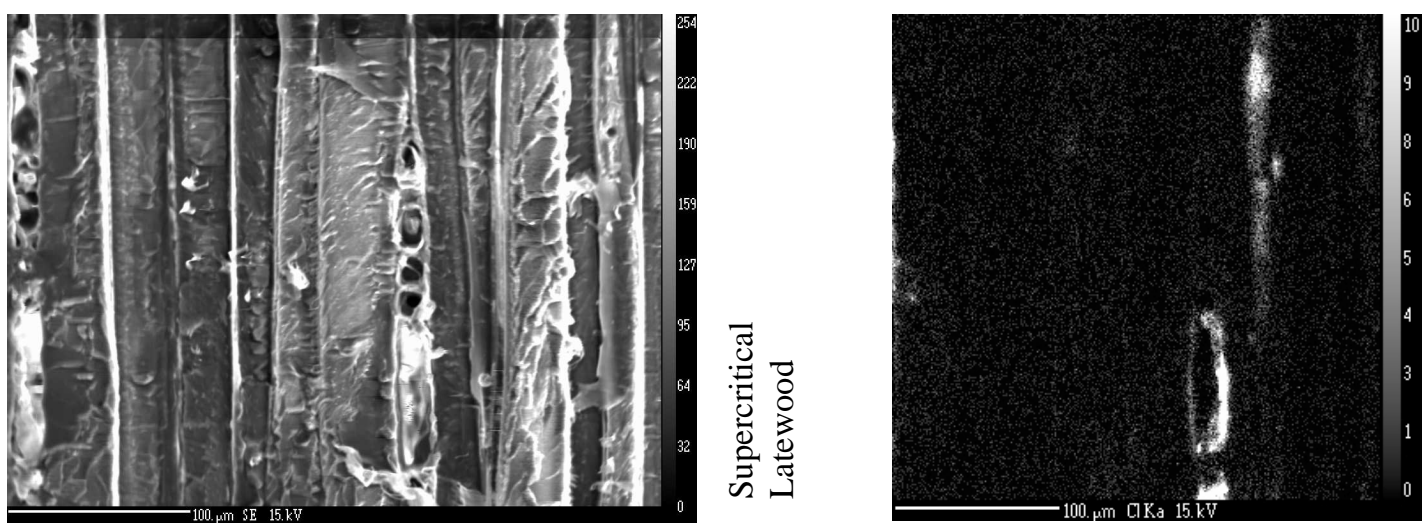

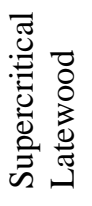
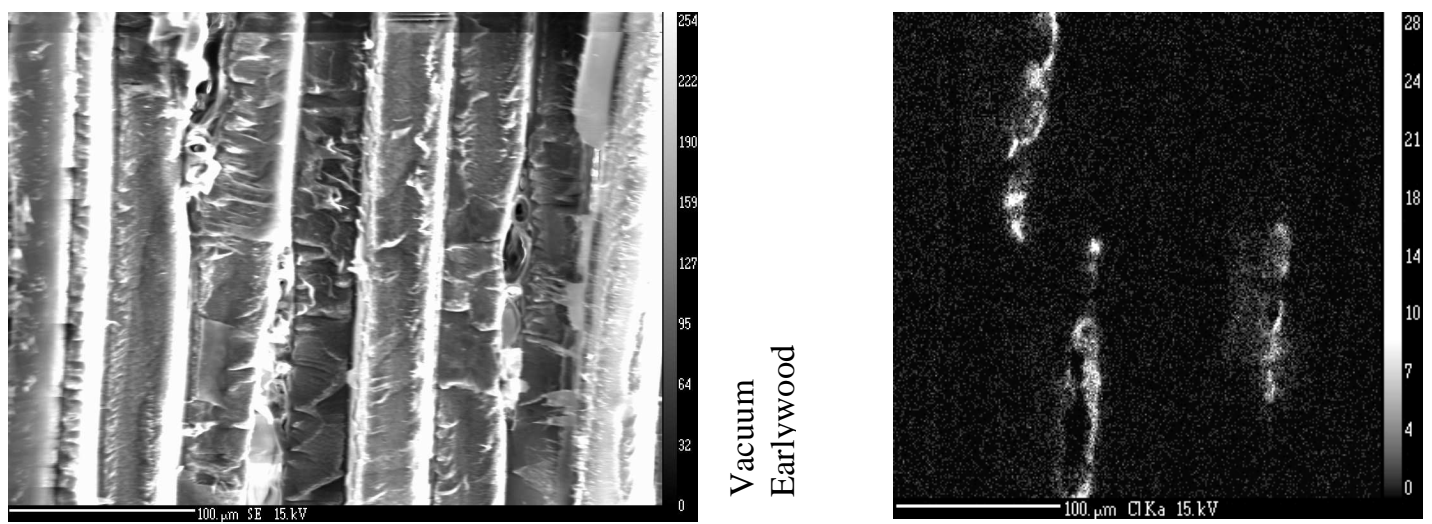

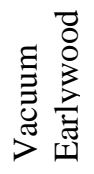
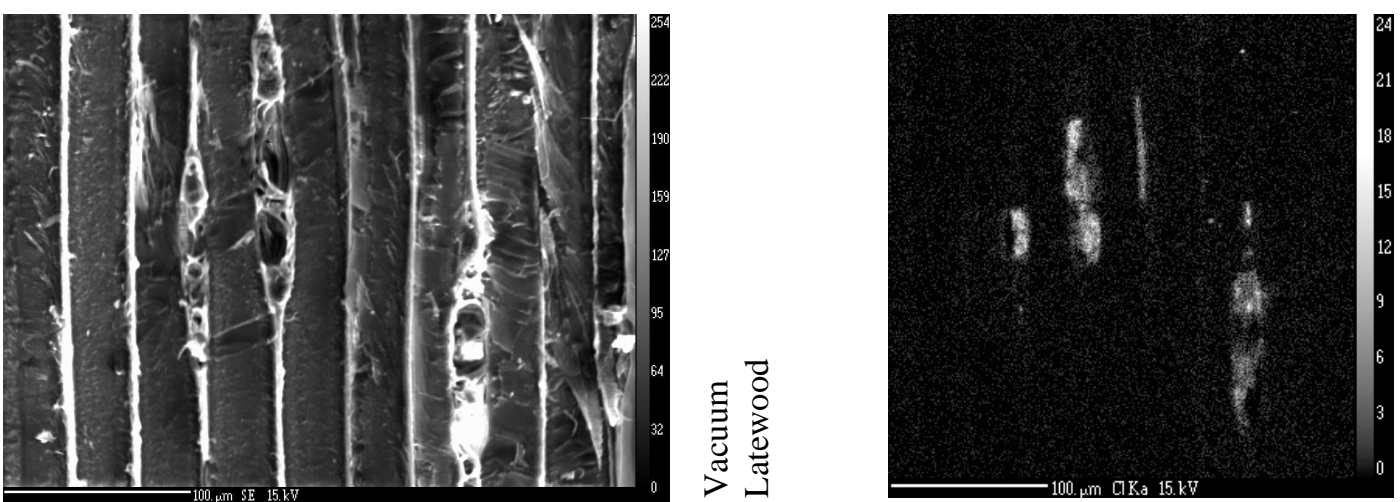

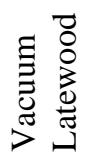

Figure 6. SEM images (left) of the scanned areas of tangentially exposed surfaces of Southern yellow pine, supercritical (top two rows) and vacuum (bottom two rows) impregnated with propiconazole. The corresponding distribution maps (328x313 pixels) of chlorine as measured by SEM-WDS are shown on the right. 
Future work on this work this subject could benefit from the following guidelines. Iodine does not seem to be easily detectable and should not be used for this purpose. Chlorine seems a better option. DeGroot and Kuster [80] successfully mapped the distribution chlorine in PCP (pentachlorophenol) impregnated wood. However, they used minimum chlorine concentrations of around $3800 \mathrm{ppm}$ which might be higher than what is achievable with deposition by supercritical carbon dioxide. Therefore, impregnation should preferably be done with saturated solutions to achieve maximum possible retention and not with use level concentrations as was done here. Alternatively, the possibility of using radioactive material could be investigated.

Having impregnated the samples, it should be established whether the microdistribution of biocides is as variable as suggested by results here. To meet this end, distribution maps should be made of both transverse, radial, and tangential sides of impregnated samples. These maps should be produced in a larger scale than the individual cell wall. Both using SEM-EDS and SEM-WDS, an area about $500 \times 500 \mu \mathrm{m}$ would be useful. Once the distribution variation on this larger scale has been established, attention can be directed at the microdistribution on a cell wall level.

It is possible that other analysis methods could be used for microdistribution studies. Kurti et al. [81] used Raman microscopy for the microdistribution studies of propiconazole in white spruce (Picea glauca). They reported a detection limit of $1000 \mathrm{ppm}$ which is achievable by supercritical impregnation. Raman microscopy would also have resolution in the range of what is needed to study for studying distributions at the cell wall level. 


\section{Summary}

Although supercritical wood impregnation has been investigated for almost two decades, our understanding of the process is still only developing. This dissertation focused on movement of carbon dioxide and biocides in wood during impregnation. Initially, past research within the field of supercritical wood impregnation was reviewed. The longitudinal permeability of wood to supercritical carbon dioxide was investigated and an equation for calculating permeability of wood when measured with non-ideal gasses was put forward. Permeability measurements suggested that supercritical treatment of Norway spruce causes a small increase in permeability of around $12 \%$ on average. The small increase in permeability might be caused by solubilization and removal of resin in the resin canals. The permeability of Norway spruce when measured with supercritical carbon dioxide was two and a half times higher than when measured with gasses. However, individual changes varied from 10-600 \%. The reasons for the apparent increase in permeability when measured with supercritical carbon dioxide is unclear, but may be caused by supercritical carbon dioxide passing through the tori of aspirated pit membranes between tracheids.

The mechanisms of biocide migration in wood during supercritical wood impregnation were examined using a supercritical chromatograph. Selected organic fungicides (tebuconazole, propiconazole, and IPBC) were transported by supercritical carbon dioxide through a column packed with Norway spruce sawdust. The retention times of the fungicides were used to calculate partition ratios as a measure of the level of wood-biocide interactions. Wood-biocide interactions were found to be substantial and highly dependent on the prevailing physical conditions. They were also highly correlated with $\mathrm{CO}_{2}$ density. The results showed that wood has a chromatographic effect on biocides and, therefore, that carbon dioxide and biocides are transported though the wood matrix at different velocities. Knowledge of the degree of interaction at different operational conditions is key to the control of biocide movement during supercritical wood impregnation and to control biocide gradients in impregnated products. In addition, as a consequence of the chromatographic behavior of wood, overall impregnation times, an important economic parameter, seems to be limited by the movement of biocides - not by the rate at which wood can be pressurized and depressurized without impairing damages. 
Microdistribution of biocides after supercritical wood impregnation using SEM-EDS was examined. Impregnation was carried out with IPBC with the aim of detecting the iodine atom of this biocide in the wood cell walls after impregnation. However, the mapping of iodine was unsuccessful since it, in the concentrations used for supercritical impregnation, was not detectable by the chosen technique. Additional experiments, carried out on wood samples impregnated with propiconazole and analyzing for chlorine using SEM-WDS, confirmed the presence of chlorine although the distribution seemed to be higher in the rays than in the tracheids. The resolution of the SEM-WDS was not high enough to plot the distribution of biocides across individual cell walls. Additional work will be needed to clarify the cell wall microdistribution of biocides deposited by supercritical fluids.

\section{Directions for research}

As frequently happens in the world of science, this work has generated more questions than answers. There should be enough challenges for several new studies within this area. Accordingly, a study on gas transport in wood at super- (and sub-) critical conditions would be valuable; as would a study focusing on the migration and distribution of biocides.

Additional work is needed to establish the development of permeability as a function of pressure. Wood seem to have a higher permeability when measured at high pressure, but it is not known whether the increase is linear from low pressure to high pressure or whether there is a sudden increase in permeability at some point e.g. beyond the critical pressure. Additional measurements of radial and tangential permeability as function of pressure could enable 3-D modeling of gas transport in wood during impregnation. Theoretical considerations of the validity of basing high pressure permeability calculations on Darcy's Law would also be welcome. Perhaps there are better ways of calculating permeability?

In this work we focused on the influence of $\mathrm{CO}_{2}$ conditions on the level of woodbiocide interactions and migration. However, the influence of the physical and chemical structure of wood is still unknown. Is biocide migration comparable in softwoods and hardwoods considering the large variation in structure? Is it comparable for softwood of different permeability? What is the role of the individual wood biopolymers in wood-biocide interactions? Which available biocides are best suited for supercritical wood impregnation? 
Finally, it should be mentioned that in the course of this work we have seen increasing evidence that there is a substantial $\mathrm{CO}_{2}$ adsorption to wood during the supercritical treatment (unpublished). The mechanisms behind the adsorption of carbon dioxide and their importance for the impregnation process are still unclear but deserve further attention. In addition, there is evidence (unpublished) that the moisture content of wood is influencing the rate of pressure equilibration during impregnation. The issue of wood moisture content and its influence on supercritical wood impregnation has been virtually non-existent in past research and is yet another area that deserves more attention. 


\section{List of symbols}

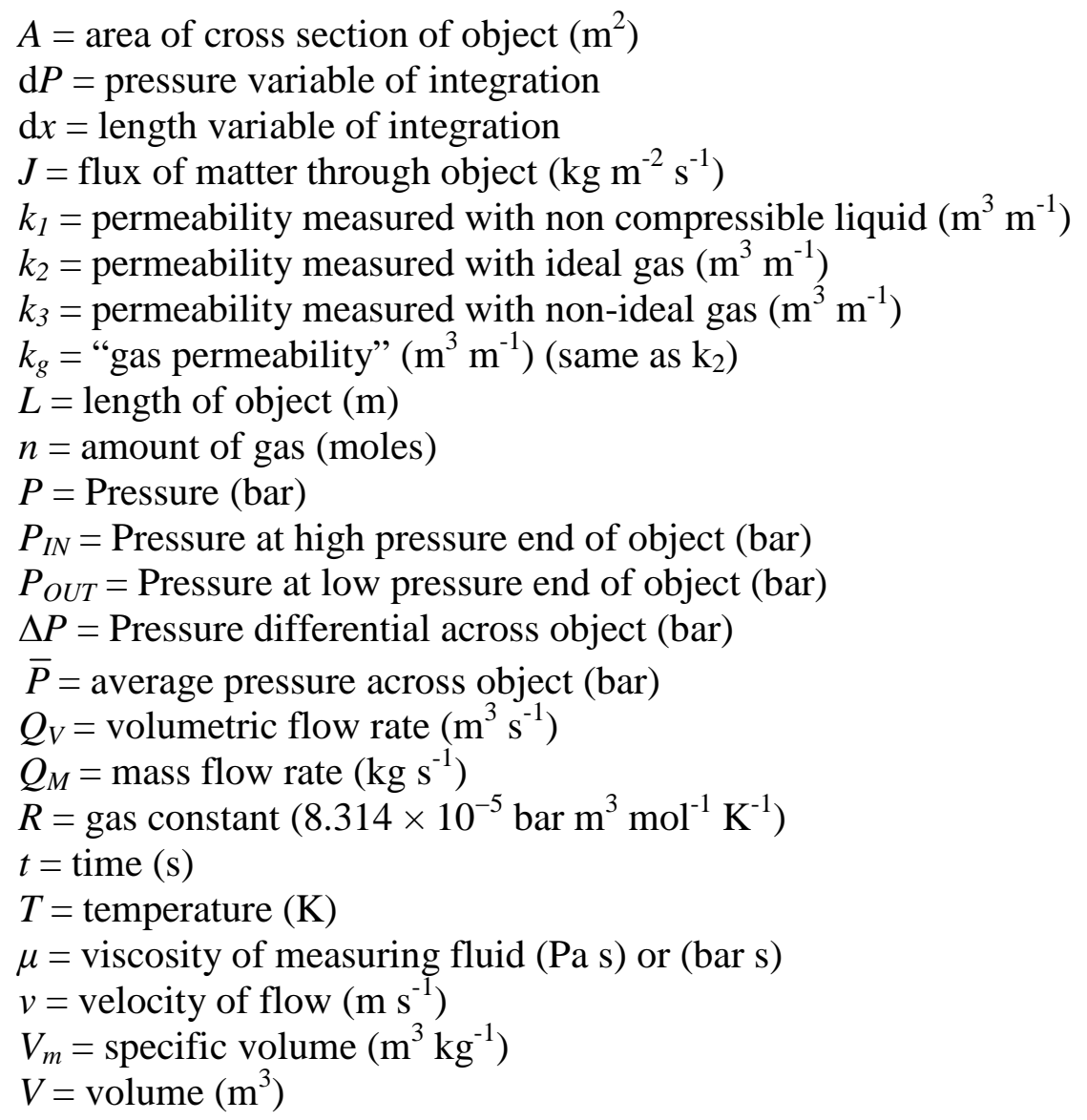




\section{References}

[1] A.W. Kjellow, O. Henriksen, Supercritical wood impregnation, Journal of Supercritical Fluids 50 (2009) 297-304.

[2] M.H. Freeman, T.F. Shupe, R.P. Vlosky, H.M. Barnes, Past, Present and Future of the Wood Preservation Industry, Forest Products Journal 53 (2003) 8-15.

[3] G. Tsoumis, Science and Technology of Wood. Structure, Properties, Utilization, Van Nostrand Reinhold, New York, 1991.

[4] J.G. Haygreen, J.L. Bowyer, Forest Products and Wood Science. An Introduction, Iowa State University Press, Ames, Iowa, 1996.

[5] S.B. Iversen, T. Larsen, O. Henriksen, K. Felsvang, The World's First Commercial Supercritical Wood Treatment Plant, The International Society for Advancement of Supercritical Fluids, 6th International Symposium on Supercritical Fluids, Versailles, France. April 28-30, 2003 (2003) 1-6.

[6] A. Pfriem, M. Zauer, A. Wagenfuhr, Alteration of the pore structure of spruce (Picea abies (L.) Karst.) and maple (Acer pseudoplatanus L.) due to thermal treatment as determined by helium pycnometry and mercury intrusion porosimetry, Holzforschung 63 (2009) 94-98.

[7] D. Fengel, G. Wegener, Wood: chemistry, ultrastructure, reactions, Walter de Gruyter, Berlin, 1983.

[8] B. Choat, A.R. Cobb, S. Jansen, Structure and function of bordered pits: new discoveries and impacts on whole-plant hydraulic function, New Phytologist 177 (2008) 608-625.

[9] W. Liese, J. Bauch, On the Closure of Bordered Pits in Conifers, Wood Science and Technology 1 (1967) 1-13

[10] U.G. Hacke, J.S. Sperry, J. Pittermann, Analysis of circular bordered pit function - II Gymnosperm tracheids with torus-margo pit membranes, American Journal of Botany 91 (2004) 386-400.

[11] M.H. Zimmermann, Xylem Structure and the Ascent of Sap, Springer-Verlag, Berlin, 1983.

[12] J.S. Sperry, U.G. Hacke, J.K. Wheeler, Comparative analysis of end wall resistivity in xylem conduits, Plant, Cell \& Environment 28 (2005) 456-465.

[13] W.E. Hillis, Heartwood and Tree Exudates, Springer-Verlag, Berlin, 1987. 
[14] R.-D. Peek, St. Goetsch, Dynamics of pressure changes in wood during impregnation, International Research Group on Wood Protection (IRG), Paper Prepared for the Twentyfirst Annual Meeting, Rotorua, New Zealand, 13-18 May, 1990. IRG/WP-3615 (1990) 1-10.

[15] M. Drescher, A. Jokisch, H. Korte, R.D. Peek, R. Steiner, Differential pressure characteristics of wood impregnated with compressed gases, liquids and supercritical fluids, Holz Als Roh-und Werkstoff 64 (2006) 178-182.

[16] T. Laursen, S.I. Andersen, S. Dahl, O. Henriksen, Measurement and modeling of the solubility of $\mathrm{CO} 2$ and $\mathrm{N} 2$ in a model resin system based on resin from spruce wood (Picea abies (L.)), Journal of Supercritical Fluids 19 (2001) 239-250.

[17] D.J. Cosgrove, Expansive growth of plant cell walls, Plant Physiology and Biochemistry 38 (2000) 109-124.

[18] E. Sjöström, Wood Chemistry. Fundementals and Applications, Academic Press, Inc, San Diego, 1993.

[19] D. Klemm, B. Heublein, H.P. Fink, A. Bohn, Cellulose: Fascinating biopolymer and sustainable raw material, Angewandte Chemie - International Edition 44 (2005) 33583393.

[20] L.R.S. Moreira, E.X.F. Filho, An overview of mannan structure and mannandegrading enzyme systems, Applied Microbiology and Biotechnology 79 (2008) 165178.

[21] W. Boerjan, J. Ralph, M. Baucher, Lignin biosynthesis, Annual Review of Plant Biology 54 (2003) 519-546.

[22] J.F. Siau, Wood: Influence of Moisture on Physical Properties, Department of Wood Science and Forest Products. Virginia Polytechnic Institute and State University, Blacksberg, Va., 1995.

[23] S. Willför, A. Sundberg, A. Pranovich, B. Holmbom, Polysaccharides in some industrially important hardwood species, Wood Science and Technology 39 (2005) 601-617.

[24] R. Schroder, R.G. Atkinson, R.J. Redgwell, Re-interpreting the role of endo-betamannanases as mannan endotransglycosylase/hydrolases in the plant cell wall, Annals of Botany 104 (2009) 197-204.

[25] L. Jones, A.R. Ennos, S.R. Turner, Cloning and characterization of irregular xylem4 (irx4): a severely lignin-deficient mutant of Arabidopsis, Plant Journal 26 (2001) 205216.

[26] T. Higuchi, Lignin biochemistry: biosynthesis and biodegradation, Wood Science and Technology 24 (1990) 23-63. 
[27] M.M. Campbell, R.R. Sederoff, Variation in lignin content and composition Mechanism of control and implications for the genetic improvement of plants, Plant Physiology 110 (1996) 3-13.

[28] C. Cagniard de la Tour, Exposé de qualques résultats obtenus par l'action combinée de la chaleur et de la compression sur certains liquides, tels que l'eau,l'alcool, l'éther sulphurique et l'essence de pétrole rectifiée, Annales de Chimie et de Physique 22 (1822) $127-132$.

[29] S.M. Smith, E. Sahle-Demessie, J.J. Morrell, K.L. Levien, H. Ng, Supercritical Fluid (SCF) Treatment: Its Effect on Bending Strength and Stiffness of Ponderosa Pine Sapwood, Wood and Fiber Science 25 (1993) 119-123.

[30] S.M. Smith, J.J. Morrell, E. Sahle-Demessie, K.L. Levien, Supercritical fluid treatment: Effects on bending strength of white spruce heartwood, International Research Group on Wood Preservation (IRG), Paper Prepared for the 24th Annual Meeting, Orlando, Florida, 17 - 21 May, 1993 (1993) 1-7.

[31] G.H. Kim, S. Kumar, E. Sahle-Demessie, K.L. Levien, J.J. Morrell, Bending properties of TCMTB-treated southern pine sapwood using supercritical carbon dioxide impregnation process, International Research Group on Wood Preservation (IRG), Paper Prepared for the 28th Annual Meeting, Whistler Conference Center, Whistler, Canada, 25-30 May, 1997 (1997) 1-7.

[32] M.N. Acda, J.J. Morrell, K.L. Levien, Supercritical fluid impregnation of selected wood species with tebuconazole, Wood Science and Technology 35 (2001) 127-136.

[33] M. Muin, A. Adachi, M. Inoue, T. Yoshimura, K. Tsunoda, Feasibility of supercritical carbon dioxide as a carrier solvent for preservative treatment of wood-based composites, Journal of Wood Science 49 (2003) 65-72.

[34] M.N. Acda, J.J. Morrell, K.L. Levien, Effects of supercritical fluid treatments on physical properties of wood-based composites, Wood and Fiber Science 29 (1997) 121-130.

[35] M. Muin, A. Adachi, K. Tsunoda, Applicability of supercritical carbon dioxide to the preservative treatment of wood-based composites, International Research Group on Wood Preservation (IRG), Paper prepared for the 32nd Annual Meeting, Nara, Japan, 20-25 May, 2001. IRG/WP 01-40199 (2001) 1-6.

[36] M.N. Acda, Supercritical Fluid Impregnation of Wood-Based Composites, $\mathrm{PhD}$ dissertation, Oregon State University (1995) 1-160.

[37] M.E. Anderson, R.J. Leichti, J.J. Morrell, The effects of supercritical CO2 on the bending properties of four refractory wood species, Forest Products Journal 50 (2000) $85-93$.

[38] P.F. Schneider, Pressure Measurement in Wood as a Method to Understand Impregnation Processes: Conventional and Supercritical Carbon Dioxide, $\mathrm{PhD}$ Dissertation, Oregon State University (1999) 1-243. 
[39] P.F. Schneider, J.J. Morrell, K.L. Levien, Internal pressure development during supercritical fluid impregnation of wood, Wood and Fiber Science 37 (2005) 413-423.

[40] P.F. Schneider, K.L. Levien, J.J. Morrell, Effect of wood characteristics on pressure responses during supercritical carbon dioxide treatment, Wood and Fiber Science 38 (2006) 660-671.

[41] G. Oberdorfer, P.E. Humphrey, R.J. Leichti, J.J. Morrell, Internal pressure development within oriented strandboard during supercritical fluid impregnation, International Research Group on Wood Protection (IRG), Paper prepared for the 31st Annual Meeting, Kona, Hawaii, 14-21 May 2000 (2000) 1-11.

[42] G. Oberdorfer, R.J. Leichti, J.J. Morrell, Internal pressure development and deformation during supercritical fluid impregnation of selected wood-based materials, Wood and Fiber Science 38 (2006) 190-205.

[43] E. Sahle-Demessie, A. Hassan, K.L. Levien, S. Kumar, J.J. Morrell, Supercritical Carbon Dioxide Treatment: Effect on Permeability of Douglas-Fir Heartwood, Wood and Fiber Science 27 (1995) 296-300.

[44] E. Sahle-Demessie, K.L. Levien, J.J. Morrell, Impregnation of Wood with Biocides Using Supercritical Fluid Carriers, ASC Symposium Series 608 (1995) 415-428.

[45] M. Acda, J.J. Morrell, K.L. Levien, Effect of process variables on supercritical fluid impregnation of composites with tebuconazole, Wood and Fiber Science 29 (1997) 282-290.

[46] M. Muin, K. Tsunoda, Retention of silafluofen in wood-based composites after supercritical carbon dioxide impregnation, Forest Products Journal 54 (2004) 168-171.

[47] S.M. Kang, K.L. Levien, J.J. Morrell, Supercritical fluid impregnation of wood with biocides using temperature reduction to induce deposition, Wood Science and Technology 39 (2005) 328-338.

[48] S.M. Kang, J.J. Morrell, Supercritical fluid impregnation of Douglas-fir heartwood with cyproconazole using temperature induced deposition, International Research Group on Wood Protection (IRG), Paper prepared for the 34th Annual Meeting, Brisbane, Australia, 18-23 May 2003 (2003) 1-9.

[49] S.M. Kang, J.B. Ra, K.L. Levien, J.J. Morrell, Developing diffusion coefficients for SCF impregnation of Douglas fir heartwood with cyproconazole, Journal of Wood Chemistry and Technology 26 (2006) 111-124.

[50] S.M. Kang, K.L. Levien, J.J. Morrell, Effect of process variations during supercritical fluid impregnation on cyproconazole retention and distribution in ponderosa pine sapwood, Wood and Fiber Science 38 (2006) 64-73. 
[51] S. Lucas, E. Gonzalez, M.P. Calvo, C. Palencia, E. Alonso, M.J. Cocero, Supercritical $\mathrm{CO}_{2}$ impregnation of Radiata pine with organic fungicides - Effect of operating conditions and two-parameters modeling, Journal of Supercritical Fluids 40 (2007) 462-469.

[52] J.J. Morrell, K.L. Levien, E. Sahle-Demessie, S. Kumar, S.M. Smith, H.M. Barnes, Treatment of wood using supercritical fluid processes, Proceedings of the 14th annual meeting of the Canadian wood preservation association 14 (1993) 6-35.

[53] M.N. Acda, J.J. Morrell, K.L. Levien, Decay resistance of composites following supercritical fluid impregnation with tebuconazole, Material und Organismen 30 (1996) 293-300.

[54] M. Muin, K. Tsunoda, Preservative treatment of wood-based composites with 3-iodo2-propynyl butylcarbamate using supercritical carbon dioxide impregnation, Journal of Wood Science 49 (2003) 430-436.

[55] M. Muin, K. Tsunoda, Termiticidal performance of wood-based composites treated with silafluofen using supercritical carbon dioxide, Holzforschung 57 (2003) 585-592.

[56] M. Muin, K. Tsunoda, Biological performance of wood-based composites treated with a formulation of 3-iodo-2-propynyl butylcarbamate and silafluofen using supercritical carbon dioxide, Journal of Wood Science 50 (2004) 535-539.

[57] K. Tsunoda, M. Muin, Preservative treatment of wood-based composites with a mixture formulation of IPBC-silafluofen using supercritical carbon dioxide as a carrier gas, International Research Group on Wood Protection (IRG), Paper prepared for the 34th Annual Meeting, Brisbane, Australia, 18-23 May, 2003 (2003) 1-8.

[58] J.J. Morrell, M.N. Acda, A.R. Zahora, Performance of Oriented Strand Board, Medium Density Fiberboard, Plywood, and Particleboard Treated with Tebuconazole in Supercritical Carbon Dioxide, International Research Group on Wood Protection (IRG), Paper prepared for the 36th Annual Meeting, Bangalore, India, 24-28 April 2005 (2005) 1-11.

[59] N. Morsing, A.H.H. Wong, F. Imsgard, O. Henriksen, How to Document the Performance of Super-Critical Treated Wood in above Ground Situations?, International Research Group on Wood Protection (IRG), Paper prepared for the 36th Annual Meeting, Bangalore, India, 24-28 April, 2005. IRG/WP 05-20316 (2005) 1-22.

[60] K.H. Henriksen, N. Morsing, Resultater for Lap-joint-prøvning af fyr og gran trykimprægneret henholdsvis vakuumimprægneret efter 3 års eksponering $\mathrm{i}$ tropisk og dansk klima, Report by Teknologisk Institut, Tåstrup, Denmark (2004)

[61] B.A. Richardson, Wood Preservation, The Construction Press Ltd, Lancaster, England, 1978.

[62] J.F. Siau, Transport Processes in Wood, Springer-Verlag, Berlin, 1984. 
[63] J.F. Siau, J.S. Shaw, The Treatability of Refractory Softwoods, Wood and Fiber Science 3 (1971) 1-12.

[64] F.O. Tesoro, E.T. Choong, Relationship of Longitudinal Permeability to Treatability of Wood, Holzforschung 30 (1976) 91-96.

[65] G.L. Comstock, Directional Permeability of Softwoods, Wood and Fiber Science 1 (1970) 283-289.

[66] F.O. Tesoro, E.T. Choong, O.K. Kimbler, Relativ Permeability and the Gross Pore Structure of Wood, Wood and Fiber Science 6 (1974) 226-236.

[67] R.W. Rice, M. D'Onofrio, Longitudinal gas permeability measurements from Eastern white pine, red spruce, and balsam fir, Wood and Fiber Science 28 (1996) 301-308.

[68] M.R. Milota, J.L. Tschernitz, S.P. Verrill, T. Mianowski, Gas-Permeability of Plantation Loblolly-Pine, Wood and Fiber Science 27 (1995) 34-40.

[69] J.X. Lu, S. Avramidis, Non-Darcian air flow in wood - Part 1. Specimen length effect, Holzforschung 51 (1997) 577-583.

[70] E.T. Choong, P.J. Fogg, Variation in Permeability and Treatability in Shortleaf Pine and Yellow Poplar, Wood and Fiber Science 4 (1972) 2-12.

[71] P.J. Fogg, E.T. Choong, Effect of Specimen Length on Longitudinal Gas Permeability in Hardwoods, Wood and Fiber Science 21 (1989) 101-104.

[72] A. Scheidegger, The physics of flow through porous media, University of Toronto Press, 1974.

[73] M.D. Hale, R.A. Eaton, The ultrastructure of soft rot fungi. I. Fine hyphae in wood cell walls, Mycologia 77 (1985) 447-463.

[74] M.D. Hale, R.A. Eaton, The Ultrastructure of Soft Rot Fungi. II. Cavity-Forming Hyphae in Wood Cell Walls, Mycologia 77 (1985) 594-605.

[75] F.W.M.R. Schwarze, J. Engels, C. Mattheck, Fungal Strategies of Wood Decay in Trees, Springer-Verlag, Berlin, 2000.

[76] H. Greaves, The microdistribution of copper-chrome-arsenic in preservative treated sapwoods using X-ray microanalysis in scanning electron microscopy, Holzforschung 28 (1974) 193-200.

[77] M. Petric, R.J. Murphy, I. Morris, Microdistribution of some copper and zinc containing waterborne and organic solvent wood preservatives in spruce wood cell walls, Holzforschung 54 (2000) 23-26.

[78] J.Z. Cao, D.P. Kamdem, Microdistribution of copper in copper-ethanolamine (Cu-EA) treated southern yellow pine (Pinus spp.) related to density distribution, Holzforschung 59 (2005) 82-89. 
[79] J.B. Zicherman, SEM X-ray analysis of pentachlorophenol in treated wood, Wood and Fiber Science 7 (1975) 110-118.

[80] R.C. DeGroot, T.A. Kuster, SEM X-ray microanalysis of tracheid cell walls in southern yellow pine sapwood treated with water-dispersible pentachlorophenol, Wood and Fiber Science 18 (1986) 58-67.

[81] E. Kurti, D.V. Heyd, R.S. Wylie, Raman microscopy for the quantitation of propiconazole in white spruce, Wood Science and Technology 39 (2005) 618-629. 


\section{Paper}

I 
Review

\title{
Supercritical wood impregnation
}

\author{
Anders W. Kjellow ${ }^{\mathrm{a}, *}$, Ole Henriksen ${ }^{\mathrm{b}}$ \\ a Forest and Landscape, University of Copenhagen, Rolighedsvej 23, DK-1958 Frederiksberg C, Denmark \\ ${ }^{\mathrm{b}}$ Hampen Træforarbejdning A/S, Palsgårdvej 3, 7362 Hampen, Denmark
}

\section{A R T I C L E I N F O}

\section{Article history:}

Received 10 March 2009

Received in revised form 12 June 2009

Accepted 17 June 2009

\section{Keywords:}

Review

Supercritical fluid

Impregnation

Wood

\begin{abstract}
A B S T R A C T
The use of supercritical fluids for delivering biocides into wood and wood composites is an attractive technique because of the high penetration capacity of these solvents compared to the liquids used in conventional treatment methods. During the past two decades supercritical wood impregnation has moved from lab scale to commercial scale.

This review presents an overview of the main research efforts that has been carried out within the field of supercritical wood impregnation. Results and conclusions of research within four main categories, i.e. (1) effects of impregnation on physical properties of samples, (2) retention and distribution of biocide in impregnated samples, (3) biological performance of impregnated samples, and (4) mathematical modeling of supercritical impregnation are reviewed and discussed.
\end{abstract}

(c) 2009 Elsevier B.V. All rights reserved.

\section{Contents}

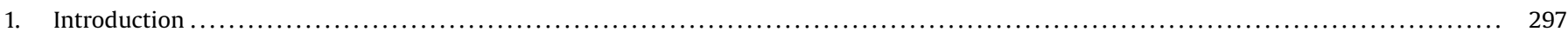

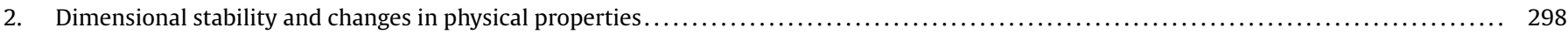

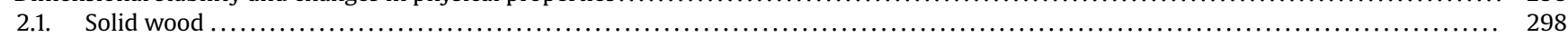

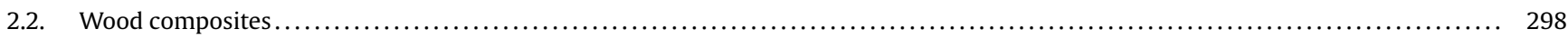

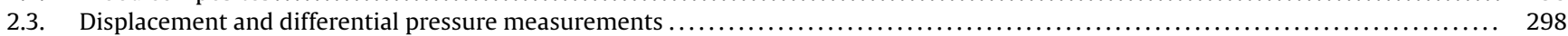

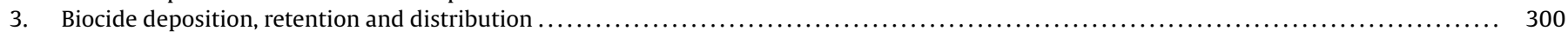

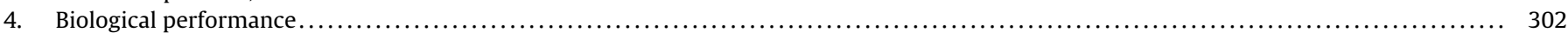

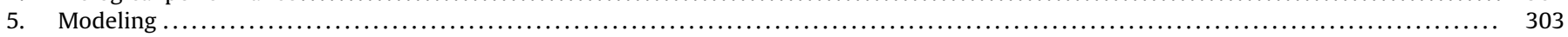

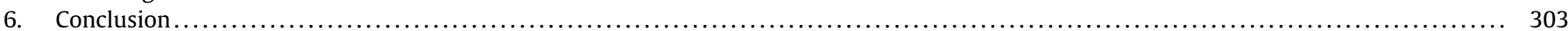

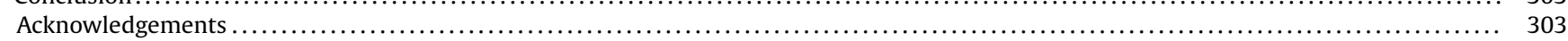

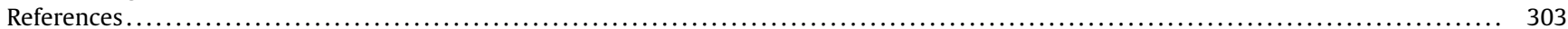

\section{Introduction}

During the past two decades, the possibility of using supercritical fluids for impregnation of wood with biocides has been investigated.

Wood is a biodegradable material that can be treated with biocides to suppress biodegradation and prolong its service life when used as a building material. Traditional pressure impregnation methods have changed little since Bethell patented the Bethell, or full cell, process in 1838 [1]. This process uses an initial period of vacuum followed by application of pressure to force a biocide loaded liquid into the wood structure. However, the process has

\footnotetext{
* Corresponding author. Tel.: +45 2281 9640; fax: +45 35331508 . E-mail addresses: awk@life.ku.dk (A.W. Kjellow), oh@superwood.dk (O. Henriksen).
}

some technical drawbacks such as the inability of treating wood species with a high internal resistance to fluid flow. It also leaves the wood more or less saturated with treatment liquid requiring additional time to dry. Environmental concerns also exist due to the difficulty of handling the treatment liquids without exposure to workers and the environment.

The use of supercritical fluids for wood impregnation has been proposed as a possible solution to the limitations presented by conventional wood impregnation methods. In the supercritical treatment, $\mathrm{CO}_{2}$ is used in its supercritical state as a carrier medium for organic biocides. Supercritical wood impregnation has evolved from lab scale experiments to commercial application [2] and a number of patents describing methods of supercritical wood impregnation exist [3-9].

The idea of using supercritical fluids for wood impregnation is appealing because of the properties of fluids in the supercritical state. While supercritical fluids have densities and solvating 
powers approaching those of liquids, allowing for dissolution of biocides, they also have zero surface tension and gas-like viscosities and diffusivities allowing for easier penetration of wood compared to liquids. Carbon dioxide has been the fluid of choice for research as well as the cited commercial application. $\mathrm{CO}_{2}$ has several advantages - it is inexpensive, readily available, non-toxic, non-flammable, and has a relatively low critical temperature of $31.1^{\circ} \mathrm{C}$. Supercritical $\mathrm{CO}_{2}$ also seem to have little reactivity towards the three main constituents of wood, i.e. cellulose, hemi-cellulose, and lignin [10]. It is, however, to some extent capable of dissolving wood extractives and has been used to collect extractives from a wide variety of wood species such as species of pine [11,12], juniper and cedar [13-15], and eucalyptus [16].

The extractive capability of supercritical $\mathrm{CO}_{2}$ has also been investigated as a means of removing chemicals such as PCP (pentachlorophenol) [17], formaldehyde [18], DDT (dichlorodiphenyl-trichloromethane) [19], and CCA (chromated copper arsenate) [20] from wood products and as a means of neutralizing and strengthening paper [21].

This paper reviews the research carried out within the field of supercritical wood impregnation and is intended for researchers seeking an overview and state of the art.

Selected results and conclusions from papers within four areas of supercritical wood impregnation covering treatment effects on physical properties of wood, biocide deposition, biological performance, and modeling are presented and discussed.

\section{Dimensional stability and changes in physical properties}

\subsection{Solid wood}

Much of the research within the field of supercritical wood impregnation has focused on examining the effects of treatment on the physical properties of treated wood. Initial studies by Smith et al. were carried out on small match-size wood pieces $(2.4 \mathrm{~mm} \times 2.4 \mathrm{~mm} \times 54 \mathrm{~mm}$ ) of ponderosa pine (Pinus ponderosa) [22] and white spruce (Picea glauca) [23] at treatment pressures up to $27.6 \mathrm{MPa}$, treatment temperatures up to $80^{\circ} \mathrm{C}$, and treatment times up to $2 \mathrm{~h}$. No significant differences in MOR (modulus of rupture) or MOE (modulus of elasticity) were detected between untreated and treated samples in these studies even at pressurization rates of $13.8 \mathrm{MPa} / \mathrm{min}$.

However, working with larger samples of southern pine (Pinus taeda) sapwood (19 $\mathrm{mm} \times 19 \mathrm{~mm} \times 510 \mathrm{~mm})$, Kim et al. [24] found significant differences in MOE and work to maximum load (WML) between untreated samples and samples treated with supercritical $\mathrm{CO}_{2}$ and TCMTB (2-(thiocyanomethylthio)-benzothiazole). The experiments were carried out at $50^{\circ} \mathrm{C}$ for $30 \mathrm{~min}$ at pressures ranging from 12.4 to $24.8 \mathrm{MPa}$. The treatment effect on MOR was inconclusive with two of the five treatment pressures showing significant decreases in MOR of treated samples.

Acda et al. [25] examined the influence of treatment pressure on MOR and MOE of Douglas-fir (Pseudotsuga menziesii), white oak (Qurcus alba), red alder (Alnus rubra), western red-cedar (Thuja plicata), and white spruce. Samples $(25 \mathrm{~mm} \times 25 \mathrm{~mm} \times 503 \mathrm{~mm}$ ) were treated with supercritical $\mathrm{CO}_{2}$ and tebuconazole at $60^{\circ} \mathrm{C}$ for 30 or $60 \mathrm{~min}$ at pressures of $12.4,24.8$, or $31.1 \mathrm{MPa}$ followed by venting at $1.24 \mathrm{MPa} / \mathrm{min}$. MOE was not significantly affected in Douglas-fir, white oak, red alder, and white spruce while a significant decrease was noted for western red-cedar especially at high treatment pressure. MOR seemed to decrease with higher treatment pressure in western red-cedar and white spruce but the changes were not significant. MOR was unaffected in Douglas-fir, white oak, and red alder.

For samples measuring $15 \mathrm{~mm} \times 15 \mathrm{~mm} \times 120 \mathrm{~mm}$, Muin et al. [26] found MOR and MOE of Japanese red pine (Pinus densiflora) and Cryptomeria (Cryptomeria japonica) to be unaffected by supercritical treatment with IPBC (iodopropynyl butylcarbamate) at $50^{\circ} \mathrm{C}$ and 9.81 MPa for $30 \mathrm{~min}$. However, MOE and MOR of Japanese larch (Larix kaempferi (Larix leptolepis in original paper)) was found to decrease to $82 \%$ and $72 \%$ of original values, respectively.

The influence of supercritical $\mathrm{CO}_{2}$ on the permeability of wood was examined by Sahle-Demessie et al. [27]. They measured longitudinal permeability of Douglas-fir heartwood before and after exposure to supercritical $\mathrm{CO}_{2}$ with and without co-solvents. They found permeability to increase significantly after treatment for 8 of 10 different treatment conditions. However, permeability was found to decrease in $19 \%$ of the samples. The authors suggested that increases in permeability could be due to solubilization and removal of extractives in pit membranes leading to unblocking of pits and thus a decrease in flow resistance of the wood. For all samples they found an average weight loss of $3.32 \%$ as a result of supercritical treatment indicating that a removal of extractives had occurred. The authors speculated that the re-deposition of extractives in pits during depressurization could be the reason for the decreased permeability in the remainder of the samples. The weight loss was comparable to the $2.1 \%$ weight loss reported by McDonald et al. [12] for supercritical $\mathrm{CO}_{2}$ extraction of southern pine while Li and Kiran [10] reported negligible weight loses of 0.5, 0.0, and $0.0 \%$ for extraction of white pine (Pinus strobus), red spruce (Picea rubens), and sugar maple (Acer saccharum), respectively.

\subsection{Wood composites}

In addition to studies on solid wood a number of studies have examined the effects of supercritical treatment on wood composites. Acda et al. [28] subjected four different wood composites to supercritical treatment with tebuconazole with methanol as a co-solvent at pressures between 12.4 and $31.0 \mathrm{MPa}$, temperatures between 45 and $75^{\circ} \mathrm{C}$, and treatment times between 5 and $30 \mathrm{~min}$. They found no significant changes in dimensional stability, MOR or MOE in any of the composites compared to untreated controls.

Muin et al. [26,29] also examined the effect of supercritical impregnation on the bending properties of wood-based composites. They found MOE and MOR to decrease significantly in OSB (oriented strand board) whereas the other tested composites (MDF (medium density fiberboard), softwood plywood, hardwood plywood, and particleboard) showed no significant decrease in strength properties with the exception of softwood plywood where MOE was lower. MOR of particleboard was found to increase significantly as a result of treatment. The effect of supercritical treatment on wood-adhesive integrity was measured by Acda [30] who examined the effect of treatment on the tensile strength perpendicular to the surface (internal bond) of various composites. In most cases tensile strength increased as a result of treatment, however, the changes were not reported to be significant.

\subsection{Displacement and differential pressure measurements}

All of the studies mentioned above are concerned with investigating the effects of treatment conditions, i.e. treatment pressure, temperature and time but do not consider the importance of pressurization rates or depressurization rates. While treatment pressure, temperature and time may influence the physical properties of treated wood, several newer studies have shown that negative effects of treatments are likelier to stem from damages occurred during pressurization and/or venting. Therefore, it is unfortunate that most of the studies above do not state both the pressurization and release rates as some of the reported detrimental effects of treatment might stem from damages occurred during pressurization or venting and not because of the actual treatment conditions. Even though wood is a permeable material and 
therefore to some extent will allow fluid flow through its interior, permeability, and thus conductivity, vary markedly both between and within species and many species provide substantial resistance to flow especially to the flow of liquids [31]. Darcy's law describing the flow of fluids through porous media is often used to characterize the flow of fluids through wood. For liquid flow, Darcy's law may be written as:

$Q=\frac{k A \Delta P}{L}$,

where $Q=$ conductivity $\left(\mathrm{m}^{3} / \mathrm{s}\right), \quad k=$ permeability $\left(\mathrm{m}^{3} /(\mathrm{m}\right.$ Pa s $\left.)\right)$, $A=$ area of cross-section through which there is flow $\left(\mathrm{m}^{2}\right)$, $\Delta P=$ pressure differential giving rise to flow (Pa), and $L=$ length of flow path $(\mathrm{m})$.

Darcy's law states that bulk flow through a piece of wood is dependent on the permeability of the wood and the differential pressure giving rise to bulk flow.

Therefore, when pressurizing a piece of wood with a fluid, a pressure differential can develop between the surface of the wood and its interior, because wood does not equilibrate pressure instantly. This has been shown to be true for liquids and gases [32,33] and recent studies have confirmed the same phenomenon when pressurizing wood with supercritical fluids [34-36].

The experiments on very small samples by Smith et al. [22,23] led to the conclusion that supercritical fluids could penetrate wood instantly without the development of differential pressure. However, Anderson et al. [37] argued with reference to Darcy's law that pressure differences can be expected to develop during supercritical treatment of wood and that treatment damages are likely to develop during pressurization or venting. They investigated the effect of pressurization rate, venting rate, and treatment pressure on the bending properties (MOR, MOE, and WML) of Douglasfir, yellow-poplar (Liriodendron tulipifera), western red-cedar, and Engelmann spruce (Picea engelmannii). All four species (in samples $38 \mathrm{~mm} \times 38 \mathrm{~mm} \times 585 \mathrm{~mm}$ ) were given eight different combinations of treatments with pressurization and venting rates of 0.34 or 3.44 MPa and maximum treatment pressures of 10.34 or $20.69 \mathrm{MPa}$.

Results varied between the species. No significant negative effects were found on the bending properties of yellow-poplar and Douglas-fir. In western red-cedar, fast venting had a negative influence on bending properties while all treatment rates had a negative effect on bending properties of Engelmann spruce. The authors suggested that the differences found between the species could be attributed to differences in permeability. Less permeable species like western red-cedar and spruce do not equilibrate pressure between the inside and outside of the sample as well as more permeable species. If pressurization or venting is done too quickly, the resulting pressure difference may build up to a level exceeding the compressive or tensile strength of the wood resulting in wood collapse or split. Therefore, they suggested that slower pressurization and venting rates might be needed to avoid build up of excessive pressure gradients in wood during supercritical impregnation.

Kim and Morrell [38] used strain gauges to measure the displacement of samples of spruce $(38 \mathrm{~mm} \times 50 \mathrm{~mm} \times 200 \mathrm{~mm})$ during supercritical treatment and the influence of pressurization and venting rates on displacement. Maximum displacement (i.e. in situ displacement during treatment) was found to increase with increasing pressurization rates while the residual displacement (i.e. permanent displacement after treatment) decreased with more rapid venting rates. However, the samples subjected to slow venting rates and showing larger permanent displacement also showed a higher maximum displacement although they were pressurized at the same rate as the samples vented more rapidly. The authors suggested that treatment conditions could be controlled to minimize displacement.
In a study by Oberdorfer et al. [39], the effect of pressurization and venting rate on deformation of OSB, MDF, LVL (laminated veneer lumber), and Douglas-fir heartwood was examined using strain gauges. They found OSB, MDF, and Douglas-fir to show minimal displacement during treatment whereas in situ and permanent displacement were recorded for LVL.

The above studies show that differences in pressure are likely to develop between the inside and outside of wood samples subjected to supercritical treatment and that the level of the pressure differential to some extent can be controlled by adjusting pressurization and venting rates to avoid permanent damages from occurring. Other researchers have confirmed the development of pressure differences in wood treated with supercritical fluids and even measured their actual magnitude. Schneider [34] developed a method to measure, in situ, pressure differences occurring in a piece of wood during supercritical treatment and used it to measure the pressure responses in wood samples from 11 different species. He found that the development of pressure differentials was dependant on pressurization and venting rates and sample geometry, i.e. the distance between the core and surface of the sample. He also indicated that permeability was directly correlated with differential pressure development.

Schneider et al. [35] measured the development of pressure differentials occurring in samples of solid wood from four species: ponderosa pine, Douglas-fir, white fir (Abies concolor), and Pacific silver fir (Abies amabilis). Pressurizing and venting samples of $30(\mathrm{R}) \times 60(\mathrm{~T}) \times 60(\mathrm{~L}) \mathrm{mm}$ at a rate of $0.276 \mathrm{MPa} / \mathrm{min}$ they found initial pressure response to be highly dependant on permeability with ponderosa pine, Douglas-fir, and white fir recording maximum avg. $\triangle P$ s during pressurization of $0.268,0.375$, and $2.089 \mathrm{MPa}$, respectively. Pacific silver fir collapsed. The effect of sample size on the pressure response of Douglas-fir was also examined with maximum avg. $\Delta P$ s apparently increasing by an approximate factor of 3 for every $15 \mathrm{~mm}$ increase of the distance from the wood center to the surface. Increasing the pressurization and venting rate for Douglasfir to $0.827 \mathrm{MPa} / \mathrm{min}$ resulted in a doubling of the maximum avg. $\Delta P$ to $0.791 \mathrm{MPa}$ which was still not sufficient to inflict damage to the samples. In a study involving heartwood of scotch pine (Pinus sylvestris) with dimensions of $20 \mathrm{~mm} \times 20 \mathrm{~mm} \times 60 \mathrm{~mm}$, Drescher et al. [36] found total pressure differential between core and surface of the samples not to exceed 1.3 MPa during pressurization in steps of $1.6 \mathrm{MPa}$ every $5 \mathrm{~min}$. None of the samples were damaged during treatment.

According to Darcy's law, pressure response in wood during pressurization and venting should be directly correlated to permeability. Intuitively, this seems a reasonable assumption since permeability is a measure of resistance to flow. Low permeability would signify large resistance to flow, which would lead to rapid build up of pressure gradients. However, Schneider et al. [40] surprisingly was unable to prove any correlation between permeability and the development of pressure differences for eight species of softwoods. $\triangle P$ s were measured continuously during treatment (pressurization and venting rates $0.276 \mathrm{MPa}$; treatment pressure at $10.3 \mathrm{MPa}$ ) and the development of pressure gradients followed the same pattern as reported by Schneider et al. [35]. Douglas-fir and especially species of pine equilibrated pressure fairly rapidly and did not suffer any damage from treatment while species of fir, Engelmann spruce, and western red-cedar equilibrated pressure slowly and eventually collapsed during pressurization. Pines are generally considered to have larger permeabilities than firs and spruces [31] and the observation that pines did not suffer damages while fir and spruce did, seems to support the assumption that higher permeability species equilibrate pressure more rapidly. However, when the authors correlated the pressure differences with actual permeability measurements from the same study they were unable to prove any correlation. They investigated the influ- 
ence of parameters such as permeability in all three dimensions, diameter, frequency and area of resin canals, and width, length, and area of tracheids but were unable to detect any meaningful relationships between parameters and pressure responses with few exceptions. They did find a significant correlation between larger longitudinal resin canal diameters and lower $\Delta P$, but this was counteracted by the finding that larger radial resin canal frequency significantly enlarged $\Delta P$.

Differential pressure measurements on composites were done by Oberdorfer et al. [41] who measured, in situ, the effect of three different pressurization and venting rates (1.03, 1.79 and $5.86 \mathrm{MPa} / \mathrm{min}$ ) on pressure difference in OSB during supercritical treatment. They found pressure equilibration to be rapid with pressure differences during pressurization and venting rarely exceeding 0.45 and $0.2 \mathrm{MPa}$, respectively, and concluded that pressurization and venting rates up to $5.86 \mathrm{MPa} / \mathrm{min}$ do not seem capable of causing damage to OSB.

Oberdorfer et al. [42] then used the same methods to investigate the effect of pressurization and venting rates on internal pressure development of OSB, MDF, LVL, and Douglas-fir heartwood. OSB and MDF were found to equilibrate pressure rapidly and show no signs of damage at pressure and venting rates up to $5.86 \mathrm{MPa} / \mathrm{min}$. Pressure development in LVL were strongly influenced by the glue lines as these were found to be almost impenetrable. Samples with flow allowed in the grain direction equilibrated pressure fairly rapidly and showed no signs of damage, while samples with this flow path sealed developed pressure gradients strong enough for the samples to collapse even at the slowest pressurization rate used at $0.14 \mathrm{MPa} / \mathrm{min}$. Pressurizing Douglas-fir samples at $5.86 \mathrm{MPa} / \mathrm{min}$ resulted in excessive pressure gradients leading to collapse in some, but not all samples. Samples pressurized and vented at $1.79 \mathrm{MPa} / \mathrm{min}$ showed no signs of damage.

Summarizing the results above it can be concluded that initial suggestions based on experiments with very small samples that supercritical $\mathrm{CO}_{2}$ provides complete and instantaneous penetration of wood without negative effects on wood properties were too optimistic. Very small samples may indeed be able to equilibrate pressure instantly, but larger samples can provide a substantial resistance to flow. This may cause build up of internal pressure gradients in the wood especially if flow in the longitudinal direction is restricted. If the compressive or expansive forces arising from pressure gradients exceed the compression or tensile strength of the wood, collapse or rupture of the wood structure may occur.

The rates of pressure application or release that can be applied without negatively affecting wood properties seem to be specific to the wood species or composite in question with permeability influencing the rate of differential pressure build up and the strength properties of the sample determining the physical stress the sample can withstand. If pressurization and venting is carried out at rates that do not cause build up of excessive internal pressure differentials, treatment of most wood species and wood composites without excessive detrimental effects on wood properties seem possible. The evidence so far suggest that high pressure in it self does not significantly affect the physical properties of wood. However, it must be said that very little is known about the interaction of supercritical $\mathrm{CO}_{2}$ and lignocellulose. Li and Kiran [10] suggested that interactions between supercritical $\mathrm{CO}_{2}$ and lignocellulose are non-reactive. This was based on the absence of weight loss from treated materials. However, $\mathrm{CO}_{2}$ may interact with lignocellulosic materials in ways that do not produce weight loss. Sorption of $\mathrm{CO}_{2}$ to synthetic polymers under supercritical conditions can cause swelling of polymers and affect their glass transition temperature and their physical and mechanical properties [43]. Since wood to a large extent consists of amorphous polymers, $\mathrm{CO}_{2}$ treatment might have a similar effect on wood properties especially at conditions far from the critical temperature and pressure.

\section{Biocide deposition, retention and distribution}

The ability of supercritical fluids to deposit biocides in wood has been investigated in a number of studies. Working with biocide saturated $\mathrm{CO}_{2}$, Sahle-Demessie et al. [44] studied the effects of treatment period and treatment pressure on maximum deposition and resulting distribution of TCMTB in Douglas-fir heartwood during supercritical treatment. At all treatment pressures and times they noticed a concentration gradient from the surface to the core of the wood samples. At a constant treatment time of $30 \mathrm{~min}$ they found retention in the center of wood pieces $(30 \mathrm{~mm} \times 30 \mathrm{~mm} \times 100 \mathrm{~mm})$ to increase 7 -fold as treatment pressure increased from 14.0 to $27.0 \mathrm{MPa}$. The concentration gradient from the surface to the core of the wood also became less pronounced at 27.0 MPa. Increasing the treatment period from 30 to $90 \mathrm{~min}$ while maintaining treatment pressure at 25.0 MPa leveled out the concentration gradient considerably, yielding retention levels of about $1 \mathrm{~kg} / \mathrm{m}^{3}$ at all depths.

Acda et al. [45] investigated the deposition of tebuconazole in wood composites. Biocide retention increased significantly when treatment pressure was increased from 12.4 to $24.8 \mathrm{MPa}$. However, a further increase in pressure to $31.0 \mathrm{MPa}$ resulted in significant decrease in biocide retention to levels in between those found for 12.4 and 24.8 MPa except for MDF where retention even dropped below the $12.4 \mathrm{MPa}$ level. The increase in retention from 12.4 to $24.8 \mathrm{MPa}$ can be explained by the increased solvent power of supercritical fluids with higher pressure. Isothermally, the higher fluid density at higher pressures should result in a higher amount of dissolved biocide provided the fluid is kept saturated. However, since solubility should have been even higher at 31.0 MPa the reported retention at this pressure is not immediately obvious. In any case, retention levels for all treatment were found to lie above the threshold values for fungal attack. Increasing temperature $45 \rightarrow 60 \rightarrow 75^{\circ} \mathrm{C}$ resulted in decreased retention levels but all retention levels were still above the reported threshold values for fungal attack. Treatment times as low as $5 \mathrm{~min}$ were found to deliver adequate amounts of biocide into the composites. Biocide penetration was found to be complete in all composites and the reported concentration gradients between inner and outer parts of the samples were found to be between 1.1 and 9.6.

Acda et al. [25], investigating the effect of treatment pressure and time on retention of tebuconazole in five species of wood, did find biocide retentions to increase consistently when pressure was increased from 12.4 to $31.0 \mathrm{MPa}$. They also reported concentration gradients between inner and outer parts of the samples. Gradients tended to increase with treatment pressure and were in the range of 2.2-8.7 which the authors suggested could be due to movement of biocide with $\mathrm{CO}_{2}$ from the core to the surface during depressurization. Treatment pressures of 24.8 or $31.0 \mathrm{MPa}$ were needed to deliver acceptable amounts of biocide in the inner part of samples. However, because of the pressure gradients, this resulted in overloading of the outer parts. In contrast to results reported by Sahle-Demessie et al. [44], treatment times were found to have no significant influence on retention.

Muin and Tsunoda [46] investigated the influence of treatment pressure and temperature on the retention and distribution of the termiticide silafluofen in five different wood composites. For every treatment they introduced $4 \mathrm{~g}$ of silafluofen, but failed to report whether this amount resulted in a saturated or sub-saturated fluid during the different treatment conditions. Treatment pressure varied between 7.85 and $11.77 \mathrm{MPa}$ and temperature between 35 and $55^{\circ} \mathrm{C}$. Treatment pressure had varying effect on retention depending on the substrate. For example at $35^{\circ} \mathrm{C}$ maximum retention for plywood, MDF, and OSB was recorded at treatment pressures of 7.85, 9.81, and $11.77 \mathrm{MPa}$, respectively. Effect of temperature was equally inconsistent. However, all treatment conditions resulted in 
biocide retention above the reported threshold for termite attack and concentration gradients between inner and outer parts of the samples were between 1.1 and 6.5.

Drescher et al. [47] investigated the use of supercritical $\mathrm{CO}_{2}$ for impregnation of wood with color agents but were only able to get superficial color retention. They suggested that the shallow penetration of color agents compared to biocides was a result of the low solubility of the investigated color agents $(5-40 \mathrm{mg} / \mathrm{kg} \mathrm{CO}$ at $20.0 \mathrm{MPa}$ ) compared to those reported for biocides. Solubilities of more than 2 mass percent were reported by Sahle-Demessie [48] for several biocides.

Many of the above studies worked with biocide saturated $\mathrm{CO}_{2}$ and therefore were really studies on the effects of operating conditions on maximum possible retentions. The results clearly indicate that it is possible to impregnate wood with adequate amounts of biocide using supercritical fluids as solvents. However, since overloading is not desirable, the question is what effect the treatment conditions would have on the deposition of a limited fixed amount of biocide under sub-saturated conditions.

Working at sub-saturated conditions, Kang et al. [49] compared the effect of two different methods of inducing biocide (cyproconazole) deposition in ponderosa pine sapwood. The methods used the same treatment conditions at $10.3 \mathrm{MPa}$ and $40^{\circ} \mathrm{C}$ for $60 \mathrm{~min}$ but differed in the venting schedule. The first method termed "pressure induced deposition" aimed at achieving biocide deposition by venting at a constant rate of $0.866 \mathrm{MPa} / \mathrm{min}$ until atmospheric pressure. In principle this is the same method that has been applied in almost all previous studies of supercritical impregnation. The second method, termed "temperature induced deposition" involved reducing the temperature by $0.4{ }^{\circ} \mathrm{C} / \mathrm{min}$ at the end of treatment. This caused a simultaneous reduction of pressure of $0.087 \mathrm{MPa} / \mathrm{min}$. When both temperature and pressure were below the critical values the vessel was vented at $0.4 \mathrm{MPa} / \mathrm{min}$. The temperature induced deposition method produced higher retentions (55\%) than the pressure induced method but it also seemed to produce steeper gradients. Using the temperature induced method, the authors were able to achieve retention targets of 0.25 and $0.5 \mathrm{~kg} / \mathrm{m}^{3}$ with relatively high accuracy. The fact that they were able to consistently achieve the retention targets was attributed to working with subsaturated fluids.

Kang and Morrell [50] examined the influence of treatment time (30 or $180 \mathrm{~min}$ ) on the retention and distribution of cyproconazole (sub-saturated fluid) in samples of Douglas-fir heartwood with varying dimensions $(20 \times 20 \mathrm{~mm}, 40 \times 40 \mathrm{~mm}$ or $90 \times 90 \mathrm{~mm}$ squares of $100 \mathrm{~mm}$ length). Like previous studies they measured a concentration gradient between the inside and outside of samples. Interestingly they noted a higher biocide concentration at a given sample depth in the $90 \times 90 \mathrm{~mm}$ samples compared to the smaller samples. The longer treatment time of $180 \mathrm{~min}$ did not have a large effect on biocide retention or distribution. Kang et al. [51] allowed a similar experiment to run for up to $720 \mathrm{~min}$ and this time they did find biocide retentions at a given sample depth to increase with treatment time, especially for the two larger samples treated for $720 \mathrm{~min}$. Based on this observation the authors suggested that diffusion is the dominant factor determining biocide movement during supercritical wood impregnation.

Another interesting study by Kang et al. [52] examined the effect of treatment pressure and temperature on the deposition of a fixed amount of cyproconazole in ponderosa pine sapwood under sub-saturated conditions. They found process conditions to have a large influence on retention levels even though the same amount of biocide was available for each treatment. The apparently most favorable conditions at $40^{\circ} \mathrm{C}, 10.3 \mathrm{MPa}$ yielded retentions levels that were more than three times as high as the least favorable conditions at $60^{\circ} \mathrm{C}, 10.3 \mathrm{MPa}$. At $40^{\circ} \mathrm{C}$, an increase in pressure from 10.3 to 20.6 MPa resulted in a decrease in biocide retention from 0.510 to

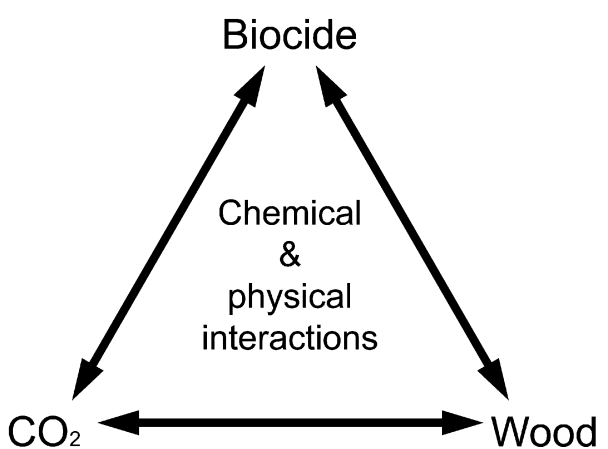

Fig. 1. The deposition and distribution of biocides in wood upon supercritical impregnation is governed by chemical and physical interactions between $\mathrm{CO}_{2}$, wood, and biocides. The addition of co-solvents will complicate matters further

$0.378 \mathrm{~kg} / \mathrm{m}^{3}$. At $60^{\circ} \mathrm{C}$ the same increase in pressure caused retention to increase from 0.153 to $0.370 \mathrm{~kg} / \mathrm{m}^{3}$. The authors suggest that the observed decrease in retention with increasing temperature at 10.3 MPa was likely the result of decreased solute solubility due to decreased fluid density at higher temperatures. At 20.6 MPa the increase in temperature would have a similar effect on fluid density but no difference in retention was observed. This could, they argue, be explained by an increase in vapor pressure and thus increased solubility of the biocide which, at the higher pressure, could be large enough to cancel the effect of the decreased fluid density caused by the increase in temperature.

It has been common practice by supercritical wood researchers to relate retention levels to biocide solubility in the supercritical fluid. The primary premise for deposition of biocide in wood during supercritical impregnation is presupposed to be loss of biocide solubility and, thus, precipitation of biocide as the fluid goes from supercritical to subcritical conditions during venting. Accordingly, biocide retentions should increase with biocide solubility. This seems reasonable when working with saturated fluids. The higher the concentration of biocide in the fluid, the higher the concentration of biocide in the impregnated wood.

When impregnation is carried out with sub-saturated fluids, however, the observed differences in deposition are unlikely to stem solely from differences in solubility because increasing biocide solubility at sub-saturated conditions does not make any more biocide available for deposition. Differences in deposition observed when working with sub-saturated fluids must also take into account the interactions between the biopolymers of the wood and the biocides under the given conditions (Fig. 1). These interactions have not been studied in detail perhaps because they are generally assumed to be negligible. However, a paper by Lucas et al. [53] suggests that these interactions might be substantial.

Lucas et al. [53] investigated the influence of treatment conditions on impregnation of radiata pine (Pinus radiata) with decanal. Their method of impregnation was different from those used in most other studies. The majority of previous studies have carried out impregnation by pressurizing and heating the impregnation vessel with $\mathrm{CO}_{2}$ and biocides to determined conditions, then sealing of the vessel and keeping the conditions allowing the $\mathrm{CO}_{2}$-biocide mixture to penetrate the wood (with or without circulation) before depressurizing the system. Lucas et al. [53] instead used a flow through column to measure equilibrium loadings of solute between wood and $\mathrm{CO}_{2}$. The $\mathrm{CO}_{2}$-biocide mixture, pressurized and heated to the desired conditions, entered the vessel at one end, flowed through at a given rate before exiting the vessel at the other end. Thus, the $\mathrm{CO}_{2}$-biocide mixture was not allowed to reenter the vessel upon exit.

The authors argued that the mechanism for impregnation of biocides in wood with supercritical fluids involves more than just 
a simple deposition due to decreased solubility of biocides upon depressurization. They described the deposition mechanism as an adsorption process whose equilibrium amongst other things is determined by the partition coefficients of solutes between wood and $\mathrm{CO}_{2}$, i.e. the relative affinity of solutes for the solid phase compared to the fluid phase. By monitoring the biocide concentrations in the $\mathrm{CO}_{2}$ before $\left(C_{0}\right)$ and after $(C)$ the vessel the authors were able to establish the saturation time (i.e. time for $C_{0}$ to equal $C$ ) and calculate the retention of decanal at this equilibrium as well as examine the effects of process conditions (pressure, temperature, and flow rate) on retention. Despite an increase in fluid density, retention levels decreased as operating pressure was increased from 10.0 to $12.5 \mathrm{MPa}$ at $35^{\circ} \mathrm{C}$. The authors explained the decrease in retention level at higher pressure by the accompanied decrease in partition coefficient, i.e. lower biocide-wood interactions compared to biocide- $\mathrm{CO}_{2}$ interactions at higher densities. At $10.0 \mathrm{MPa}$, increasing the temperature from 35 to $46.8^{\circ} \mathrm{C}$ resulted in a decrease in retention which again was explained by a decrease in the partition coefficient with rising temperature. Changing the flow rate influenced the time to reach equilibrium but had little, if any, influence on retention levels. The study highlights the importance of considering wood/biocide interactions when analyzing biocide retentions in supercritical impregnated wood.

Supercritical fluids have been shown to be capable of delivering adequate amounts of biocide into wood and wood composites. Impregnation to target retentions has also proved possible. Evidence is inconclusive as to what extent biocide distribution is dominated by bulk flow or diffusion. Impregnation usually leaves a more or less pronounced concentration gradient between the surface and core of treated samples. Most investigations of biocide retention and distribution have focused on biocide solubility in supercritical $\mathrm{CO}_{2}$ in trying to explain the observed retentions and gradients. However, wood/biocide interactions are likely to play an equally important role in determining biocide deposition and these interactions need to be studied more thoroughly.

\section{Biological performance}

Morrell et al. [54] established a soil block test to compare the biological performance of supercritical or conventional (full cell process using toluene) treated spruce. They used IPBC or PCP as fungicides and the results indicated no significant difference in performance between the two treatment methods. In another lab scale test, Acda et al. [55] tested the performance of tebuconazole treated wood composites against different fungi in a soil block test. They found the supercritical treatment with tebuconazole to provide excellent protection against basidiomycetes in plywood and particleboard. Thresholds for plywood and particleboard exposed to the brown rot fungi Gloeophyllum trabeum were 0.12 and $0.01 \mathrm{~kg} / \mathrm{m}^{3}$, respectively, while the threshold for flakeboard was $2.48 \mathrm{~kg} / \mathrm{m}^{3}$. However, the treatment provided little protection for MDF. For samples exposed to the white rot fungi Phlebia subserialis thresholds for plywood, particleboard, flakeboard, and MDF were 0.25, 0.16, 1.45, and $1.50 \mathrm{~kg} / \mathrm{m}^{3}$, respectively. They also found the treatment to be effective against soft rot fungi.

Muin and Tsunoda [56] tested the performance of wood composites impregnated with IPBC at varying treatment pressures and temperatures. They found that most of the treatments did not provide a satisfactory decay resistance of $<3 \%$ mean mass loss of samples exposed to decay fungi. The results were probably due to a limited and insufficient amount of biocide being used per treatment. The authors did not undertake a chemical analysis to establish the retention of IPBC in the treated samples, meaning that the conclusions were limited. Muin and Tsunoda [57] then tested the performance of wood composites treated with the termiticide silafluofen at different treatment conditions. Although treatment efficiency varied with operating conditions, for every composite tested (MDF, soft- and hardwood plywood, particleboard, and OSB) they were able to obtain retention levels above the reported toxic threshold of $0.025 \mathrm{~kg} / \mathrm{m}^{3}$ and mean mass losses of less than $3 \%$ in samples exposed to the termite Coptotermes formosanus.

Finally, Muin and Tsunoda [58,59] tested the performance of wood composites treated with a mixture of IPBC and silafluofen (10:1) at three different combinations of pressure and temperature. The biocide mixture contained a larger amount of IPBC and a lower amount of silafloufen compared to the previous studies. This time they found that IPBC levels in most of the treatments were high enough to suppress the mean mass loss of samples exposed to the brown rot fungi Trametes versicolor or the white rot fungi Fomitopsis palustris to a satisfactory level of less than 3\% mass loss. Performance against $C$. formosanus was lower than the previous study involving silafluofen [57] indicating that the amount of silafluofen in the mixture was now too low.

Field tests of biological performance of supercritical treated wood are scarce. Morrell et al. [60] reported results from a 48month field test of tebuconazole treated wood composites set up in Hilo, Hawaii. The test involved samples of OSB (from aspen), MDF (from softwood), particleboard (from softwood), and plywood (from Douglas-fir) treated to different retention levels by varying the treatment conditions (pressure, temperature, and treatment time). The natural durability of untreated samples varied substantially between the four types of composites with aspen OSB being the least durable and Douglas-fir plywood the most durable of the tested materials. The performance of the treated samples reflected the natural durability in the way that after impregnation, the samples with a high natural durability performed better than samples with a low natural durability. Samples treated to low retentions $\left(<0.20 \mathrm{~kg} / \mathrm{m}^{3}\right)$ generally decayed at rates only slightly slower than untreated samples. All OSB samples failed within 30 months regardless of retention level. It was possible to suppress significant decay in MDF and particleboard even after 48 months of exposure but it took relatively high retention levels to do so. MDF and particleboard treated to retention levels above $2.4-3.0 \mathrm{~kg}$ were in very good condition even after 48 months suggesting a threshold for protection of MDF and particleboard around this level. Results were not entirely consistent however since one set of MDF samples treated at $0.13 \mathrm{~kg} / \mathrm{m}^{3}$ and another set of particleboard samples treated to retention of $0.10 \mathrm{~kg} / \mathrm{m}^{3}$ showed surprisingly high resistance to degradation even after 48 months. The best performing composite was Douglas-fir plywood which showed little or no decay after 48 months when treated at retention levels $>1.12 \mathrm{~kg} / \mathrm{m}^{3}$. Tebuconazole impregnation by supercritical fluids was thus shown to provide a reasonable protection against decay, but the concentrations of biocide needed were larger than what was previously reported for laboratory decay tests [55].

Morsing et al. [61] reported of ongoing Malaysian field tests (lap-joint according to ENV 12037 and L-joint according to EN 330) involving both supercritical and pressure impregnated samples of Scots pine sapwood (P. sylvestris) and Norway spruce (Picea abies) but their discussion of results is limited. This paper also reported results from laboratory tests (according to EN 113) where the toxic threshold found for supercritical impregnated samples were comparable to those found for samples impregnated by conventional methods using the same biocides, i.e. a mixture of tebuconazole, propiconazole, and IPBC. Finally, the study concluded that the supercritical treated samples were not especially sensitive to evaporation due to high temperature (according to EN 73) or leaching (according to EN 84).

Although results from biological tests are limited they show that biocides deposited by supercritical $\mathrm{CO}_{2}$ are capable of slowing biodegradation rates of wood. Threshold values will of course depend on the biocide(s) in question, but there the limited studies 
give no indications that supercritical deposition gives weaker performance in comparison with conventional treatment methods if the same biocides are used. Therefore, indications are that biocides retain their toxicity after deposition by supercritical $\mathrm{CO}_{2}$.

\section{Modeling}

Some attempts at developing mathematical models to describe and predict different aspects of supercritical wood impregnation have been conducted. Hasan et al. [62] tried to model the phase behavior of multi-component mixtures of $\mathrm{CO}_{2} /$ biocide/co-solvent but concluded that the models were only successful at conditions far from the critical point. In an attempt to minimize the problems associated with resin bleeding during supercritical treatment of wood due to the solubility of $\mathrm{CO}_{2}$ in wood resin, Laursen et al. [63] modeled the solubility of $\mathrm{CO}_{2}$ and $\mathrm{N}_{2}$ in wood resin by measuring the solubilities of the two gases in a model resin mixture of $\alpha$-pinene, oleic acid, and abietic acid and using the data to estimate the parameters for a modified Huron-Vidal first order model. They concluded that the model was able to qualitatively describe the $\mathrm{CO}_{2} / \mathrm{N}_{2} /$ resin mixtures.

Sahle-Demessie and co-workers $[44,48]$ formulated a model to predict the retention and spatial distribution of biocides in supercritical treated wood. The model was based on one-dimensional compressible flow through a porous media and depended on a single constant based on measurable fluid and wood characteristics. The model predicted a concentration slope from the surface to the core of treated samples as well as a larger retention of biocide at any given point with higher treatment pressure. This was in good agreement with the experimental data from impregnation of solid Douglas-fir in the same study. However, the reason for the modeled gradient was that the $\mathrm{CO}_{2}$ was not modeled to fill up the wood completely during the treatment schedule. This is not in agreement with the differential pressure measurements carried out by Schneider et al. [35] in which the $\mathrm{CO}_{2}$ is shown to penetrate similar samples. The authors concluded that the model needed improvement especially to allow for incorporation of wood/biocide interactions such as reaction and adsorption/desorption behavior.

Kang et al. [51] used experimental data and Egner's solution method for one-directional diffusion to calculate diffusion coefficients for movement of cyproconazole in Douglas-fir during supercritical treatment. They found diffusion coefficients tended to increase over time suggesting an increased permeability over time as well perhaps as a result of dissolving of wood extractives blocking intercellular pits. Diffusion coefficients were, however, found to be abnormally high as concentration gradients approached zero.

Lucas and co-workers $[53,64]$ developed a two parameter model to describe the impregnation of radiata pine ( $P$. radiata) with decanal and compared the predictions of the model with experimental results. The authors argued that the effectiveness of the impregnation process is chiefly determined by mass transfer from the fluid, modeled by a mass transfer coefficient, and equilibrium distribution of biocide between the solid (wood) and fluid $\left(\mathrm{CO}_{2}\right)$ under given process conditions, modeled by a partition coefficient. The model predictions corresponded well with experimental data and thus the model seemed capable of predicting impregnation curves of decanal impregnation of radiata pine using the described set up. Due to its chemical structure, decanal probably has a higher solubility in supercritical $\mathrm{CO}_{2}$ compared to the biocides used in most other studies (e.g. tebuconazole, cyproconazole, IPBC, PCP) and is capable of bonding chemically as well as physically to lignocellulosic material. Therefore, the maximum retention levels reported by Lucas et al. [53] approached $250 \mathrm{~kg} / \mathrm{m}^{3}$ which was substantially higher than maximum retention levels reported elsewhere.
Limited success has been achieved in trying to model the supercritical impregnation of wood with biocides. The model developed by Lucas et al. [53] was successful in predicting total retention of decanal in radiata pine, but did not consider the issue of concentration gradients. From the viewpoint of the manufacturer a successful impregnation model should, ideally, be able to predict not only total retention but also distribution of biocides. Such a model has yet to be developed.

\section{Conclusion}

Summarizing the results from the research reviewed above, it can be concluded that impregnation of wood using supercritical $\mathrm{CO}_{2}$ has proven to be a viable way of impregnating wood with biocides. Initial reports based on experiments with very small wood samples indicated that supercritical $\mathrm{CO}_{2}$ was able to penetrate the wood structure instantly without causing damage to impregnated samples. This conclusion turned out to be overly optimistic when studies involving larger samples showed that excessive pressurization or depressurization rates caused failure in many types of wood. Nevertheless, the studies on larger samples also showed that if process conditions are monitored and controlled according to limits given by the properties of the wood species or composite being treated, impregnation of most wood materials is possible without causing excessive detrimental effects on wood properties. Biocide retention studies, as well as studies on the performance of supercritical impregnated wood against biological attack, have shown that it is possible to deposit sufficient amounts of biocides in the wood using supercritical technology to slow biodegradation to acceptable levels. However, gradients between concentration levels in inner and outer parts of treated samples are likely to exist and could be a challenge when impregnating wood of larger sizes. Therefore, one of the main future challenges for researchers within this field will be to reduce the observed concentration gradients in impregnated wood. Another major challenge will be to develop mathematical models that can describe the movement of $\mathrm{CO}_{2}$, biocides and co-solvents in wood during impregnation. A key means of meeting these challenges is to develop a better understanding of $\mathrm{CO}_{2} /$ wood/biocide/co-solvent interactions.

\section{Acknowledgements}

The authors would like to thank the Danish Forest and Nature Agency for financial support.

\section{References}

[1] M.H. Freeman, T.F. Shupe, R.P. Vlosky, H.M. Barnes, Past, present and future of the wood preservation industry, Forest Products Journal 53 (2003) 8-15.

[2] S.B. Iversen, T. Larsen, O. Henriksen, K. Felsvang, The World's first commercial supercritical wood treatment plant, in: Proceedings of the International Society for Advancement of Supercritical Fluids 6th International Symposium on Supercritical Fluids, Versailles, France, April 28-30, 2003.

[3] N. Ito, T. Ougiya, M. Taniguchi, H. Imamura, An antiseptic treatment method of wood, JP 59-101311 (1984).

[4] A.K. Sunol, Supercritical fluid-aided treatment of porous materials, WO 90/02612 (1990).

[5] F. Kayihan, A.K. Sunol, Method of perfusing a porous workpiece with a chemical composition using co-solvents, WO 90/05621 (1990).

[6] O. Henriksen, A method of performing an impregnating or extracting treatment on a resin-containing wood substrate, WO 00/27601 (2000).

[7] A. Qader, Wood preservation, WO 01/05564 (2001).

[8] O. Henriksen, T. Larsen, S.B. Iversen, K. Felsvang, Process for treatment of wood using a carrier fluid under high pressure without damaging the wood, WO 03/095165 (2003).

[9] H. Korte, Verfahren zum imprägnieren von gasdurchlässigen feststoffen mit einem imprägniermittel, EP 1440779 (2004).

[10] L. Li, E. Kiran, Interaction of supercritical fluids with lignocellulosic materials, Industrial \& Engineering Chemistry Research 27 (1988) 1301-1312.

[11] D.C. Ritter, A.G. Campbell, Supercritical carbon-dioxide extraction of southern pine and ponderosa pine, Wood and Fiber Science 23 (1991) 98-113. 
[12] E.C. Mcdonald, J. Howard, B. Bennett, Chemicals from forest products by supercritical fluid extraction, Fluid Phase Equilibria 10 (1983) 337-344.

[13] M. Acda, J.J. Morrell, A. Silva, K.L. Levien, J. Karchesy, Using supercritical carbon dioxide for extraction of western juniper and Alaska-cedar, Holzforschung 52 (1998) 472-474.

[14] F.J. Eller, J.W. King, Supercritical carbon dioxide extraction of cedarwood oil: a study of extraction parameters and oil characteristics, Phytochemical Analysis 11 (2000) 226-231.

[15] F.J. Eller, S.L. Taylor, Pressurized fluids for extraction of cedarwood oil from Juniperus virginianna, Journal of Agricultural and Food Chemistry 52 (2004) $2335-2338$.

[16] F.J. Gonzalez-Vila, J.M. Bautista, A. Gutierrez, J.C. Del Rio, A.G. Gonzalez, Supercritical carbon dioxide extraction of lipids from Eucalyptus globulus wood, Journal of Biochemical and Biophysical Methods 43 (2000) 345-351.

[17] E. SahleDemessie, J.S. Yi, K.L. Levien, J.J. Morrell, Supercritical fluid extraction of pentachlorophenol from pressure-treated wood, Separation Science and Technology 32 (1997) 1067-1085.

[18] A. Larsen, N.A. Jentoft, T. Greibrokk, Extraction of formaldehyde from particleboard with supercritical carbon-dioxide, Forest Products Journal 42 (1992) $45-48$.

[19] S.M. Kang, A. Unger,J.J. Morrell, The effect of supercritical carbon dioxide extraction on color retention and pesticide reduction of wooden artifacts, Journal of the American Institute for Conservation 43 (2004) 151-160.

[20] S. Abd El-Fatah, M. Goto, A. Kodama, T. Hirose, Supercritical fluid extraction of hazardous metals from CCA wood, Journal of Supercritical Fluids 28 (2004) 21-27.

[21] C. Perre, A. Beziat, M. Carles, Neutralization and strengthening of papers with supercritical $\mathrm{CO}_{2}$, in: Proceedings of the 3rd International Symposium on Supercritical Fluids, Strasbourg, France, 1994, pp. 19-24.

[22] S.M. Smith, E. Sahle-Demessie, J.J. Morrell, K.L. Levien, H. Ng, Supercritical fluid (SCF) treatment: its effect on bending strength and stiffness of ponderosa pine sapwood, Wood and Fiber Science 25 (1993) 119-123.

[23] S.M. Smith, J.J. Morrell, E. Sahle-Demessie, K.L. Levien, Supercritical fluid treatment: effects on bending strength of white spruce heartwood, in: Proceedings of the International Research Group on Wood Preservation(IRG) Paper Prepared for the 24th Annual Meeting, Orlando, FL, 17-21 May, 1993.

[24] G.H. Kim, S. Kumar, E. Sahle-Demessie, K.L. Levien, J.J. Morrell, Bending properties of TCMTB-treated southern pine sapwood using supercritical carbon dioxide impregnation process, in: Proceedings of the International Research Group on Wood Preservation (IRG) Paper Prepared for the 28th Annual Meeting, Whistler Conference Center, Whistler, Canada, 25-30 May, 1997.

[25] M.N. Acda, J.J. Morrell, K.L. Levien, Supercritical fluid impregnation of selected wood species with tebuconazole, Wood Science and Technology 35 (2001) $127-136$.

[26] M. Muin, A. Adachi, M. Inoue, T. Yoshimura, K. Tsunoda, Feasibility of supercritical carbon dioxide as a carrier solvent for preservative treatment of wood-based composites, Journal of Wood Science 49 (2003) 65-72.

[27] E. Sahle-Demessie, A. Hassan, K.L. Levien, S. Kumar, J.J. Morrell, Supercritical carbon dioxide treatment: effect on permeability of douglas-fir heartwood, Wood and Fiber Science 27 (1995) 296-300.

[28] M.N. Acda, J.J. Morrell, K.L. Levien, Effects of supercritical fluid treatments on physical properties of wood-based composites, Wood and Fiber Science 29 (1997) 121-130.

[29] M. Muin, A. Adachi, K. Tsunoda, Applicability of supercritical carbon dioxide to the preservative treatment of wood-based composites, in: Proceedings of the International Research Group on Wood Preservation (IRG) Paper prepared for the 32nd Annual Meeting, Nara, Japan, 20-25 May, 2001.

[30] M.N. Acda, Supercritical fluid impregnation of wood-based composites, Ph.D. Dissertation, Oregon State University, Corvallis, Oregon, 1995.

[31] J.F. Siau, Transport Processes in Wood, Springer-Verlag, Berlin, 1984.

[32] R.-D. Peek, St. Goetsch, Dynamics of pressure changes in wood during impregnation, in: Proceedings of the International Research Group on Wood Protection (IRG) Paper Prepared for the 21st Annual Meeting, Rotorua, New Zealand, 13-18 May, 1990.

[33] P.F. Schneider, K.L. Levien, J.J. Morrell, Internal pressure measurement techniques and pressure response in wood during treating processes, Wood and Fiber Science 35 (2003) 282-292.

[34] P.F. Schneider, Pressure measurement in wood as a method to understand impregnation processes: conventional and supercritical carbon dioxide, Ph.D. Dissertation, Oregon State University, Corvallis, Oregon, 1999.

[35] P.F. Schneider, J.J. Morrell, K.L. Levien, Internal pressure development during supercritical fluid impregnation of wood, Wood and Fiber Science 37 (2005) 413-423.

[36] M. Drescher, A. Jokisch, H. Korte, R.D. Peek, R. Steiner, Differential pressure characteristics of wood impregnated with compressed gases, liquids and supercritical fluids, Holz Als Roh- und Werkstoff 64 (2006) 178-182.

[37] M.E. Anderson, R.J. Leichti, J.J. Morrell, The effects of supercritical $\mathrm{CO}_{2}$ on the bending properties of four refractory wood species, Forest Products Journal 50 (2000) 85-93.

[38] G.H. Kim, J.J. Morrell, In-situ measurement of dimensional changes during supercritical fluid impregnation of white spruce lumber, Wood and Fiber Science 32 (2000) 29-36.

[39] G. Oberdorfer, R.J. Leichti, J.J. Morrell, Deformation of wood-based material during supercritical carbon dioxide treatment, Wood and Fiber Science 36 (2004) 511-519.
[40] P.F. Schneider, K.L. Levien, J.J. Morrell, Effect of wood characteristics on pressure responses during supercritical carbon dioxide treatment, Wood and Fiber Science 38 (2006) 660-671.

[41] G. Oberdorfer, P.E. Humphrey, R.J. Leichti, J.J. Morrell, Internal pressure development within oriented strandboard during supercritical fluid impregnation, in: Proceedings of the International Research Group on Wood Protection (IRG) Paper prepared for the 31st Annual Meeting, Kona, Hawaii, 14-21 May, 2000.

[42] G. Oberdorfer, R.J. Leichti, J.J. Morrell, Internal pressure development and deformation during supercritical fluid impregnation of selected wood-based materials, Wood and Fiber Science 38 (2006) 190-205.

[43] P. Alessi, A. Cortesi, I. Kikic, F. Vecchione, Plasticization of polymers with supercritical carbon dioxide: experimental determination of glass-transition temperatures, Journal of Applied Polymer Science 88 (2003) 2189-2193.

[44] E. Sahle-Demessie, K.L. Levien, J.J. Morrell, Impregnation of wood with biocides using supercritical fluid carriers, ASC Symposium Series 608 (1995) 415-428.

[45] M. Acda, J.J. Morrell, K.L. Levien, Effect of process variables on supercritical fluid impregnation of composites with tebuconazole, Wood and Fiber Science 29 (1997) 282-290.

[46] M. Muin, K. Tsunoda, Retention of silafluofen in wood-based composites after supercritical carbon dioxide impregnation, Forest Products Journal 54 (2004) $168-171$.

[47] M. Drescher, A. Jokisch, H. Korte, R.-D. Peek, R. Steiner, Untersuchungen zur Tiefenfärbung von Holz unter Verwendung von verdichtetem Kohlendioxid, Chemie Ingenieur Technik 77 (2005) 436-441.

[48] E. Sahle-Demessie, Deposition of chemicals in semi-porous solids using supercritical fluid carriers, Ph.D. Dissertation, Oregon State University, Corvallis, Oregon, 1994.

[49] S.M. Kang, K.L. Levien, J.J. Morrell, Supercritical fluid impregnation of wood with biocides using temperature reduction to induce deposition, Wood Science and Technology 39 (2005) 328-338.

[50] S.M. Kang, J.J. Morrell, Supercritical fluid impregnation of Douglas-fir heartwood with cyproconazole using temperature induced deposition, in: Proceedings of the International Research Group on Wood Protection (IRG) Paper prepared for the 34th Annual Meeting, Brisbane, Australia, 18-23 May, 2003.

[51] S.M. Kang, J.B. Ra, K.L. Levien, J.J. Morrell, Developing diffusion coefficients for SCF impregnation of douglas fir heartwood with cyproconazole, Journal of Wood Chemistry and Technology 26 (2006) 111-124.

[52] S.M. Kang, K.L. Levien, J.J. Morrell, Effect of process variations during supercritical fluid impregnation on cyproconazole retention and distribution in ponderosa pine sapwood, Wood and Fiber Science 38 (2006) 64-73.

[53] S. Lucas, E. Gonzalez, M.P. Calvo, C. Palencia, E. Alonso, M.J. Cocero, Supercritical $\mathrm{CO}_{2}$ impregnation of Radiata pine with organic fungicides-effect of operating conditions and two-parameters modeling, Journal of Supercritical Fluids 40 (2007) 462-469.

[54] J.J. Morrell, K.L. Levien, E. Sahle-Demessie, S. Kumar, S.M. Smith, H.M. Barnes, Treatment of wood using supercritical fluid processes, in: Proceedings of the 14th Annual Meeting of the Canadian Wood Preservation Association, vol. 14, 1993, pp. 6-35.

[55] M.N. Acda, J.J. Morrell, K.L. Levien, Decay resistance of composites following supercritical fluid impregnation with tebuconazole, Material und Organismen 30 (1996) 293-300.

[56] M. Muin, K. Tsunoda, Preservative treatment of wood-based composites with 3-iodo-2-propynyl butylcarbamate using supercritical carbon dioxide impregnation, Journal of Wood Science 49 (2003) 430-436.

[57] M. Muin, K. Tsunoda, Termiticidal performance of wood-based composites treated with silafluofen using supercritical carbon dioxide, Holzforschung 57 (2003) 585-592.

[58] M. Muin, K. Tsunoda, Biological performance of wood-based composites treated with a formulation of 3-iodo-2-propynyl butylcarbamate and silafluofen using supercritical carbon dioxide, Journal of Wood Science 50 (2004) 535-539.

[59] K. Tsunoda, M. Muin, Preservative treatment of wood-based composites with a mixture formulation of IPBC-silafluofen using supercritical carbon dioxide as a carrier gas, in: Proceedings of the International Research Group on Wood Protection (IRG) Paper prepared for the 34th Annual Meeting, Brisbane, Australia, 18-23 May, 2003.

[60] J.J. Morrell, M.N. Acda, A.R. Zahora, Performance of oriented strand board, medium density fiberboard, plywood, and particleboard treated with tebuconazole in supercritical carbon dioxide, in: Proceedings of the International Research Group on Wood Protection (IRG) Paper prepared for the 36th Annual Meeting, Bangalore, India, 24-28 April, 2005.

[61] N. Morsing, A.H.H. Wong, F. Imsgard, O. Henriksen, How to document the performance of super-critical treated wood in above ground situations? in: Proceedings of the International Research Group on Wood Protection (IRG) Paper prepared for the 36th Annual Meeting, Bangalore, India, 24-28 April, 2005.

[62] A. Hassan, K.L. Levien, J.J. Morrell, Modeling phase behavior of multicomponent mixtures of wood preservatives in supercritical carbon dioxide with cosolvents Fluid Phase Equilibria 179 (2001) 5-22.

[63] T. Laursen, S.I. Andersen, S. Dahl, O. Henriksen, Measurement and modeling of the solubility of $\mathrm{CO}_{2}$ and $\mathrm{N}_{2}$ in a model resin system based on resin from spruce wood (Picea abies (L.)), Journal of Supercritical Fluids 19 (2001) 239-250.

[64] S. Lucas, M.P. Calvo, J. Garcia-Serna, C. Palencia, M.J. Cocero, Two-parameter model for mass transfer processes between solid matrixes and supercritical fluids: analytical solution, Journal of Supercritical Fluids 41 (2007) 257-266. 


\section{Paper}

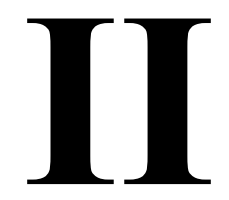




\title{
Permeability of wood to supercritical carbon dioxide
}

\author{
Anders W. Kjellow ${ }^{1}$, Ole Henriksen ${ }^{2}$, Joao Luis Fernandez ${ }^{2}$, Hans Erik Lundager Madsen ${ }^{3}$ and \\ Claus Felby ${ }^{1}$
}

${ }^{1}$ Forest and Landscape, Faculty of Life Sciences, University of Copenhagen, Rolighedsvej 23, 1958 Frederiksberg C, Denmark
${ }^{2}$ Hampen Træforarbejdning A/S, Palsgårdvej 3, 7362 Hampen, Denmark

${ }^{3}$ Department of Basic Sciences and Environment, University of Copenhagen, Thorvaldsensvej 40, 1871 Frederiksberg C, Denmark

\begin{abstract}
Wood permeability is a key factor in determining pressurization and depressurization rates for supercritical wood impregnation. However, permeability data for supercritical fluids in wood has not been previously published. Here we report the permeability of Norway spruce measured with supercritical carbon dioxide. An equation for the calculation of permeability to supercritical fluids is presented. The supercritical $\mathrm{CO}_{2}$ permeability was found to be 250 percent higher than the $\mathrm{CO}_{2}$ permeability measured at atmospheric levels. It is hypothesized that the higher supercritical permeability may be caused by the aspirated pits being permeable to supercritical carbon dioxide. In addition, permeability values measured with gasses at atmospheric levels before and after exposure to supercritical carbon dioxide are presented. Exposure to supercritical carbon dioxide resulted in a small but significant increase in permeability of 12 percent.
\end{abstract}

\section{Introduction}

Supercritical carbon dioxide can be used as solvent for wood impregnation [1]. The technique is commercialized [2] and exploits the combination of physical properties possessed by supercritical fluids. While having density comparable to liquids, carbon dioxide in its supercritical phase has low viscosity and low surface tension which allows it to flow through wood with less resistance than solvents in the liquid phase. Thus, by using supercritical $\mathrm{CO}_{2}$ as solvent, impregnation of wood species otherwise considered refractory such as spruce (Picea $s p$.) is now possible.

However, despite the low viscosity and surface tension of supercritical fluids, wood can provide a substantial resistance to the flow of these fluids through its interior. The magnitude of resistance to fluid flow is dependant on the permeability of the wood species. Permeability data for many wood species are available in the literature and are often computed using one of two versions of Darcy's law - one version for calculation of permeability to liquids, and another version for calculation of permeability to gases [3].

No permeability data exists for permeability of wood to supercritical fluids. For modeling purposes it is important to establish the permeability of wood to supercritical fluids.

This paper examines the permeability of Norway spruce (Picea abies) to supercritical carbon dioxide. It also presents an equation for calculating permeability when measured with supercritical fluids.

\section{Materials and methods}

\section{Experimental}

Wood from Norway spruce was provided by Vida Wood, Sweden. Two cylindrical dowels (final dimensions $\mathrm{L}=50 \mathrm{~mm}, \varnothing=6 \mathrm{~mm}$ ) were drilled in the longitudinal direction from each of 27 different boards. The dowels, conditioned to $10 \%$ moisture content, were glued into $50 \mathrm{~mm}$ long pieces of high pressure steel tubing (ID $=6 \mathrm{~mm}$ ) using two component epoxy.

After hardening of the glue, the ends of the wood pieces, which had intentionally been cut several millimeters too long, was shaved off to the level of the tubing assuming their final dimension of $50 \mathrm{~mm}$ in length. The shaving was done to eliminate the risk of fines from the band saw cut in the tracheid entrances affecting the permeability [4]. The tubing with the end cut dowel was attached with fittings to mount it on the experimental set-up as demonstrated in figure 1 .

Additionally, an inert permeability reference dowel was produced from sintered metal by Dansk Sintermetal A/S, Denmark. The metal dowel was also glued into high pressure steel tubing.

The experimental set-up (figure 1) was designed to measure the permeability of wood to $\mathrm{CO}_{2}$ at both atmospheric and supercritical conditions. Two bottles of $\mathrm{CO}_{2}$ (Linde 4.8) provided flow for the system. One was equipped with a pressure reduction valve and used for low pressure measurements while the other was connected to a diaphragm pump (Burdosa MV 055.3/5) and used for high pressure measurements.

Downstream from the $\mathrm{CO}_{2}$ bottles the tubing containing the wood dowel was mounted. A by-pass 
valve allowed for simultaneous pressurization and depressurization of both ends of the dowel. Thermometers and pressure gauges with accuracies of $\pm 0.1{ }^{\circ} \mathrm{C}$ and \pm 0.1 bar, respectively was fitted on both the inlet and the outlet side of the dowel. A differential pressure meter (Smar LD301) measured the differential pressure between inlet and outlet pressure with \pm 0.01 bar accuracy.

The values of the inlet pressure and the differential pressure meter were recorded during the experiment using a data logger (DataQ 148U) connected to a computer. Downstream from the dowel, two differently sized needle valves controlled system pressure. One was a large diameter needle valve (V5) to use for pressure regulation during the pressurization and the depressurization phases. The other was a small diameter needle valve that enabled precise control of the differential pressure needed for the high pressure measurement. Flow was measured with a wet-test drum type flow meter (Schlumberger) or, for very low flow rates, with a bubble flow meter. The temperature of the system was controlled by water heating to $45^{\circ} \mathrm{C}$.

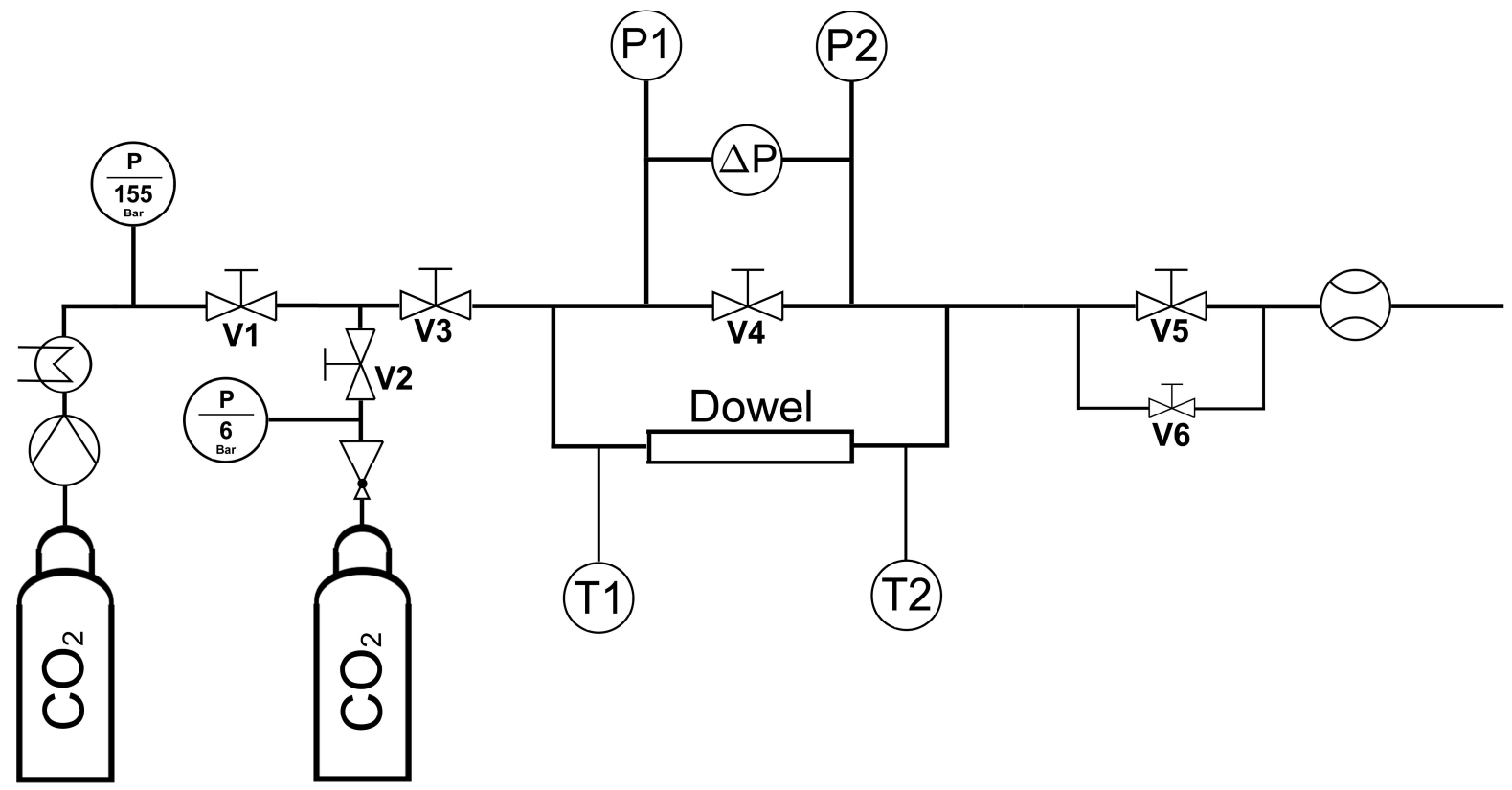

Figure 1. Schematic presentation of the experimental setup.

Each individual dowel was subjected to three permeability measurements in succession: One at atmospheric levels before exposure to supercritical conditions $\left(\mathrm{k}_{1}\right)$, one at supercritical conditions $\left(\mathrm{k}_{2}\right)$, and then one at atmospheric levels again after exposure to supercritical conditions $\left(\mathrm{k}_{3}\right)$.

The individual measurements were carried out as follows. For the first measurement at atmospheric levels, V2, V3, and V5 were opened. The flow through the dowel was now measured with one of the two flow meters while the values of $\mathrm{T} 1, \mathrm{~T} 2, \mathrm{P} 1, \mathrm{P} 2$, and $\Delta \mathrm{P}$ were recorded. Next, with V1, V3, and V4 open and all other valves closed, the pressure of the system was increased at a rate of 5 bar per minute until the inlet pressure had reached 155 bar. The by pass valve (V4) was then closed and V6 were opened to provide a pressure differential of about 2 bar. The flow was measured again while the temperature and pressure readings were recorded. V1 and V6 were then closed while V4 was opened and the system was depressurized at a rate of 5 bars per minute by opening and closing V5 until atmospheric pressure was obtained. The second measurement at atmospheric level was then repeated.

Finally, the permeability of the metal dowel was measured at the same conditions as the wood dowels.

\section{Calculations}

Calculations were carried out using an equation based on Darcys law and adapted for non-ideal gasses. Frequently, gas permeability values are calculated from the following equation based on Darcys Law that accounts for the compressibility of gasses [5-9]:

$$
k=\frac{Q x \mu P_{I N}}{A \Delta P \bar{P}}
$$

where, $\mathrm{k}$ is the permeability and $Q$ is the volumetric flow through a sample with cross area $A$ and length $x$. $\mu$ is the viscosity of the measuring fluid and $\mathrm{P}_{\mathrm{IN}}, \Delta P$, and $\bar{P}$ is the inlet pressure, differential over the object, and mean pressure in the object, respectively. Equation (1) can be modified, e.g. to account for the possible 
influence of molecular slip flow as described by several authors [3,10-12].

However, since equation 1 is based on ideal gas behavior it will likely not be accurate when applied to supercritical fluids. A new equation was therefore constructed based on Darcys Law but adapted for nonideal gasses.

Permeability, $k$, can be expressed in differential form by the general formula:

$k=-\frac{Q}{A d P / d x}$

where, $Q$ is the volumetric flow through a sample with cross area $A$ and length $x$, and $\Delta P$ is the pressure differential over the object. $Q / A=v$ is the velocity of the flow, thus:

$$
v=-k \frac{d P}{d x}
$$

Dividing (2) by the molar volume $\left(V_{m}\right)$ yields the flux of matter $J$ :

$$
J=-\frac{k}{V_{m}} \frac{d P}{d x}
$$

Multiplying (3) with $A$ gives the flow of matter per unit of time, $q$ :

$$
q=-k \frac{A}{V_{m}} \frac{d P}{d x}
$$

Rearrangement and integration yields:

$$
k \int_{P_{\text {in }}}^{P_{\text {out }}} \frac{d P}{V_{m}}=-\frac{q L}{A}
$$

where, $P_{\text {in }}$ and $P_{\text {out }}$ is the inlet and outlet pressure, respectively. $L$ is the length of the object. Since $P_{i n}>$ $P_{\text {out }}$, the integral is $<0$ and is termed $-I_{p}$. Multiplication with the viscosity, $\mu$, makes $k$ independent of the fluid used for measurements and we arrive at a general formula for calculating $k$ for non-ideal gases:

$k=\frac{q L \mu}{A I_{P}}$

At constant conditions, the value of $q$ is the same anywhere in the object and can be calculated, using an equation of state for the appropriate fluid, from the volume of the gas passing per unit of time at the inlet or outlet of the object. $I_{p}$ can be determined by numerical integration. Here, we determined $I_{p}$ using Simpsons rule with $n=10$. Eq. (6) was used to calculate permeability at atmospheric as well as supercritical pressures. The differences in permeability between $k_{1}$ and $\mathrm{k}_{2}$ and between $\mathrm{k}_{1}$ and $\mathrm{k}_{3}$ were calculated for each of the samples $(n=27)$ followed by a paired difference tests to evaluate the null hypotheses of mean differences being equal to zero.

\section{Results and discussion}

Table 1 shows the mean permeability values of $k_{1}, k_{2}$, and $\mathrm{k}_{3}$. Mean permeability before treatment $\left(\mathrm{k}_{1}\right)$ was found to be $0.0064 \mu \mathrm{m}^{2}$. The variation between individual samples was relatively high as permeability values ranged from 0.0008 to $0.0307 \mu^{2}$ before treatment.

Figure 2 shows the individual pair-wise percentage changes in permeability from $\mathrm{k}_{1}$ to $\mathrm{k}_{3}$ (the two low pressure measurements). Mean permeability increased $12 \%$ as a result of exposure to supercritical $\mathrm{CO}_{2}$. The increase was found to be significant. However, individual permeability changes ranged from $-14 \%$ to

\begin{tabular}{|c|c|c|c|c|c|c|}
\hline Measurement $^{\mathrm{a}}$ & $\begin{array}{l}\bar{P} \\
\text { (bar) }\end{array}$ & $\begin{array}{l}\text { \# of } \\
\text { samples } \\
\text { (n) }\end{array}$ & $\begin{array}{l}\text { Mean } \\
\text { permeability } \\
\left(\mu \mathrm{m}^{2}\right)^{\mathrm{b}}\end{array}$ & $\begin{array}{l}\text { Mean of paired } \\
\text { differences from } \mathrm{k}_{1}\end{array}$ & t-value ${ }^{c}$ & p-value \\
\hline $\mathrm{k}_{1}$ & 3.5 & 27 & $0.0064(0.0062)$ & - & - & - \\
\hline $\mathrm{k}_{2}$ & 154 & 27 & $0.0198(0.0205)$ & $1.34 \mathrm{e}-02$ & 4.603 & $9.58 \mathrm{e}-05^{* * *}$ \\
\hline $\mathrm{k}_{3}$ & 3.5 & 27 & $0.0072(0.0066)$ & $7.65 \mathrm{e}-04$ & 3.087 & $4.76 \mathrm{e}-03^{\text {**** }}$ \\
\hline
\end{tabular}
+62\% with $19 \%$ of the samples showing a decrease in permeability after treatment.

Table 1. Mean permeability of samples measured before, during, and after treatment with supercritical carbon dioxide. 


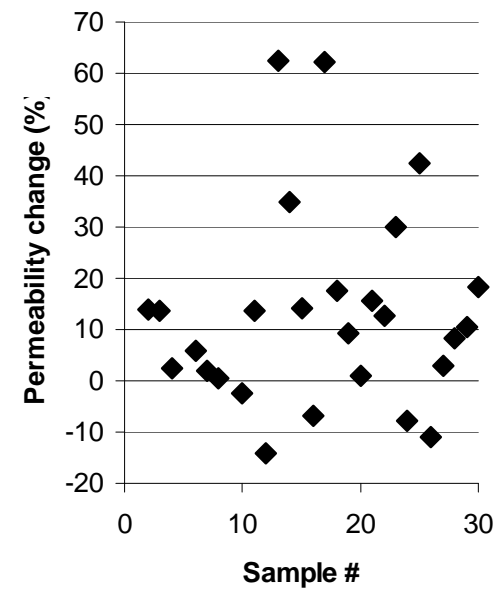

Figure 2. Permeability change in percent as a result of exposure to supercritical $\mathrm{CO}_{2}$.

The slight but significant permeability increase of $12 \%$ between the $\mathrm{k}_{1}$ and $\mathrm{k}_{3}$ measurement could be caused by physical or chemical changes in the wood as a result of exposure to supercritical $\mathrm{CO}_{2}$. Excessive pressurization and depressurization rates have previously been shown to have detrimental effects on wood structure $[13,14]$. Large pressure differences during pressurization and de-pressurization can cause collapse or rupture in the cellular structure of the wood opening up larger flow paths. Chemically, supercritical $\mathrm{CO}_{2}$ could solubilize extractives in the cell walls and in the intercellular pits which might lead to "deaspiration" of aspirated pits. De-aspiration of pits might also be facilitated by smaller pressure differences during the process.

Sahle-Demessie et al. [15] examined the change in permeability of wood of Douglas fir (Pseudotsuga menziesii) before and after exposure to supercritical $\mathrm{CO}_{2}$. They found the permeability to increase $117 \%$ on average after supercritical treatment. As in the present study they found permeability to decrease in $19 \%$ of the samples. Douglas fir contains a high amount of extractives compared to Norway spruce. The increased permeability found by Sahle-Demessie et al. might therefore be explained by removal of extractives from the wood. However, despite an average weight-loss of more than $3 \%$ the authors found no significant correlation between weight loss and permeability. For this reason, they suggested that the increased permeability might be the cause of structural changes in the wood structure during treatment. The authors did not mention the pressurization and de-pressurization rates, but if those rates were excessive it seems likely that the increased permeability could have been caused by structural changes. Furthermore, it was hypothesized that the reason for the decrease in permeability in $19 \%$ of the dowels could be clogging of pit membranes due to redeposition of solubilized extractives during depressurization.

In the present study pressurization and depressurization rates were kept at low levels. It is unlikely that the increase in permeability after treatment could be caused by collapse or split in the wood as a result of excessive pressure differences.

A more likely possibility for the slightly increased permeability could be solubilization of resin in resin canals. Resin canals are not widely abundant in Norway spruce but nevertheless present on a consistent basis. Solubilization of resin in these canals might not bring about a significant weight change but could be sufficient to open up flow paths significantly wider than the tracheid to tracheid flow paths otherwise available which might lead to an increase in permeability.

Figure 3 shows the individual pair-wise percentage changes in permeability from $\mathrm{k}_{1}$ to $\mathrm{k}_{2}$ (the initial low pressure measurement and the supercritical measurement). All samples showed an increase in permeability $\mathrm{k}_{1}$ to $\mathrm{k}_{2}$. The increase was found to be significantly different from zero with a p-value of 9.58e-05. On average the increase was $250 \%$.

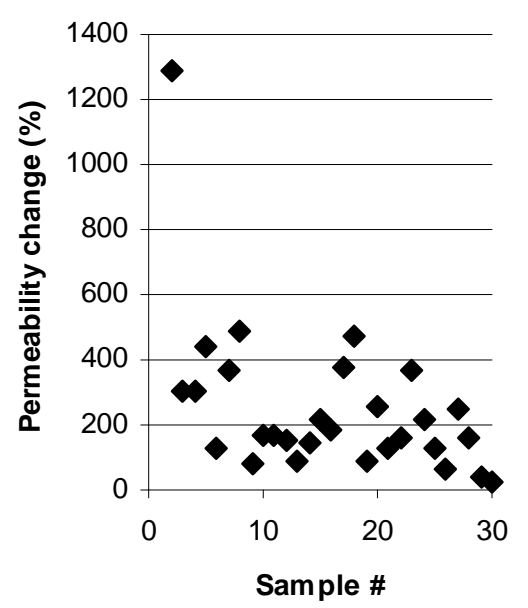

Figure 3. Percent change in permeability from measurements at close to atmospheric pressures to measurements with supercritical carbon dioxide at 150 bar pressure.

Measurements on the metal dowel did not show a corresponding significant increase in the permeability at supercritical levels. The permeability at 154 bars $\left(0.0016 \mu^{2}\right)$ was only $3 \%$ higher than the permeability at atmospheric levels $\left(0.0017 \mu \mathrm{m}^{2}\right)$.

The substantial increase in permeability at supercritical levels is not immediately obvious, but could either be caused by temporary changes in the wood structure, differences in flow patterns at supercritical conditions, and/or interactions between the fluid and the substrate.

Since no significant changes were detected between the high pressure and low pressure measurement of the 
inert reference dowel, it is likely that the high differences for the wood dowels is caused by changes in the wood structure, or wood- $\mathrm{CO}_{2}$ interactions at higher pressures.

Pressurization and depressurization rates were kept low so changes in wood structure caused by damages due to excessive internal pressure differences are unlikely. Furthermore, if the increased permeability was the result of damages to the wood structure, the permeability after treatment should also have been substantially higher than the before treatment values.

Interactions between wood and $\mathrm{CO}_{2}$ might possibly affect the permeability. Supercritical $\mathrm{CO}_{2}$ have been shown to adsorb in significant amounts to many different organic polymers [16]. Supercritical $\mathrm{CO}_{2}$ is might likewise adsorb to some extend to wood. If adsorption is occurring it is likely to cause some degree of swelling of the wood. However, in the case of swelling one would expect the permeability to decrease due to the decreased porosity which is contrary to our observations.

Since the permeability increase was exclusive to the supercritical measurement, there seem to be flow paths available for supercritical $\mathrm{CO}_{2}$ which are not available for $\mathrm{CO}_{2}$ at atmospheric pressures.

A possible explanation for increased amount of flow paths at supercritical conditions could be that $\mathrm{CO}_{2}$ in its supercritical phase is able to penetrate the aspirated tori of the intertracheid bordered pits. In spruce wood, the larger part of the bordered pits are aspirated which accounts for the low permeability of this species. The tori consist of a network of cellulose and hemicellulose which is embedded in a matrix of pectin $[17,18]$. It is evolutionary developed to protect against the spread of air embolisms in the conducting xylem of the living tree [19]. Therefore, it is impermeable to flow of both liquids and gasses at atmospheric pressure but might be permeable to the flow of supercritical $\mathrm{CO}_{2}$.

Supercritical $\mathrm{CO}_{2}$ can interact with a range of organic polymers [20]. Interaction with supercritical $\mathrm{CO}_{2}$ can change the physical and mechanical properties of polymers and cause weight gain through $\mathrm{CO}_{2}$ adsorption, swelling, and plasticization through the lowering of glass transition temperatures [21]. It is likely that supercritical $\mathrm{CO}_{2}$ could swell and soften the torus polymers, especially the pectins, to allow for the mass transfer of $\mathrm{CO}_{2}$ through the torus.

The increased permeability at supercritical conditions has implications for the supercritical wood impregnation process. Wood permeability is a key factor in determining how fast wood can be pressurized and depressurized without suffering internal damages as a result of excessive internal pressure gradients. For the economic performance of the process it is important to minimize overall impregnation times. If the limits of pressurization and depressurization rates are calculated on the basis of permeability measurements with gases at atmospheric levels, they will be underestimated in the supercritical region.

\section{Conclusion}

The exposure of wood dowels (Norway spruce) to supercritical carbon dioxide had a small but significant effect on the permeability of the dowels. Average permeability values after exposure were 12 percent higher than the before exposure values. During exposure to supercritical $\mathrm{CO}_{2}$, average permeability was 250 percent higher than the gas permeability measured at atmospheric levels. It is hypothesized that the increased permeability at supercritical conditions could be explained by the tori of aspirated intertracheid bordered pits acting as semipermeable membranes, impermeable to liquids and gasses at atmospheric levels but permeable to supercritical carbon dioxide. The increased permeability of Norway spruce measured with supercritical carbon dioxide means that pressurization and depressurization of Norway spruce can be carried out at higher rates in the supercritical region without creation of internal damages in the wood.

\section{References}

[1] A.W. Kjellow, O. Henriksen, Supercritical wood impregnation, Journal of Supercritical Fluids 50 (2009) 297304.

[2] S.B. Iversen, T. Larsen, O. Henriksen, K. Felsvang, The World's First Commercial Supercritical Wood Treatment Plant, The International Society for Advancement of Supercritical Fluids, 6th International Symposium on Supercritical Fluids, Versailles, France. April 28-30, 2003 (2003) 1-6.

[3] J.F. Siau, Transport Processes in Wood, Springer-Verlag, Berlin, 1984.

[4] E.T. Choong, C.W. McMillin, F.O. Tesoro, Effect of Surface Preperation on Gas Permeability of Wood, Wood Science 7 (1975) 319-322. 
[5] F.O. Tesoro, E.T. Choong, O.K. Kimbler, Relativ Permeability and the Gross Pore Structure of Wood, Wood and Fiber Science 6 (1974) 226-236.

[6] R.W. Rice, M. D'Onofrio, Longitudinal gas permeability measurements from eastern white pine, red spruce, and balsam fir, Wood and Fiber Science 28 (1996) 301-308.

[7] M.R. Milota, J.L. Tschernitz, S.P. Verrill, T. Mianowski, Gas-Permeability of Plantation Loblolly-Pine, Wood and Fiber Science 27 (1995) 34-40.

[8] G.L. Comstock, Relationship Between Permeability of Green and Dry Eastern Hemlock, Forest Products Journal 18 (1968) 20-23.

[9] J.X. Lu, S. Avramidis, Non-Darcian air flow in wood - Part 1. Specimen length effect, Holzforschung 51 (1997) 577-583.

[10] G.L. Comstock, Longitudinal Permeability of Wood To Gases and Nonswelling Liquids, Forest Products Journal 17 (1967) 41-46.

[11] J.K. Wiedenbeck, K. Hofmann, P. Peralta, C. Skaar, P. Kock, Air Permeability, Shrinkage, and Moisture Sorption of Lodgepole Pine Stemwood, Wood and Fiber Science 22 (1990) 229-245.

[12] J.X. Lu, S. Avramidis, Non-Darcian air flow in wood - Part 3. Molecular slip flow, Holzforschung 53 (1999) 85-92.

[13] M.N. Acda, J.J. Morrell, K.L. Levien, Supercritical fluid impregnation of selected wood species with tebuconazole, Wood Science and Technology 35 (2001) 127-136.

[14] M.E. Anderson, R.J. Leichti, J.J. Morrell, The effects of supercritical CO2 on the bending properties of four refractory wood species, Forest Products Journal 50 (2000) 85-93.

[15] E. Sahle-Demessie, A. Hassan, K.L. Levien, S. Kumar, J.J. Morrell, Supercritical Carbon Dioxide Treatment: Effect on Permeability of Douglas-Fir Heartwood, Wood and Fiber Science 27 (1995) 296-300.

[16] J. von Schnitzler, R. Eggers, Mass transfer in polymers in a supercritical CO2-atmosphere, Journal of Supercritical Fluids 16 (1999) 81-92.

[17] J. Bauch, H. Berndt, Variability of Chemical Composition of Pit Membranes in Bordered Pits of Gymnosperms, Wood Science and Technology 7 (1973) 6-19.

[18] Y. Imamura, H. Harada, H. Saiki, Embedding Substances of Pit Membranes in Softwood Tracheids and Their Degradation by Enzymes, Wood Science and Technology 8 (1974) 243-254.

[19] U.G. Hacke, J.S. Sperry, J. Pittermann, Analysis of circular bordered pit function - II. Gymnosperm tracheids with torus-margo pit membranes, American Journal of Botany 91 (2004) 386-400.

[20] Y.T. Shieh, J.H. Su, G. Manivannan, P.H.C. Lee, S.P. Sawan, W.D. Spall, Interaction of supercritical carbon dioxide with polymers. II. Amorphous polymers, Journal of Applied Polymer Science 59 (1996) 707-717.

[21] P. Alessi, A. Cortesi, I. Kikic, F. Vecchione, Plasticization of polymers with supercritical carbon dioxide: Experimental determination of glass-transition temperatures, Journal of Applied Polymer Science 88 (2003) 2189-2193. 
Paper

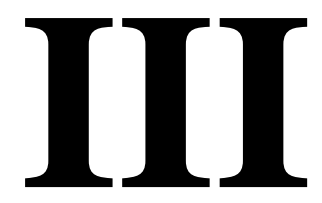




\title{
Partitioning of organic biocides between wood and supercritical carbon dioxide
}

\author{
Anders W. Kjellow ${ }^{\mathrm{a}, *}$, Ole Henriksen ${ }^{\mathrm{b}}$, Jens Christian Sørensen ${ }^{\mathrm{c}}$, Monika Johannsen ${ }^{\mathrm{d}}$, Claus Felby ${ }^{\mathrm{a}}$ \\ a Forest and Landscape, Faculty of Life Sciences, University of Copenhagen, Rolighedsvej 23, 1958 Frederiksberg C, Denmark \\ ${ }^{b}$ Hampen Træforarbejdning A/S, Palsgårdvej 3, 7362 Hampen, Denmark \\ ${ }^{c}$ Department of Basic Science and Environment, Faculty of Life Sciences, University of Copenhagen, Thorvaldsensvej 40, 1870 Frederiksberg C, Denmark \\ d Institut für Thermische Verfahrenstechnik, Technische Universität Hamburg-Harburg, Eißendorfer Straße 38, 21073 Hamburg, Germany
}

\section{A R T I C L E I N F O}

\section{Article history:}

Received 29 September 2009

Received in revised form 8 December 2009

Accepted 9 December 2009

\section{Keywords:}

Supercritical fluid

Impregnation

Wood

Biocide

Interaction

\begin{abstract}
A B S T R A C T
The degree of interaction between selected organic biocides (tebuconazole, propiconazole, and IPBC) and wood under supercritical conditions was investigated using a supercritical fluid chromatograph. The biocides were carried through a sawdust column by $\mathrm{CO}_{2}$ at various conditions. Retention times differed markedly both between the examined biocides and between physical conditions. Tebuconazole showed a higher affinity for wood than the other biocides. For all biocides, wood affinity was highest and, thus, fluid affinity lowest, at lowest pressures.
\end{abstract}

(c) 2010 Elsevier B.V. All rights reserved.

\section{Introduction}

The service life of wood and wood products can be prolonged by impregnation with biocides that decrease the level of biodegradation. Most industrial impregnation is carried out under pressure using liquids as carrier solvents for biocides. However, wood has a high resistance to fluid flow. Supercritical fluids have a combination of physical properties such as low viscosity, low surface tension, high diffusivity, and high solvent power, which makes them an attractive alternative to solvents in the liquid phase for wood impregnation.

A number of studies were carried out to investigate the deposition and distribution of biocides from supercritical wood impregnation [1]. An important aspect of impregnation is the movement and deposition of biocides during impregnation. This aspect has, however, received little attention. The main principle behind biocide deposition in wood during supercritical impregnation is often described to be the loss of biocide solubility as the fluid undergoes the phase transition from super- to sub-critical state during depressurization. However, the often reported existence of concentration gradients between biocide loadings in inner and outer parts of impregnated samples [2-6] suggests that other factors are influencing biocide movement and deposition.

\footnotetext{
* Corresponding author. Tel.: +45 2281 9640; fax: +45 35331508 .

E-mail addresses: awk@life.ku.dk (A.W. Kjellow), oh@superwood.dk (O. Henriksen), jchs@life.ku.dk (J.C. Sørensen), m.johannsen@tuhh.de (M. Johannsen).
}

It is known from in situ differential pressure measurements during supercritical impregnation that the supercritical fluid fully penetrates the wood matrix during treatment $[7,8]$. If the supercritical fluid is evenly distributed in the wood matrix and the biocides are not, it indicates that the wood is retaining the biocides as the fluid penetrates the wood matrix. In other words there is a strong indication that deposition of biocides is taking place at supercritical conditions and that deposition is therefore not only due to a sudden loss of solubility during depressurization. Lucas et al. [9] measured equilibrium loadings of decanal in wood during supercritical $\mathrm{CO}_{2}$ treatment. They showed that equilibrium loadings were substantial and concluded that the mechanism of deposition was a favorable partition ratio of biocide to wood under supercritical conditions $\left[C_{\text {wood }} / C_{\text {fluid }}\right]$ instead of deposition of biocides during depressurization.

This work examines the interaction of three organic biocides with wood under supercritical conditions and shows that the key to understanding the deposition of biocide in supercritical impregnation lies in the partitioning of biocides between wood and $\mathrm{CO}_{2}$. Implications for supercritical wood impregnation are discussed.

\section{Materials and methods}

\subsection{Chromatographic system}

A Hewlett Packard G1850A SFC was used for the experiments. The system was equipped with a dual pistons reciprocating pump, cooled to $5{ }^{\circ} \mathrm{C}$ by Peltier cooling system, and a column oven with $\pm 1 \%$ accuracy. It also included an automatic injection system con- 


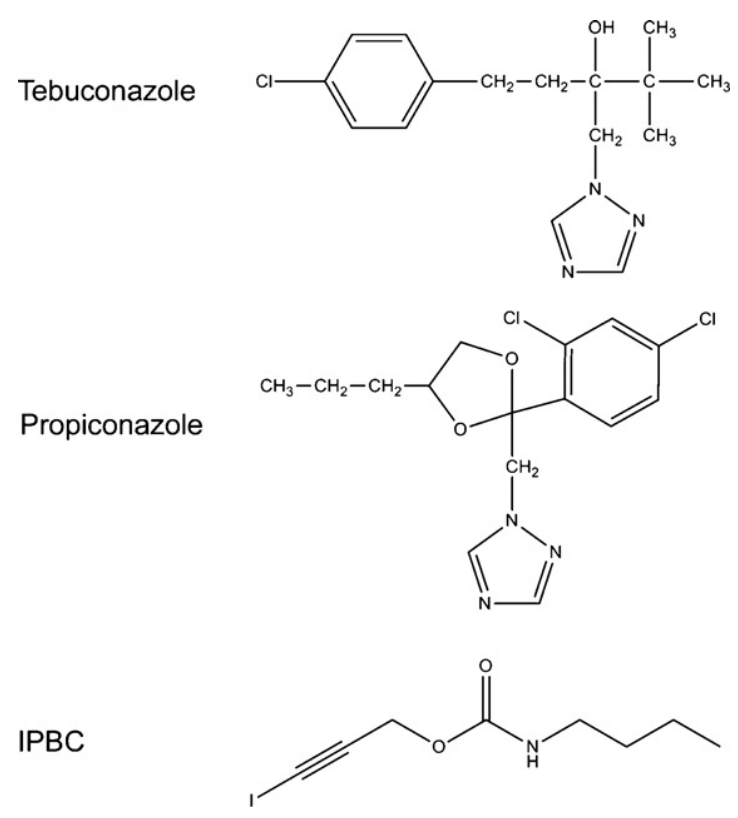

Fig. 1. Chemical structure of the investigated biocides.

sisting of an HP GC AutoSampler Controller G1512AX and an HP 7673 Automatic liquid sampler. A UV detector, HP 1050, was also built in. All system parameters were controlled by HP ChemStation software. The pump was fed by $\mathrm{CO}_{2}$ from a pressurized bottle (Air Liquide E290).

\subsection{Column}

Wood particles from Norway spruce (Picea abies) was ground to a particle size less than $0.125 \mathrm{~mm}$ of which $3.4 \mathrm{~g}$ (dry weight) was used to pack a column ( $L: 294 \mathrm{~mm}$; ID: $6.35 \mathrm{~mm}$ ). At this particle size, the greater part of the wood cells is reduced to fragments of cell walls. Consequently, the porosity and pore volume of the material should be low and the greater part of the column material should be available for interaction. To keep the wood particles from flushing out of the column, both ends of the column were packed tight with glass wool, a thin cellulose filter, and a thin metal sieve (labelled "fine" but otherwise no data). To remove the extractives from the wood particles, which could otherwise influence the detector response, the column was extracted at $40^{\circ} \mathrm{C}$ and $300 \mathrm{bar}$ for $4 \mathrm{~h}$, before it was mounted on the chromatograph.

\subsection{Biocides}

Tebuconazole (CAS 107534-96-3), propiconazole (CAS 7588182-2) and IPBC (3-iodo-2-propynylbutylcarbamate CAS 55406-536 ) (Fig. 1) were obtained ( $>96 \%$ purity) from Lanxess AG, Janssen Pharmaceutica, and Troy Chemical Company, respectively.

\subsection{Method}

Pressures were set at $8.0,10.0,11.0$ or $15.0 \mathrm{MPa}$ while the temperature was set at either 40 or $50^{\circ} \mathrm{C}$. The pressure drop over the column was 0.4 MPa, so a pressure of 8.0 MPa signified an inlet and outlet pressure of 8.2 and $7.8 \mathrm{MPa}$, respectively. The pump was set to provide a constant flow of $2 \mathrm{ml} \mathrm{CO}_{2} \mathrm{~min}^{-1}$ measured at $5{ }^{\circ} \mathrm{C}$ and 57 bar.

For each combination of pressure and temperature the biocides dissolved in ethanol were injected to the column and the retention times recorded. For each biocide the retention time was determined as the average of two separate runs. Initial test were performed

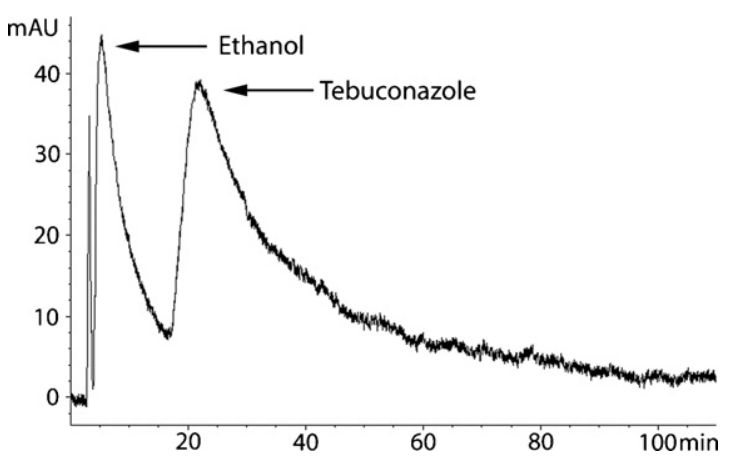

Fig. 2. Chromatogram of the detector response (mAU at $200 \mathrm{~nm}$ ) to tebuconazole $0.5 \%$ dissolved in ethanol. Conditions at $50{ }^{\circ} \mathrm{C}$ and $11.0 \mathrm{MPa}$. The first peak was due to disturbance of the flow by the injection.

in order to establish an appropriate concentration of biocides in the injected ethanol. For every run the injection volume was $7 \mu \mathrm{l}$. Concentrations were selected to produce the best possible detector response with emphasis on avoiding overloading of the column.

A UV spectrum (in ethanol) was obtained from each of the three biocides and for each biocide the detector was tuned to match the wavelength of maximum absorption, i.e. 200, 204 and $202 \mathrm{~nm}$ for tebuconazole, propiconazole, and IPBC, respectively. After injection, the retention time of the given biocide was established from the chromatogram (Fig. 2) and a new run was initiated.

\section{Results and discussion}

The measured retention times are listed in Table 1 along with the calculated retention factors $\left(k^{\prime}\right)$ and partition ratios $\left(K_{D}\right)$. The partition ratio can be interpreted as the concentration of biocide in the stationary phase relative to the concentration in the fluid phase and is in this work equal to the linear adsorption coefficient since the concentrations of biocides used were relatively low. Retention factors and partition ratios were calculated as follows:

$k^{\prime}=\frac{t_{R i}-t_{M}}{t_{M}}$

and

$K_{D}=\frac{k^{\prime} V_{M}}{V_{S}}$

where $t_{R i}$ is the retention time of biocide $i, t_{M}$ is the hold-up time, $V_{M}$ and $V_{S}$ are the volumes of the mobile phase and the stationary phase which were $6.73 \mathrm{~cm}^{3}$ and $2.27 \mathrm{~cm}^{3}$, respectively.

The hold-up times, i.e. the time it would take the hold-up volume $\left(V_{M}\right)$ surrounding the stationary phase to elute were calculated. Because the specific volume of the mobile phase at either side of the pump was different, the hold-up time changed depending on the experimental conditions. The pump was fed by $\mathrm{CO}_{2}$ at a flow rate of $2 \mathrm{ml} / \mathrm{min}$ at constant conditions, i.e. liquid $\mathrm{CO}_{2}$ at $5^{\circ} \mathrm{C}$ and $5.7 \mathrm{MPa}$ with a specific volume of $1.09 \mathrm{~cm}^{3} \mathrm{~g}^{-1}$. On the column side of the pump the specific volume of $\mathrm{CO}_{2}$ varied between 1.28 and $3.60 \mathrm{~cm}^{3} \mathrm{~g}^{-1}$ resulting in variations in mobile phase flow and holdup time accordingly. The hold-up time $\left(t_{M}\right)$ can be calculated from the flow entering the pump $\left(F_{I N}\right)$, the specific volume of $\mathrm{CO}_{2}$ at either side of the pump $\left(v_{I N}\right.$ and $\left.v_{O U T}\right)$, and the volume of the mobile phase $\left(V_{M}\right)$ :

$t_{M}=\frac{V_{M} v_{I N}}{F_{I N} v_{O U T}}$

The calculations of the hold-up time were done under the assumption that $\mathrm{CO}_{2}$ does not interact with the stationary phase.

The initial intention was to measure retention times at temperatures of 40 and $50^{\circ} \mathrm{C}$ and pressures of 8.0, 10.0, and 15.0 MPa. 
Table 1

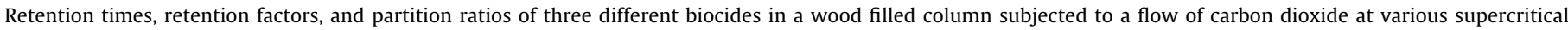
conditions.

\begin{tabular}{|c|c|c|c|c|c|c|}
\hline$T\left({ }^{\circ} \mathrm{C}\right)$ & $P(\mathrm{MPa})$ & $\rho\left(\mathrm{CO}_{2}\right)\left(\mathrm{g} / \mathrm{cm}^{3}\right)$ & Biocide $^{\mathrm{a}}$ (i) & Retention time $^{\mathrm{b}}, t_{R(i)}(\mathrm{min})$ & Retention factor ${ }^{\mathrm{c}}, \boldsymbol{k}^{\prime}$ & Partition ratio ${ }^{\mathrm{c}}, K_{D}$ \\
\hline \multirow{12}{*}{40} & \multirow{4}{*}{8.0} & \multirow{4}{*}{0.278} & Tebuconazole & - & - & - \\
\hline & & & Propiconazole (0.2) & $16.0(0.3)$ & $14.6( \pm 0.4)$ & $43.4( \pm 1.0)$ \\
\hline & & & IPBC (10) & $6.6(0.4)$ & $5.5( \pm 0.4)$ & $16.2( \pm 1.1)$ \\
\hline & & & $\mathrm{CO}_{2}$ (Hold-up time) & $1.0^{\mathrm{d}}$ & - & - \\
\hline & \multirow{4}{*}{10.0} & \multirow{4}{*}{0.629} & Tebuconazole (0.25) & $16.0(0.3)$ & $5.9( \pm 0.1)$ & $17.5( \pm 0.4)$ \\
\hline & & & Propiconazole (0.05) & $6.4(0.0)$ & $1.8( \pm 0.1)$ & $5.2( \pm 0.1)$ \\
\hline & & & $\operatorname{IPBC}(5)$ & $5.7(-)^{e}$ & $1.5(-)$ & $4.3(-)$ \\
\hline & & & $\mathrm{CO}_{2}$ (Hold-up time) & $2.3^{\mathrm{d}}$ & - & - \\
\hline & \multirow{4}{*}{15.0} & \multirow{4}{*}{0.780} & Tebuconazole (0.1) & $8.7(0.0)$ & $2.0( \pm 0.0)$ & $6.0( \pm 0.0)$ \\
\hline & & & Propiconazole (0.02) & $5.5(0.1)$ & $0.9( \pm 0.0)$ & $2.7( \pm 0.1)$ \\
\hline & & & IPBC (5) & $5.8(0.1)$ & $1.0( \pm 0.0)$ & $3.0( \pm 0.1)$ \\
\hline & & & $\mathrm{CO}_{2}$ (Hold-up time) & $2.9^{\mathrm{d}}$ & - & - \\
\hline \multirow{12}{*}{50} & \multirow{5}{*}{10.0} & \multirow{5}{*}{0.384} & Tebuconazole (1.5) & $39.4(0.4)$ & $27.2( \pm 0.3)$ & $80.6( \pm 1.0)$ \\
\hline & & & Propiconazole (0.2) & $19.5(1.0)$ & $12.9( \pm 0.8)$ & $38.4( \pm 2.3)$ \\
\hline & & & $\operatorname{IPBC}(10)$ & $9.0(0.4)$ & $5.4( \pm 0.3)$ & $16.1( \pm 0.9)$ \\
\hline & & & $\mathrm{CO}_{2}$ (Hold-up time) & $1.4^{\mathrm{d}}$ & - & - \\
\hline & & & Tebuconazole (0.5) & $21.0(0.5)$ & $10.3( \pm 0.3)$ & $30.7( \pm 0.8)$ \\
\hline & \multirow{3}{*}{11.0} & \multirow{3}{*}{0.503} & Propiconazole (0.05) & $10.0(0.5)$ & $4.4( \pm 0.3)$ & $13.1( \pm 0.8)$ \\
\hline & & & IPBC (5) & $6.8(0.5)$ & $2.6( \pm 0.3)$ & $7.9( \pm 0.8)$ \\
\hline & & & $\mathrm{CO}_{2}$ (Hold-up time) & $1.9^{\mathrm{d}}$ & - & - \\
\hline & \multirow{4}{*}{15.0} & \multirow{4}{*}{0.700} & Tebuconazole (0.1) & $10.0(0.1)$ & $2.9( \pm 0.0)$ & $8.5( \pm 0.2)$ \\
\hline & & & Propiconazole (0.02) & $5.4(0.0)$ & $1.1( \pm 0.0)$ & $3.3( \pm 0.1)$ \\
\hline & & & IPBC (5) & $5.8(0.0)$ & $1.3( \pm 0.1)$ & $3.7( \pm 0.0)$ \\
\hline & & & $\mathrm{CO}_{2}$ (Hold-up time) & $2.6^{\mathrm{d}}$ & - & - \\
\hline
\end{tabular}

a Value in parenthesis is the concentration of biocide in the injection fluid in percent (weight).

b First value is the mean of two measurements. Value in parenthesis is one standard deviation.

c First value calculated from the mean retention time. Value in parenthesis is the deviation to the first value caused by \pm one standard deviation of the retention time.

d Calculated value.

e Only one measurement.

However, due to the low efficiency of the sawdust column (discussed below) it was not possible to establish retention times for any of the biocides at $50^{\circ} \mathrm{C}$ and $8.0 \mathrm{MPa}$. We made an extra set of measurements at $50^{\circ} \mathrm{C}$ and $11.0 \mathrm{MPa}$ instead. At $40^{\circ} \mathrm{C}$ and $8.0 \mathrm{MPa}$ it was only possible to establish the retention time for propiconazole and IPBC.

Figs. 3 and 4 show a graphic presentation of the partition ratios at the examined physical conditions.

The results show that the physical conditions had a large influence on the partition ratios of the three biocides and the partition ratios were markedly different for each biocide at constant conditions. The partition ratios increased with decreasing pressure and increased at the higher temperature. This hints at a correlation between partition ratios and $\mathrm{CO}_{2}$ density. Fig. 5 shows the partition ratios as a function of $\mathrm{CO}_{2}$ density.

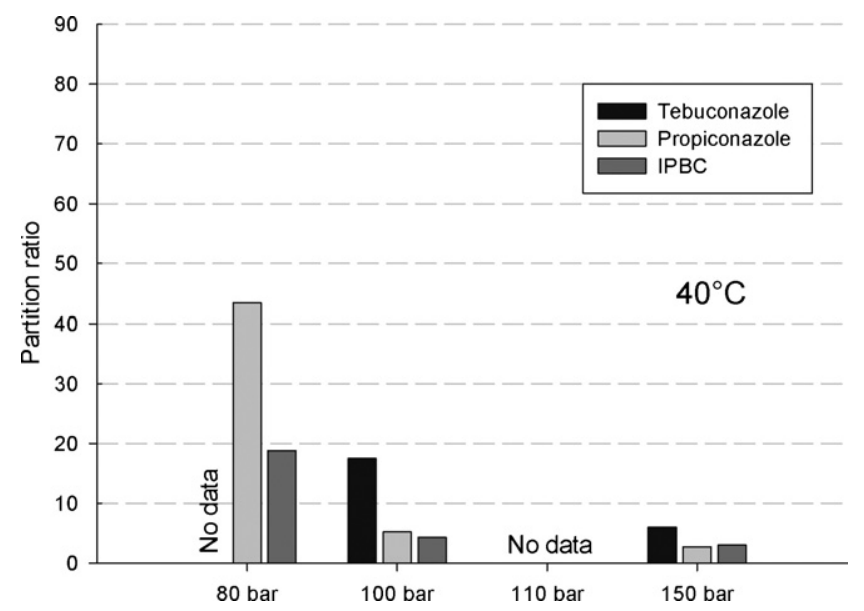

Fig. 3. Partition ratios of biocides at $40^{\circ} \mathrm{C}$ and varying pressures.
The results show a strong correlation. As $\mathrm{CO}_{2}$ density increases the solubility of the biocide in the fluid increases and the equilibrium (4) is shifted to the left-hand side which will cause a decrease of the partition ratio.

[Biocide $]_{\mathrm{CO}_{2}} \leftrightarrow[\text { Biocide }]_{\text {Wood }}$

However, the equilibrium (4), and thus the partition ratio, is not only influenced by biocide solubility in $\mathrm{CO}_{2}$ but also by the affinity of the biocides for wood. Previously, some solubility measurements of the three biocides in supercritical $\mathrm{CO}_{2}$ were carried out by the authors at nine different combinations of temperature and pressure, i.e. three different isotherms (at 40,50 , and $60^{\circ} \mathrm{C}$ ) with three measurements $(110,130$, and 150 bar). The data showed that for any one of the examined conditions propiconazole had the highest $(\sim 0.7-7.0 \%, \mathrm{w} / \mathrm{w})$ and tebuconazole the lowest $(\sim 0.1-1.0 \%, \mathrm{w} / \mathrm{w})$

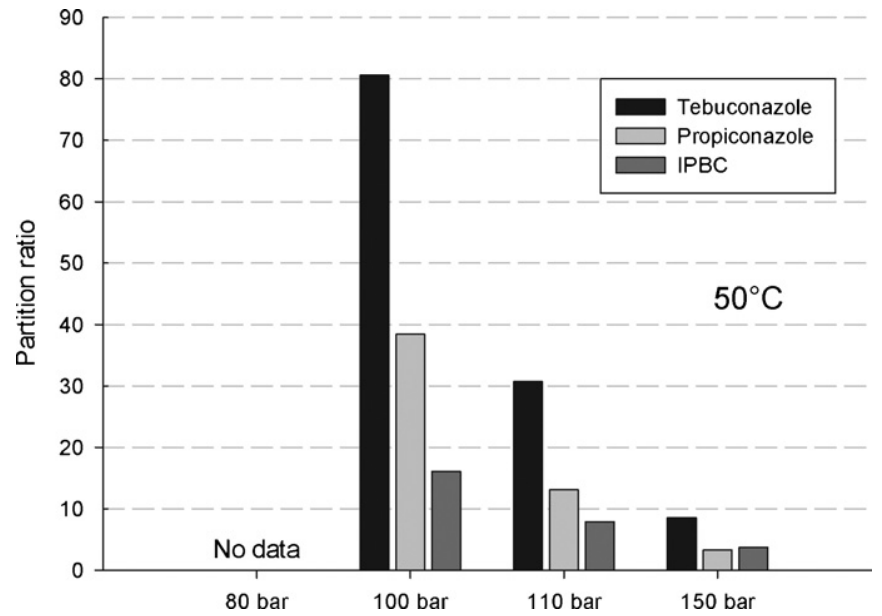

Fig. 4. Partition ratios of biocides at $50^{\circ} \mathrm{C}$ and varying pressures. 


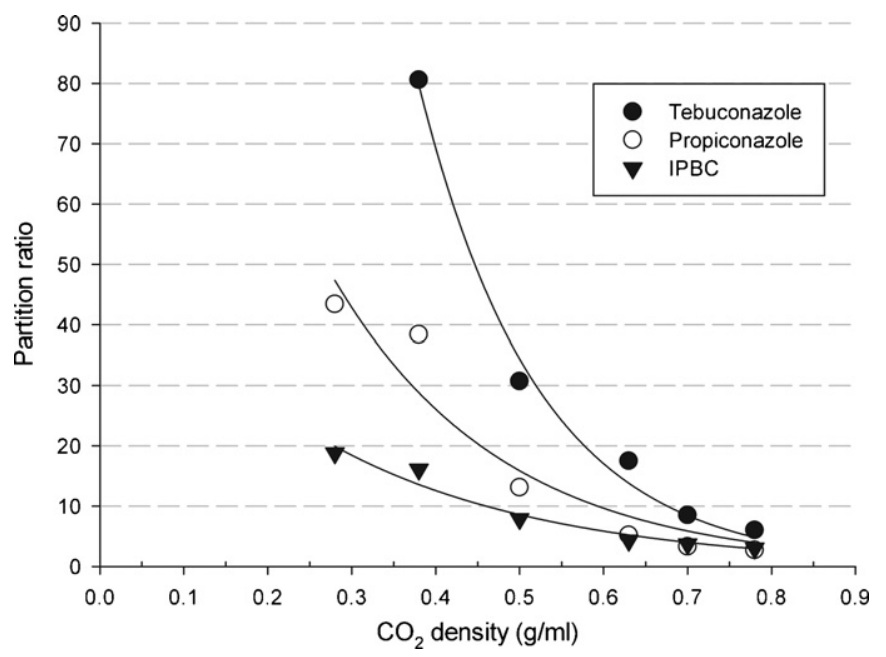

Fig. 5. Partition ratio as a function of $\mathrm{CO}_{2}$ density.

solubility of the three biocides. Comparing with the results of the present work, it can be seen that the biocide showing the highest solubility (in this case propiconazole) may not be the same as the one showing the lowest partition ratio (in this case IPBC).

The present study supports the conclusion by Lucas et al. [9] that deposition of biocides is controlled by more than just loss of biocide solubility at the super- to sub-critical transition during depressurization. At any time during the impregnation process a substantial part of the biocide will be adsorbed to the wood. In this study, even at a $\mathrm{CO}_{2}$ density of $0.78 \mathrm{~g} \mathrm{ml}^{-1}$, the partition ratio was still above 2.6. During depressurization the partition ratio is gradually increased to such a degree that by far the larger part of the introduced biocide will already be adsorbed to the wood when the fluid undergoes the phase transition from super- to sub-critical state.

Previous reports on biocide deposition following supercritical impregnation frequently report of a concentration gradient between the inner and outer parts of impregnated samples but have been undecided in their explanations of the observed gradients [2-6]. The results presented here indicate that the reason for the observed gradients is that wood acts as chromatographic material which filters the biocides from the $\mathrm{CO}_{2}$ as the fluid moves through the wood matrix.

During pressurization, the wood gradually fills up with $\mathrm{CO}_{2}$, i.e. there is a bulk flow of $\mathrm{CO}_{2}$ from the outside to the interior of the wood. At low pressures the solubility of the biocides will be negligible meaning that the wood matrix fills up with $\mathrm{CO}_{2}$ without biocides. As the pressure and temperature is increased the biocides gradually dissolve and travel with the $\mathrm{CO}_{2}$ to the interior of the wood. However, because of the high degree of interaction between wood and the biocides the movement of biocides through the wood matrix is slower than the movement of $\mathrm{CO}_{2}$. Therefore, when $\mathrm{CO}_{2}$ penetration of the wood sample is complete the penetration of biocides is likely to be incomplete. After pressure equilibration, the biocides will move through the wood matrix by diffusion and the rate of diffusion will depend on the partition ratios. During depressurization, the direction of flow of both $\mathrm{CO}_{2}$ and biocides in the wood matrix is reversed. Thus, the wood-biocide interactions now work to the benefit of the wood preserver by holding back the biocides in the wood structure. However, there will still be a net migration of biocides towards the surface of the wood adding to the steepness of the concentration gradient.

The exact nature of interactions between wood and the examined biocides are unknown. In principle, the interactions could be both physical and chemical. Physically, sawdust has a very irregular structure and each grain of sawdust could have numerous microcavities able to temporarily hold back molecules. More likely though, the interaction can be considered chemical in nature. Wood has a complex chemical structure and the possibilities for chemical interaction with the biocides are numerous. Wood consists primarily of three major biopolymeric units: cellulose, hemicellulose, and lignin. Cellulose is an unbranched polysaccharide composed of $\beta$ D-glucopyranose units, hemicellulose is a branched polysaccharide composed mainly of hexoses, pentoses and hexuronic acids, and lignin is a complex matrix consisting of a randomized polyphenolic backbone of monolignols (coniferyl alcohol, $p$-coumaryl alcohol, and sinapyl alcohol). In the case of Norway spruce, cellulose, hemicellulose, and lignin account for approximately 48,22 , and $28 \%$ of the mass of the wood, respectively, although the exact composition will vary between trees and even within a single tree [10]. Due to the $\mathrm{OH}$-groups present on the cellulose and especially hemicellulose, wood is generally hydrophilic in nature. However, lignin is more hydrophobic meaning that wood can interact with both hydrophilic and hydrophobic substances. Thus, the biocides could potentially interact with a wide range of macromolecules present in the wood matrix.

Tebuconazole has a hydroxyl group located across from its azole group. The hydroxyl group may form hydrogen bonds to the hydroxyl groups in the wood increasing the partition ratio, explaining the high partition ratios of tebuconazole.

Considering the cause for the different retention times, it should be taken into consideration that the experiments were done with sawdust as the stationary phase. When industrial scale impregnation is carried out the stationary phase is solid wood. There is a large structural difference between a matrix consisting of solid wood and a matrix of sawdust. This could give rise to differences in flow patterns that might influence biocide movement. In addition, the surface available for chemical interactions could be slightly different from sawdust to solid wood. A fluid flowing through a matrix of sawdust would likely come into contact with more lignin than it would if it passed through a piece of solid wood because the lignin rich middle lamellas would be exposed in sawdust but unexposed in solid wood. It is possible that these differences between sawdust and solid wood could lead to different retention times and partition coefficients had the experiments been carried out using a piece of solid wood as the stationary phase.

The sawdust column was able to fulfill the purpose of the present study. However, compared to a pre-packed chromatographic column, the efficiency of the sawdust column was very low with an estimated number of theoretical plates of about 10. Consequently, peak broadening increased considerably with time meaning that at the longer retention times the introduced amount of biocide needed to be higher to produce a peak. In doing so, we introduced the risk of overloading the column as is evident from Fig. 2. This likely resulted in underestimated retention times and thus underestimated partition ratios. At $8.0 \mathrm{MPa}$ and $50^{\circ} \mathrm{C}$ we were unable to produce a peak for any of the biocides without heavily overloading the column while at $8.0 \mathrm{MPa}$ and $40^{\circ} \mathrm{C}$ we were unable to produce a peak for tebuconazole. To minimize the problems associated with overloading of the column, future experiments would likely benefit from increasing the amount of stationary phase.

The results presented here could have implications for the evaluation of biocides to be used for supercritical impregnation, but may also be relevant for other pressurized impregnation processes. Overall treatment time is an important parameter in determining the economic viability of the impregnation process. With the evidence that some biocides are transported more quickly through the wood than others, there would be an incentive to choose these biocides over the slower moving ones as long as the toxicity is at the same level. Passing the biocides through a sawdust column subjected to supercritical conditions provides a means of screening the biocides in this respect. 


\section{Conclusion}

Wood in the form of sawdust has been shown to have a chromatographic effect on the biocides tebuconazole, propiconazole, and IPBC when subjected to a flow of supercritical $\mathrm{CO}_{2}$. The biocides had markedly different retention times and thus partition ratios and the values were highly dependent on the physical conditions, i.e. pressure and temperature. Tebuconazole recorded the highest retention time and partition ratio which could be caused by its hydroxyl group interacting with the hydroxyl groups in the wood. The results indicate that the retention times and partition ratios of biocides need to be taken into account when evaluating new - and existing - biocides for compatibility with the supercritical impregnation process because the partition ratios could have a significant influence on the overall treatment time, and thus the economy of the impregnation process. Running biocides through a column of sawdust seems to be a useful method of evaluating the compatibility of biocides with the supercritical wood impregnation process.

\section{Acknowledgement}

The authors would like to thank the Danish Forest and Nature Agency for financial support.

\section{References}

[1] A.W. Kjellow, O. Henriksen, Supercritical wood impregnation, Journal of Supercritical Fluids 50 (2009) 297-304.

[2] M. Acda, J.J. Morrell, K.L. Levien, Effect of process variables on supercritical fluid impregnation of composites with tebuconazole, Wood and Fiber Science 29 (1997) 282-290.

[3] M. Muin, K. Tsunoda, Retention of silafluofen in wood-based composites after supercritical carbon dioxide impregnation, Forest Products Journal 54 (2004) 168-171.

[4] S.M. Kang, K.L. Levien, J.J. Morrell, Supercritical fluid impregnation of wood with biocides using temperature reduction to induce deposition, Wood Science and Technology 39 (2005) 328-338.

[5] S.M. Kang, J.B. Ra, K.L. Levien, J.J. Morrell, Developing diffusion coefficients for SCF impregnation of douglas fir heartwood with cyproconazole, Journal of Wood Chemistry and Technology 26 (2006) 111-124.

[6] S.M. Kang, K.L. Levien, J.J. Morrell, Effect of process variations during supercritical fluid impregnation on cyproconazole retention and distribution in ponderosa pine sapwood, Wood and Fiber Science 38 (2006) 64-73.

[7] M. Drescher, A. Jokisch, H. Korte, R.D. Peek, R. Steiner, Differential pressure characteristics of wood impregnated with compressed gases, liquids and supercritical fluids, Holz Als Roh-und Werkstoff 64 (2006) 178-182.

[8] P.F. Schneider, J.J. Morrell, K.L. Levien, Internal pressure development during supercritical fluid impregnation of wood, Wood and Fiber Science 37 (2005) 413-423.

[9] S. Lucas, E. Gonzalez, M.P. Calvo, C. Palencia, E. Alonso, M.J. Cocero, Supercritical $\mathrm{CO}_{2}$ impregnation of Radiata pine with organic fungicides-effect of operating conditions and two-parameters modeling, Journal of Supercritical Fluids 40 (2007) 462-469.

[10] F. Bertaud, B. Holmbom, Chemical composition of earlywood and latewood in Norway spruce heartwood, sapwood and transition zone wood, Wood Science and Technology 38 (2004) 245-256. 
Paper

IV 


\title{
THE INTERNATIONAL RESEARCH GROUP ON WOOD PROTECTION
}

Section 4

Processes and properties

\section{Interactions between wood and propiconazole in supercritical carbon dioxide}

\author{
Anders W. Kjellow and Ole Henriksen* \\ Forest and Landscape \\ University of Copenhagen \\ Rolighedsvej 23 \\ 1958 Frederiksberg, Denmark \\ *Hampen Træforarbejdning A/S \\ Palsgårdvej 3 \\ 7362 Hampen, Denmark
}
Paper prepared for the $40^{\text {th }}$ Annual Meeting
Beijing, China
24-28 May 2009

\section{Disclaimer}

The opinions expressed in this document are those of the author(s) and are not necessarily the opinions or policy of the IRG Organization.

\author{
IRG SECRETARIAT \\ Box 5609 \\ SE-114 86 Stockholm \\ Sweden \\ www.irg-wp.com
}




\title{
Interactions between wood and propiconazole in supercritical carbon dioxide
}

\author{
Anders W. Kjellow ${ }^{1}$ and Ole Henriksen ${ }^{2}$ \\ ${ }^{1}$ Forest and Landscape, University of Copenhagen, Rolighedsvej 23, DK-1958 Frederiksberg C, Denmark, \\ awk@life.ku.dk \\ ${ }^{2}$ Hampen Træforarbejdning A/S, Palsgårdvej 3, DK-7362 Hampen, Denmark, oh@superwood.dk
}

\begin{abstract}
Understanding the movement and deposition of biocides in wood is a fundamental aspect of the supercritical wood impregnation process and a key issue in developing the process e.g. to handle wood of larger dimensions. Previous research on supercritical wood impregnation frequently reports of a biocide concentration gradient in impregnated samples i.e. a lower concentration of biocides in the core of the samples than nearer the surface. Researchers seldom comment on the reasons for the observed gradients, and the subject of biocide/wood interactions is generally overlooked. In this paper we investigate the interactions between wood and propiconazole in supercritical carbon dioxide and hypothesize that the reasons for the observed gradients is that wood has a chromatographic effect on the biocides as they move with the carbon dioxide through the wood matrix. The degree of interaction at different conditions is estimated by calculation of partition ratios.
\end{abstract}

Keywords: propiconazole, supercritical carbon dioxide, supercritical chromatography, interaction, impregnation

\section{INTRODUCTION}

During the past two decades supercritical carbon dioxide has repeatedly been investigated as a solvent for wood impregnation. The majority of the research has focused on the effects of supercritical treatment on the physical properties of wood and a wide variety of wood species have been treated with an equally wide array of organic biocides (e.g. Anderson et al. 2000, Acda et al. 2001). Researchers often report of a concentration gradient between biocide concentrations in the inner and outer parts of supercritical impregnated samples (e.g. SahleDemessie et al. 1995, Acda et al. 1997, Kang et al. 2006). Despite these observations, the issue of biocide movement and deposition has received little attention and most studies do not discuss these gradients beyond noting their existence.

From differential pressure measurements carried out in-situ during supercritical wood impregnation, it is known that the carbon dioxide penetrates the wood during treatment to the extent that pressure inside and outside of the sample equilibrates (Schneider et al. 2005, Schneider et al. 2006, Drescher et al. 2006). The biocide concentration gradient is therefore not the result of incomplete penetration of wood samples by the $\mathrm{CO}_{2} /$ biocide mixture. Probable causes for the gradients could then be that either 1) part of the biocides gets re-extracted from the wood as the carbon dioxide leaves the wood during depressurization, or 2) the biocides get filtered from the carbon dioxide as the mixture fills up the wood matrix. 
Understanding biocide movement and the deposition mechanisms is an important part of the continued development of the supercritical wood impregnation process especially when impregnating wood of larger dimensions. This paper examines the interaction of propiconazole, an organic anti-fungal triazole-compound, and wood in a supercritical carbon dioxide atmosphere by measuring the retention times of propiconazole in a wood filled column mounted on a supercritical chromatograph.

\section{MATERIALS AND METHODS}

\subsection{Materials}

Propiconazole $>96 \%$ purity was supplied by Janssen Pharmaceutica, Belgium. Sawdust with a particle size $<125 \mu \mathrm{m}$ was prepared from boards of Norway spruce (Picea abies) supplied by Vida Wood, Sweden. The supercritical chromatograph was a HP G1850A ChemStation equipped with a HP 1050 UV detector. Carbon dioxide was from a pressurized bottle, Air Liquide E290.

\subsection{Methods}

A column was build by filling a metal cylinder with sawdust. The column had a length of 294 $\mathrm{mm}$ and an inside diameter of $6.4 \mathrm{~mm}$. Sawdust was prepared from Norway spruce and passed through a $125 \mu \mathrm{m}$ mesh. $3.4 \mathrm{~g}$ of the fraction passing the mesh was transferred to the column. The ends of the column were packed tight with metal sieves and cellulose filters on top of glass wool to prevent the sawdust from leaving the column during the experiments. Thus the column build-up was as follows: metal sieve - cellulose filter - glass wool - sawdust - glass wool cellulose filter - metal sieve. The metal sieves were intended for column preparation and labeled "fine" but the actual mesh size was unknown.

The column was mounted on the chromatograph and subjected to a flow of carbon dioxide at various supercritical conditions. For each run the propiconazole was dissolved in ethanol and the ethanol-propiconazole mixture was injected into the pre-column flow path of the carbon dioxide. The propiconazole was then moved downstream through the column to the detector. The retention time was established from the resulting chromatogram and the procedure was repeated. All system parameters i.e. pressure, temperature, flow rate, injection volume, and detector wavelength were controlled via system software (HP ChemStation). Temperature was set to either 40 or $50^{\circ} \mathrm{C}$ and the pressures were set to either 8,10 , or $15 \mathrm{MPa}$ when running at $40^{\circ} \mathrm{C}$, and 10,11 , or $15 \mathrm{MPa}$ when running at $50^{\circ} \mathrm{C}$. We were unable to record a retention time at $50^{\circ} \mathrm{C}$ and $8 \mathrm{MPa}$ and therefore made an extra set of measurements at $11 \mathrm{MPa}$ instead. For all runs the flow rate was set at $2 \mathrm{ml} \mathrm{CO} / \mathrm{min}$ and the detector was set to measure the absorbance at $204 \mathrm{~nm}$ based on the measured UV spectra of propiconazole in ethanol.

\section{RESULTS AND DISCUSSION}

The measured retention times are reported in Tab. 1 . Also reported are the retention factors and the partition ratios calculated as follows:

$k^{\prime}=\frac{t_{R}-t_{M}}{t_{M}}$

and 
$K_{D}=\frac{k V_{M}}{V_{S}}$

where $k^{\prime}$ is the retention factor, $t_{R}$ is the recorded retention time, $t_{M}$ is the hold-up time, $K_{D}$ is the partition ratio ${ }^{1}, V_{M}$ is the volume of the mobile phase (i.e. the hold-up volume), and $V_{S}$ is the volume of the solid phase (i.e. the volume of the sawdust). $K_{D}$ is essentially a measure of the partitioning of biocide between the solid phase and the fluid phase i.e. the ratio of the biocide concentration in the wood to the biocide concentration in the fluid phase at equilibrium. A value higher than 1, would signify a higher affinity of propiconazole for wood than for $\mathrm{CO}_{2}$. The table also lists the hold-up times i.e. the retention times of the carbon dioxide. The hold-up times were calculated under the assumption that the $\mathrm{CO}_{2}$ did not interact with the sawdust. Under this assumption the hold-up time can be calculated from the flow rate into the pump $\left(\mathrm{F}_{\mathrm{IN}}\right)$ and the volume of the mobile phase $\left(\mathrm{V}_{\mathrm{M}}\right)$ taking into account the difference in fluid specific volume at either side of the pump ( $v_{\text {IN }}$ and $\left.v_{\text {OUT }}\right)$ :

$t_{M}=\frac{V_{M} v_{I N}}{F_{I N} v_{\text {OUT }}}$

The pump input was liquid $\mathrm{CO}_{2}$ at 57 bars cooled to $5^{\circ} \mathrm{C}$ so $v_{\text {IN }}$ was a constant $1.09 \mathrm{~cm}^{3} / \mathrm{g} \cdot v$ out varied depending on the physical conditions of the run between $1.28 \mathrm{~cm}^{3} / \mathrm{g}$ and $3.60 \mathrm{~cm}^{3} / \mathrm{g}$.

Table 1. Retention times of propiconazole in the wood column under the indicated physical conditions. Corresponding retention factors and partition ratios are shown together with the calculated hold-up times of $\mathrm{CO}_{2}$.

\begin{tabular}{|c|c|c|c|c|c|}
\hline $\begin{array}{c}\mathrm{T} \\
\left({ }^{\circ} \mathrm{C}\right)\end{array}$ & $\begin{array}{c}\mathbf{P} \\
\text { (MPa) }\end{array}$ & Molecule & $\begin{array}{c}\text { Retention time } \\
\mathbf{R}_{\mathrm{t}}(\mathrm{min})\end{array}$ & $\begin{array}{l}\text { Retention } \\
\text { factor (k') }\end{array}$ & $\begin{array}{c}\text { Partition ratio } \\
\left(K_{\mathrm{D}}\right)\end{array}$ \\
\hline \multirow{5}{*}{40} & 8.0 & $\begin{array}{l}\text { Propiconazole } \\
\mathrm{CO}_{2} \text { (hold-up time) }\end{array}$ & $\begin{array}{c}16.0 \\
1.07^{*}\end{array}$ & 5.2 & 43.3 \\
\hline & \multirow{2}{*}{10.0} & Propiconazole & 6.4 & 1.7 & 5.1 \\
\hline & & $\mathrm{CO}_{2}$ (hold-up time) & $2.42 *$ & & \\
\hline & \multirow{2}{*}{15.0} & Propiconazole & 5.5 & 0.8 & 2.6 \\
\hline & & $\mathrm{CO}_{2}$ (hold-up time) & $2.99 *$ & & \\
\hline \multirow{6}{*}{50} & \multirow{2}{*}{10.0} & Propiconazole & 19.5 & 12.4 & 38.3 \\
\hline & & $\mathrm{CO}_{2}$ (hold-up time) & $1.46^{*}$ & & \\
\hline & \multirow{2}{*}{11.0} & Propiconazole & 10.0 & 4.2 & 12.9 \\
\hline & & $\mathrm{CO}_{2}$ (hold-up time) & $1.93 *$ & & \\
\hline & \multirow{2}{*}{15.0} & Propiconazole & 5.4 & 1.0 & 3.1 \\
\hline & & $\mathrm{CO}_{2}$ (hold-up time) & $2.68 *$ & & \\
\hline
\end{tabular}

*) Calculated value

Fig. 1 and Fig. 2 show the estimated partition ratios at the examined physical conditions. First, experiments were run at a constant temperature of $40^{\circ} \mathrm{C}$ and three different pressures 8,10 and $15 \mathrm{MPa}$. Next, the temperature was increased to $50^{\circ} \mathrm{C}$ and the measurements were repeated at the same pressures. However, we were unable to record a retention time at $8 \mathrm{MPa}$, because the affinity of propiconazole to wood at these conditions were so large that a peak could not be established from the chromatogram. The efficiency of the sawdust column was very low meaning that peak broadening increased considerably with time. At $50^{\circ} \mathrm{C}$ and $8 \mathrm{MPa}$, the

\footnotetext{
${ }^{1}$ ) $\mathrm{K}_{\mathrm{D}}$ has often in the past been termed partition coefficient. However, the International Union of Pure and Applied Chemistry (IUPAC) has discontinued this term and instead recommend using the term partition ratio (IUPAC 2009).
} 
chromatogram did not show a peak but rather a very long low hill which made a correct establishment of the retention time impossible. A measurement was made at $11 \mathrm{MPa}$ instead.

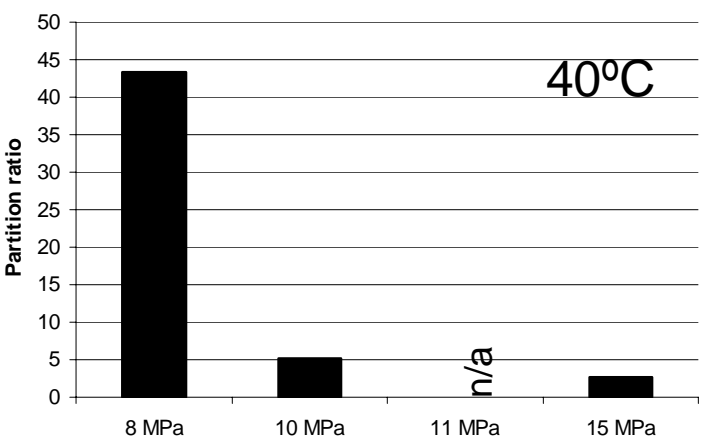

Figure 1. Estimated partition ratios for propiconazole in a wood $/ \mathrm{CO}_{2}$ system at $40^{\circ} \mathrm{C}$ and varying pressures. No experiments were done at $11 \mathrm{MPa}$.

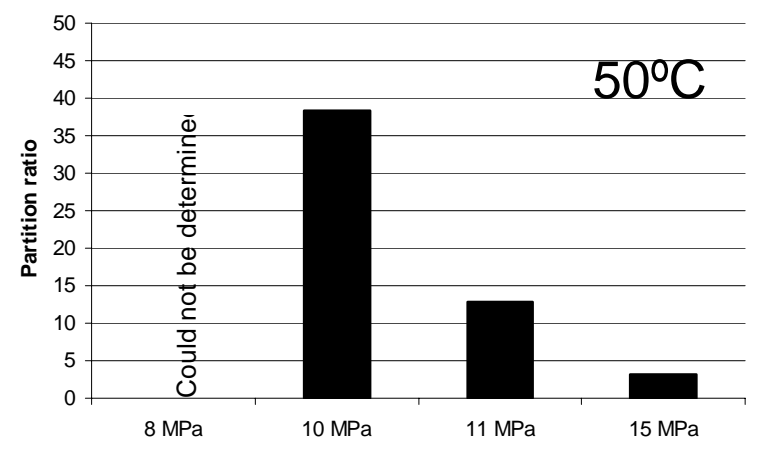

Figure 2. Estimated partition ratios for propiconazole in a wood $/ \mathrm{CO}_{2}$ system at $50^{\circ} \mathrm{C}$ and varying pressures. Experiments at $8 \mathrm{MPa}$ were done but the retention time could not be recorded at this pressure.

The results show that the experimental conditions had a large influence on the wood/propiconazole interactions. Partition ratios decreased isothermally with increasing pressures. Isobarically, partition ratios decreased with decreasing temperatures. These results indicate a correlation between the $\mathrm{CO}_{2}$ density and the partition ratios. Fig. 3 shows the partition ratios as a function of $\mathrm{CO}_{2}$ density.

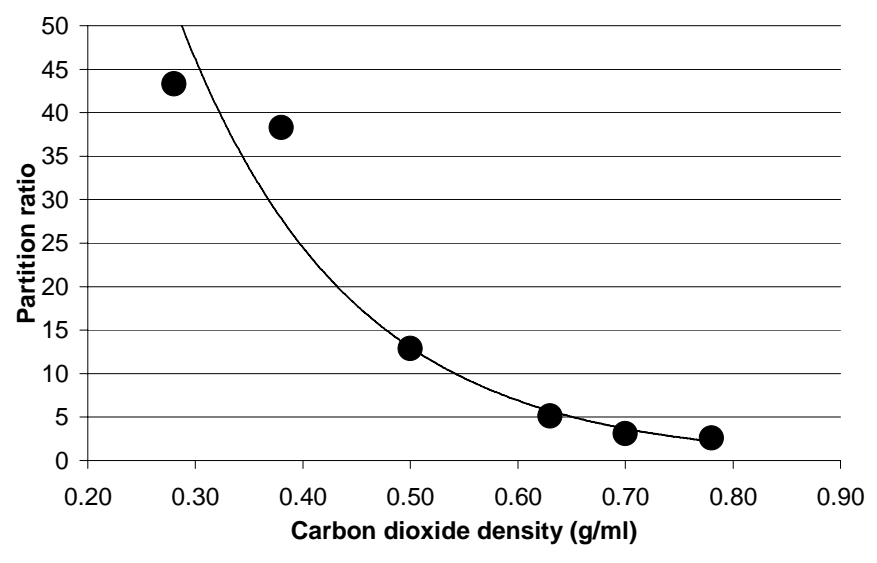

Figure 3. Partition ratios as a function of $\mathrm{CO}_{2}$ density.

As can be seen from Fig. 3 there is a strong relationship between the density of the $\mathrm{CO}_{2}$ and the partition ratio. This tendency is not surprising since at the higher densities there are more molecules of $\mathrm{CO}_{2}$ available for interaction with the propiconazole which leads to a higher solvating capacity which in turn shifts the equilibrium $[\text { Biocide }]_{\text {Wood }} \Leftrightarrow[\text { Biocide }]_{\mathrm{CO}_{2}}$ to the right. However, the magnitude of propiconazole interactions with wood surprising was unexpected. All partition ratios were above 1.0 signifying that the affinity of propiconazole for wood was significantly higher than for $\mathrm{CO}_{2}$ at all conditions. Even at $\mathrm{CO}_{2}$ densities approaching $0.8 \mathrm{~g} / \mathrm{ml}$, propiconazole still has a higher affinity for wood than for $\mathrm{CO}_{2}$. At lower densities the affinity for wood is such that the equilibrium is shifted almost completely to the side of the wood. 
The deposition of biocides in supercritical wood impregnation is often described to be caused by precipitation of the biocide as the fluid undergoes the super- to sub-critical phase transition during depressurization. However, based on studies involving impregnation of radiata pine (Pinus radiata) with decanal, Lucas et al. 2007) concluded that the controlling mechanism of biocide deposition is not precipitation but rather a favorable partition ratio of the biocide for the wood compared to the $\mathrm{CO}_{2}$. Our results support the findings by Lucas et al. (2007). The deposition of biocides is likely the result of adsorption/desorption behavior rather than a precipitation process.

The results presented here could help explain the concentration gradients often reported by supercritical wood impregnation researchers. As the wood fills up with the wood/biocide mixture during pressurization it separates chromatographically the biocide from the $\mathrm{CO}_{2}$. The concentration of biocide in the treatment solution will thus decrease from the surface of the wood towards the center. When the impregnation pressure has been reached and there is no longer a net flux of $\mathrm{CO}_{2}$ into the wood, the biocide is left to move by diffusion towards the center of the wood. The velocity by which the biocides move by diffusion will be dependant on the $\mathrm{K}_{\mathrm{D}}$-value. During depressurization there is, of course, a net flux of $\mathrm{CO}_{2}$ out of the wood but now the high wood affinity of the fungicides become beneficial to the wood preserver as the biocides are held back in the wood as the $\mathrm{CO}_{2}$ exits.

Minimizing treatment times is important for the economic viability of the supercritical treatment process. Therefore, a lot of research has focused on examining the effects of different pressurization and depressurization rates on the mechanical properties of impregnated wood in order to try to establish just how fast wood can be pressurized and depressurized without being damaged. However, the results presented here indicate that the rate limiting factor in supercritical wood impregnation might not be how fast wood can be pressurized without causing failures but rather how fast biocides can be delivered to the center of impregnated samples. To ensure a rapid movement of biocides through the wood structure, the equilibrium [Biocide $]_{\text {Wood }} \Leftrightarrow[\text { Biocide }]_{\mathrm{CO}_{2}}$ should be moved as far as possible towards $\mathrm{CO}_{2}$ during the pressurization and impregnation part of the treatment cycle. Ways of doing this include 1) increasing the gas phase concentration of biocides by adding more biocides to the system, 2) controlling process parameters, 3) adding co-solvents to the $\mathrm{CO}_{2}$.

In addition, it could be that the choice of biocide could have an impact on the $\mathrm{K}_{\mathrm{D}}$-value. This experiment only included propiconazole, but other biocides would likely have $\mathrm{K}_{\mathrm{D}}$-values different from those of propiconazole. We intend to establish the $K_{D}$-values of other biocides in forthcoming research.

\section{CONCLUSION}

Retention times of propiconazole in the sawdust column were found to be highly dependant on the physical conditions. Wood/propiconazole interactions were found to be substantial at all examined conditions and propiconazole affinity for wood was higher than for $\mathrm{CO}_{2}$ even at $\mathrm{CO}_{2}$ densities approaching $0.8 \mathrm{~g} / \mathrm{ml}$. The results show that deposition of biocides in the supercritical wood impregnation process is controlled by adsorption/desorption behavior rather than being a precipitation process. The results could explain the biocide concentration gradients often reported to exist in supercritical impregnated samples. The concentration gradient likely develops because the wood has a chromatographic effect on the biocides as they are moved through the wood structure by the $\mathrm{CO}_{2}$. 


\section{REFERENCES}

Acda, M, Morrell, J J, Levien, K L (1997): Effect of process variables on supercritical fluid impregnation of composites with tebuconazole. Wood and Fiber Science, 29(3), 282-290.

Acda, M N, Morrell, J J, Levien, K L (2001): Supercritical fluid impregnation of selected wood species with tebuconazole. Wood Science and Technology, 35(1-2), 127-136.

Anderson, M E, Leichti, R J, Morrell, J J (2000): The effects of supercritical CO2 on the bending properties of four refractory wood species. Forest Products Journal, 50(11-12), 85-93.

Drescher, M, Jokisch, A, Korte, H, Peek, R D, Steiner, R (2006): Differential pressure characteristics of wood impregnated with compressed gases, liquids and supercritical fluids. Holz Als Roh-und Werkstoff, 64(3), 178-182.

IUPAC (2009): Compendium of Chemical Terminology - The Gold Book. International Union of Pure and Applied Chemistry. Available from: http://goldbook.iupac.org

Kang, S M, Ra, J B, Levien, K L, Morrell, J J (2006): Developing diffusion coefficients for SCF impregnation of douglas fir heartwood with cyproconazole. Journal of Wood Chemistry and Technology, 26(2), 111-124.

Lucas, S, Gonzalez, E, Calvo, M P, Palencia, C, Alonso, E, Cocero, M J (2007): Supercritical CO2 impregnation of Radiata pine with organic fungicides - Effect of operating conditions and two-parameters modeling. Journal of Supercritical Fluids, 40(3), 462-469.

Sahle-Demessie, E, Levien, K L, Morrell, J J (1995): Impregnation of Wood with Biocides Using Supercritical Fluid Carriers. ASC Symposium Series, 608, 415-428.

Schneider, P F, Levien, K L, Morrell, J J (2006): Effect of wood characteristics on pressure responses during supercritical carbon dioxide treatment. Wood and Fiber Science, 38(4), 660671.

Schneider, P F, Morrell, J J, Levien, K L (2005): Internal pressure development during supercritical fluid impregnation of wood. Wood and Fiber Science, 37(3), 413-423. 